Ana Alice dos Santos Dias

\title{
PAPEL DA PROTEINA DISSULFETO ISOMERASE NA REATIVIDADE VASCULAR À \\ ANGIOTENSINA II E NORADRENALINA: \\ ENVOLVIMENTO DA NADPH OXIDASE
}

Tese apresentada ao Programa de Pós- Graduação em Farmacologia do Instituto de Ciências Biomédicas da Universidade de São Paulo, para obtenção do Título de Doutor em Ciências. 


\section{Ana Alice dos Santos Dias}

\section{PAPEL DA PROTEINA DISSULFETO ISOMERASE NA REATIVIDADE VASCULAR À \\ ANGIOTENSINA II E NORADRENALINA: \\ ENVOLVIMENTO DA NADPH OXIDASE}

Tese apresentada ao Programa de PósGraduação em Farmacologia do Instituto de Ciências Biomédicas da Universidade de São Paulo, para obtenção do Título de Doutor em Ciências.

Área de concentração: Farmacologia

Orientadora: Prof. Dr. ${ }^{\circ}$ Lucia Rossetti Lopes

Versão corrigida: a versão original se encontra arquivada no Serviço de Comunicação do ICB 
DADOS DE CATALOGAÇÃO NA PUBLICAÇÃO (CIP)

Serviço de Biblioteca e Informação Biomédica do

Instituto de Ciências Biomédicas da Universidade de São Paulo

(c) reprodução total

Dias, Ana Alice dos Santos.

Papel da proteina dissulfeto isomerase na reatividade vascular à angiotensina II e noradrenalina: envolvimento da NADPH oxidase Ana Alice dos Santos Dias. -- São Paulo, 2011.

Orientador: Profa Lucia Rossetti Lopes.

Tese (Doutorado) - Universidade de São Paulo. Instituto de Ciências Biomédicas. Departamento de Farmacologia. Área de concentração: Farmacologia. Linha de pesquisa: Sinalização redox.

Versão do título para o inglês: Role of protein disulfide isomerase in vascular reactivity to angiotensin $I I$ and noradrenaline: involvement of NADPH oxidase.

Descritores: 1. Proteína dissulfeto isomerase (PDI) 2. Reatividade vascular 3. Angiotensina II 4. Noradrenalina 5. NADPH oxidase 6. Espécies reativas de oxigênio (EROs) I. Lopes, Profa Lucia Rossetti II. Universidade de São Paulo. Instituto de Ciências Biomédicas. Programa de Pós-Graduaçāo em Farmacologia III. Título. 
Candidato(a):

Título da Tese:

Orientador(a):
Ana Alice dos Santos Dias.

Papel da proteína dissulfeto isomerase na reatividade vascular à angiotensina II e noradrenalina: envolvimento da NADPH oxidase.

Lucia Rossetti Lopes.

A Comissão Julgadora dos trabalhos de Defesa da Tese de Doutorado, em sessão pública realizada a

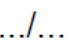
, considerou

\section{( ) Aprovado(a) \\ ( ) Reprovado(a)}

\begin{tabular}{|c|c|}
\hline \multirow[t]{2}{*}{ Examinador(a): } & 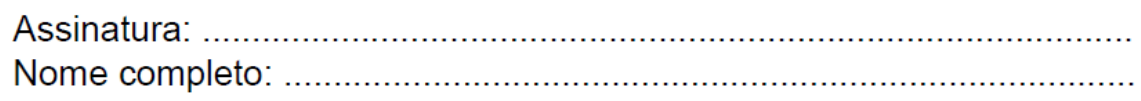 \\
\hline & Instituição: ..... \\
\hline \multirow{3}{*}{ Examinador(a): } & Assinatura: ............ \\
\hline & Nome completo: .. \\
\hline & Instituição: .. \\
\hline \multirow{3}{*}{ Examinador(a): } & Assinatura: ........... \\
\hline & Nome completo: . \\
\hline & Instituição: . \\
\hline \multirow{3}{*}{ Examinador(a): } & Assinatura: . \\
\hline & Nome completo: ... \\
\hline & Instituição: . \\
\hline \multirow{3}{*}{ Presidente: } & Assinatura: \\
\hline & Nome completo: .................................... \\
\hline & Instituição: . \\
\hline
\end{tabular}


Certificamos que o protocolo registrado sob $n^{\circ} \mathbf{1 5 7}$ nas fls. 40 do livro 2 para uso de animais em experimentação, sob a responsabilidade de Lucia Rossetti Lopes, Coordenador(a) da Linha de pesquisa "Papel da proteina dissulfeto isomerase (PDI na geração de espécies reativas de oxigênio pela NADPH oxidase em artérias de ratos espontaneamente hipertensos (SHR)" do qual participou(aram) o(s) alunos Ana Alice dos Santos Dias e os pesquisadores Luciana Venturini Rossoni e Wothan Tavares de Lima, está de acordo com os Principios Éticos de Experimentação Animal adotado pelo Colégio Brasileiro de Experimentação Animal (COBEA) e foi aprovado pela COMISSÃO DE ÉTICA EM EXPERIMENTAÇÃO ANIMAL (CEEA) em 27.02.2007.

São Paulo, 27 de fevereiro de 2007.

$$
\text { We }
$$

Prof. Dr. Carlos Pelleschi Taborda Vice-Coordenador CEEA - ICB/USP

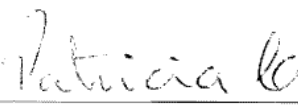

Profa. Dra. PATRICIA CASTELUCC Secretária da CEEA - ICB/USP 
Analita Dias dos Santos

(In memorian)

Com quem tive o privilégio de conviver e aprender a viver

"Olhai para as aves do céu, que nem semeíam, nem segam, nem ajuntam em celeiros; e vosso Pai celestial as alimenta.

Não tendes vós muito maís valor do que elas?"

Mateus 6:26 
AGRADECIMENTO ESPECIAL

Aos meus pais e minha irmã Nicole, pelo amor, apoio, carinho incondicionais e por sempre acreditarem em mim!

Ao Eduardo, pelo amor e incentivo. Pelo apoío em todos os momentos! 


\section{AGRADECIMENTO}

A Deus, pelo dom da vida e por dar forças para quando não mais existia!

À Prof. Lucia Lopes, pela confiança, por ter aberto as portas de seu laboratório e dado condições para que este trabalho fosse realizado.

Aos meus irmãos, Marilon e Marlone, e familiares, Roberta, Bruno, Vinicius, Analícia, Valquiria, Bruna, Alyne, Peterson e os anexos da família (Luciane, Itiel, Louise, Renato, Reury, Ezequias, Oscarlina) pelo apoio constante e compreensão nos meus momentos de ausência.

Aos amigos do Laboratório de Sinalização Redox, ao Sidney pelo excelente apoio técnico durante este trabalho. Às amigas Aline Androwiki, Luciana Guimarães e Lívia de Lucca pela amizade e apoio técnico que foram fundamentais para a execução deste trabalho. Aos novos colegas de Laboratório, Flavia e Leandro, obrigada pela companhia e amizade!

Ao Prof. Francisco Laurindo, pela contribuição cientifica que enriqueceu trabalho. Agradeço também à Denise Fernandes pelas sugestões e discussões cientificas e Maria Bertollini pelo auxilio técnico nos experimentos no HLPC. Ao Victor Debbas, por também contribuir com a realização de alguns experimentos e pela inestimável amizade. Agradeço também ao Marcus Paes, Thalita e Andréia pela amizade valiosa construída ao longo deste período.

Às Professoras Maria Helena, Zuleica e Rita Tostes pela permissão para a utilização de seus Laboratórios, sugestões e discussões que foram de extrema valia para a concretização deste trabalho.

Ao Prof. Wothan T. Lima por abrir as portas de seu Laboratório (Inflamação Pulmonar) para a realização dos experimentos de Reatividade Vascular. Agradeço ainda pelas conversas filosóficas e por transmitir o olhar sensível a respeito das ciências e da vida. Aos amigos que fiz neste Laboratório, Adriana, Helory, Zilma, Isabelli, Ana Paula, Fernando, Luana e em especial, Alexandre e João.

Aos funcionários do Biotério, em especial, Marcelo e lone, pela prontidão no fornecimento de animais e especialmente à Renaide, pelo auxilio e momentos de descontração.

À Prof. Luciana Rossoni, pela atenção dispensada nos momentos de dúvidas e descontração nos Congressos.

À Graziela Ceravolo, sou grata pelas discussões e ensinamentos. Sinto-me privilegiada por ter sua amizade! 
Aos amigos que não participaram diretamente deste trabalho, mas que sempre muito me apoiaram! Marco Antonio, Fernanda Barreto, Cristiano Ricardo, Eliana Varise, Viviani Millan, Priscila Monteforte, Patricia Nancy, Vivian Zollar, Erika Teixeira, Adriana Prato, Carla Guimarães, Aline Maia, Paula Campi, Simone Bolonheis, Carly, obrigada por tudo!

Agradeço pelo auxilio técnico e pelas conversas (cientificas ou não) à Eliana Akamine, Aparecida de Oliveira, Thiago, Antonio, Ana Rita, Marta, Alice Barreto. Pela ajuda nos experimentos de Reatividade Vascular, agradeço à Sonia pelos ensinamentos práticos.

Ao prof. Luiz Carlos G. Britto pela realização de parte dos experimentos de imunohistoquímica em seu Laboratório. Ao Adilson, pelo auxílio nos experimentos, conversas e muitos cafés ao longo deste trabalho.

Às funcionárias da Biblioteca, Eva e Tereza, pela importante ajuda na estruturação deste trabalho e às Secretárias da Pós-Graduação do Departamento, Selma, Julieta e Camila, no auxílio com assuntos burocráticos. 
Este trabalho contou com o apoio financeiro do Conselho Nacional de Desenvolvimento Científico e Tecnológico (CNPq). 


\section{RESUMO}

Dias, A.A.S. Papel da Proteína Dissulfeto Isomerase na Resposta Contrátil à Angiotensina II e Noradrenalina: Envolvimento da NADPH oxidase. Tese (Doutorado em Farmacologia) - Instituto de Ciências Biomédicas, Universidade de São Paulo, São Paulo, 2011.

As espécies reativas de oxigênio (EROs) são intermediários de vias de sinalização que regulam eventos celulares relevantes na função de células musculares lisas vasculares como migração, proliferação e contração. A NADPH oxidase é a principal fonte enzimática de EROs com finalidade sinalizadora no sistema cardiovascular. Estudos do nosso grupo demonstraram que a proteína dissulfeto isomerase (PDI), uma chaperona redox do retículo endoplasmåtico é capaz de modular a geração de EROs e a ativação de vias de sinalização redox dependentes pela Ang II. Apesar dos recentes avanços na compreensão dos mecanismos que regulam a interação entre a PDI e NADPH oxidase, o papel desta chaperona nos efeitos biológicos relacionados a EROs, como a contração vascular, não estão esclarecidos. A inibição da resposta contrátil pelo DTNB, um oxidante de tióis sugere o envolvimento de proteínas contendo tióis como a PDI e a NADPH oxidase na contração de aortas isoladas estimuladas com Ang II. Estes resultados foram confirmados por experimentos que demonstraram a expressão de PDI em todas as camadas vasculares da aorta de ratos Wistar e uma co-localização desta proteína com a isoforma NOX-1. A inibição da PDI diminuiu a geração de EROs e a reatividade vascular induzida por Ang II e NOR independente da presença do endotélio. A investigação dos mecanismos envolvidos sugere um papel da PDI na mobilização de cálcio dos estoques intracelulares via NADPH oxidase. A ativação de MAP quinases contribuiu para aumentar a mobilização de cálcio intracelular em aortas estimuladas com Ang II e NOR. No entanto, a inibição da PDI reduziu a fosforilação da ERK 1/2 em aortas estimuladas com Ang II, mas não com NOR. A análise conjunta dos nossos resultados sugere que mecanismos redox dependentes e independentes estariam envolvidos na regulação da resposta contrátil à Ang II e NOR pela PDI.

Palavras - chaves: Proteína dissulfeto isomerase (PDI). Reatividade vascular. Angiotensina II. Noradrenalina. NADPH oxidase. Espécies reativas de oxigênio (EROs). 


\begin{abstract}
Dias, AAS. Role of Protein disulfide isomerase in vascular reactivity of Angiotensin II and Noradrenaline: Involvement of NADPH oxidase [Ph. D thesis (Pharmacology)]. São Paulo: Instituto de Ciências Biomédicas, Universidade de São Paulo, São Paulo: 2011.

Reactive oxygen species (ROS) are intermediates of signaling pathways which regulates cellular events relevant for the vascular smooth cells function as migration, proliferation and contraction.The NADPH oxidase is the main enzimatic source of ROS with the signaling purpose on the cardiovascular system. We previously demonstrated that the protein disulfide isomerase (PDI), a redox chaperone of endoplasmic reticulum, is able to modulate the ROS generation and the activation of signaling redox ways dependent of Ang II. Although the recent advances in the understanding of mechanisms that regulate the interaction of PDI and NADPH oxidase, the role of this chaperone in the biological effects related to ROS, as vascular contraction, are not well clarified. The inhibition of the contractile response by DTNB, an oxidant thiol, suggest the involvement of proteins containing thiols as the PDI and NADPH oxidase in the contraction of isolated aortas stimulated with Ang II. These results were confirmed by experiments that demonstrated the PDI expression in Wistar rats vascular layers and a co-localization of this protein with the NOX-1 isoform. PDI inhibition decreased ROS generation and the Ang II and NOR induced vascular reactivity endothelium independent. The investigation of involved mechanisms suggest that one PDI role is the calcium mobilization from the intracellular storage by NADPH oxidase way. MAPkinases activation contributed to increase de intracellualar calcium in stimulated aortas with Angll and NOR. However, the PDI inhibition reduced the ERK $1 / 2$ fosforilation in Angll- stimulated aorta, but not with NOR. Analyses of all of our results suggests that dependent and independent redox mechanims were involved in the regulation of contractile response to Ang II and NOR by PDI.
\end{abstract}

Key words: Protein Disulfide Isomerase (PDI). Vascular reactivity. Angiotensin II. Noradrenaline. NADPH oxidase. Reactive Oxygen Species (ROS). 
Ang II - Angiotensina II

ANOVA - Análise de variância

BAC- bacitracina

$\mathrm{CaCl}_{2}$ - Cloreto de cálcio

CAT- Catalase

CCE- Curvas concentração-efeito

CMLV - Células de músculo liso vascular

DAB - Diaminobenzidina

DAG - Diacilglicerol

DHE - Dihidroetidina

DHE- Dihidroetidina

DHPR - Canais sensíveis a dihidropiridina

DMEM - Meio eagle modificado por Dulbecco

DPI - Difenileno-iodônio

DTNB -5,5-ditio-bis ácido 2-nitrobenzóico

E- Etídeo

EDHF - Fatores hiperpolarizantes do endotélio

EDTA- Ácido tetracético-etilenediamino

EGFR - Receptor de fator epitelial de crescimento

EGTA - Acido tetracético etileno glicol

$\mathrm{EOH}$ - 2-hidroxietídio

ERK $1 / 2$ - Quinases 1 e 2 reguladas por sinais extracelulares

EROs - Espécies reativas de oxigênio

GCPR - Receptores acoplados à proteína G

GEF - Fatores ativadores da troca GDP/GTP 
HRP- Peroxidase extraída de raiz forte

ip- Via intraperitoneal

$\mathrm{IP}_{3}$ - Inositol trifosfato

$\mathrm{IP}_{3} \mathrm{R}$ - Receptor de Inositol trifosfato

$\mathrm{KCl}$ - cloreto de potássio

$\mathrm{KH}_{2} \mathrm{PO}_{4}$ - Monofosfato de potássio

$\mathrm{MgSO}_{4}$ - Sulfato de magnésio

MLC - Cadeia leve de miosina

MLC fosfatase - Fosfatase de cadeia leve de miosina

MLCK - Cadeia leve de miosina quinase

$\mathrm{NaCl}$ - Cloreto de sódio

NADPH oxidase - Nicotinamida adenina dinucleotídeo fosfato oxidase

NCSS - Canais não seletivos permeáveis à cátions

NO - Óxido nítrico

NOR - Noradrenalina

$\mathrm{O}_{2}$ - Oxigênio molecular

$\mathrm{O}_{2}^{-}$- Anion superóxido

$\mathrm{ONOO}^{-}$- Peroxinitrito

p- ERK1/2 - Quinases 1 e 2 reguladas por sinais extracelulares fosforilada PB - Tampão fosfato

PB- Tampão fostafato

PDI - Proteína dissulfeto isomerase

PFA- Paraformaldeído

$\mathrm{PGI}_{2}$ - Prostaglandinas

PKC - Proteína quinase C

PKG - Proteína quinase dependente de GMP cíclico

PMCA - Cálcio - ATPase da membrana plasmática 
PMSF - Fluoreto de fenilmetilsulfonil

ROC - Canais de cálcio operados por receptor

RS - Retículo sarcoplasmático

RyR - Receptores de rianodina

SCRN- Scrambled RNase

SDS- Lauril sulfato de sódio

SERCA - Cálcio-ATPase do reticulo sarcoplasmático

SOC - Canais de cálcio operados por estoque

SOD- Superóxido dismutase

TRPC - Canais de potencial transiente associados a receptor

VOC - Canais de cálcio operados por voltagem 


\section{LISTA DE ILUSTRAÇÕES}

Figura 1 - Regulação da contração vascular: mecanismos que envolvem a mobilização e influxo de cálcio e inativação da MLC fosfatase.

Figura 2 - Mecanismos de regulação de cálcio pelas EROs nas células vasculares

Figura 3 - Modelo de ativação das proteínas NOX 32

Figura 4 - Via de ativação da NADPH oxidase mediada por Angiotensina II em CMLV

Figura 5 - Reações realizadas pela PDI em substratos protéicos portadores de dissulfetos ou ditióis

Figura 6 - Representação esquemática da estrutura da PDI 38

Figura 7 - Registro típico do estudo da participação do cálcio intracelular e extracelular na resposta vasoconstritora induzida pela Noradrenalina

Figura 8 - Desenho experimental do estudo da participação do cálcio intracelular e extracelular na resposta vasoconstritora induzida pela Noradrenalina na presença de inibidores de PDI

Figura 9 - Efeito de um oxidante de tióis (DTNB) na resposta contrátil à Angiotensina II

Figura 10 - Determinação da expressão e localização da PDI na aorta por imunohistoquímica

Figura 11- Co-localização entre PDI e NOX-1 por microscopia de fluorescência

Figura 12 - Papel da PDI na geração de espécies reativas de oxigênio (EROs) pela NADPH oxidase em aortas isoladas estimuladas com Angiotensina II

Figura 13 - Papel da PDI na geração de espécies reativas de oxigênio pela NADPH oxidase em aortas isoladas estimuladas com Noradrenalina

Figura 14 - Efeito da bacitracina na resposta contrátil a Angiotensina II

Figura 15 - Papel do endotélio na inibição da resposta contrátil à Angiotensina II pela bacitracina 
Figura 16- Papel do endotélio na inibição da resposta contrátil à Angiotensina II pela Scrambled RNase

Figura 17- Efeito da Bacitracina na resposta contrátil à Noradrenalina 66

Figura 18 - Papel da PDI e das espécies reativas de oxigênio na resposta contrátil à Angiotensina II

Figura 19 - Papel da NADPH oxidase na inibição da resposta contrátil à Angiotensina II pela bacitracina

Figura 20 - Papel da NADPH oxidase na inibição da resposta contrátil à Noradrenalina pela bacitracina

Figura 21 - Papel da inibição da PDI na mobilização e influxo de cálcio durante a contração induzida por Noradrenalina em aortas isoladas

Figura 22 - Efeito da estimulação de aortas isoladas com Angiotensina II e Noradrenalina na fosforilação da ERK 1/2

Figura 23 - Efeito da inibição da PDI sobre a fosforilação da ERK 1/2 após estimulação com Angiotensina II

Figura 24 - Efeito da inibição da PDI sobre a fosforilação da ERK 1/2 após estimulação com Noradrenalina 


\section{LISTA DE TABELAS}

Tabela 1- NADPH oxidase vascular. 


\section{SUMÁRIO}

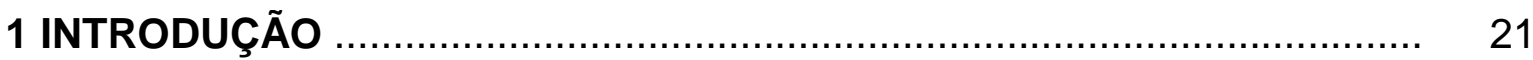

1.1 Mecanismos envolvidos na regulação do tônus vascular ............................ 21

1.1.1 Angiotensina II e Noradrenalina como fatores vasoconstritores ............... 22

1.1.2 Mecanismos dependentes de cálcio .................................................. 23

1.1.3 Mecanismos independentes de cálcio: papel da Rho quinase ................. 25

1.1.4 Papel de EROs na Regulação da concentração de cálcio intracelular pela Ang II ....

1.2 NADPH oxidase: principal sistema gerador de espécies reativas de

oxigênio no sistema vascular ................................................................ 30

1.3 Proteína dissulfeto isomerase (PDI) ..................................................... 36

1.3.1 Estrutura e funções da PDI .......................................................... 36

1.3.2 Papel fisiológico da PDI................................................................. 38

1.3.3 PDI como reguladora da atividade da NADPH oxidase............................ 39

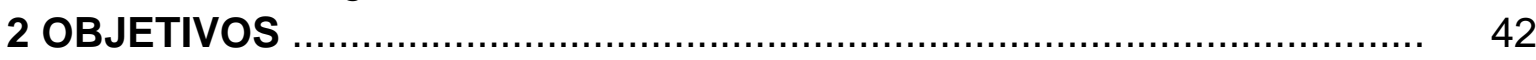

3 MATERIAL E METODOS ……....................................................... 43

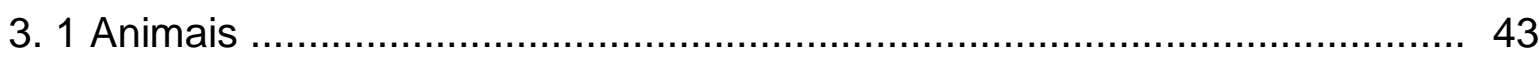

3.2 Determinação da localização da proteína dissulfeto isomerase na aorta de ratos Wistar .................................................................................... 43

3.2.1 Obtenção do material....................................................................... 43

3.2.2 Imunohistoquímica....................................................................... 44

3.3 Análise da co localização da proteína dissulfeto isomerase e NOX-1 na

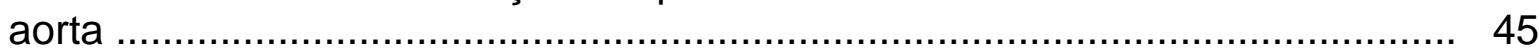

3.3.1 Obtenção do material........................................................................ 45

3.3.2 Imunofluorescência.......................................................................... 45

3.4 Análise da fluorescência derivada dos produtos de oxidação da diihidroetidina em cortes histológicos ................................................................ 46

3.5 Estudo da reatividade vascular à Ang II em anéis de aorta de ratos Wistar 46

3.5.1 Estudo in vitro da reatividade de anéis de aorta torácica isolada de ratos Wistar ............................................................................................ 46

3.5.2 Análise do papel de inibidores da PDI na resposta contrátil induzida pela Angiotensina II e Noradrenalina................................................................. 48

3.5.3 Análise da participação de proteínas contendo grupos tióis na resposta vascular induzida pela Angiotensina II...................................................... 48

3.5.4 Análise da participação da NADPH oxidase na modulação da resposta contrátil pela PDI............................................................................. 49

3.5.5 Análise participação das EROs na modulação da resposta contrátil pela PDI.

3.6 Análise do papel do cálcio intracelular e extracelular na resposta vasoconstritora à Noradrenalina.................................................................... 49

3.6.1 Análise da participação da PDI na mobilização e influxo de cálcio induzida pela NOR.

3.7 Análise do papel da PDI na ativação de MAP quinases pela Angiotensina II

e Noradrenalina em aortas com endotélio

3.7.1 Análise da curva temporal de fosforilação da ERK $1 / 2$ em aortas estimuladas com Angiotensina II e Noradrenalina.

3.7.2 Análise do papel da PDI na fosforilação de ERK 1/2 em aortas 
estimuladas com Angiotensina I/ e Noradrenalina

3.7.2.1 Estimulação das aortas............................................................ 51

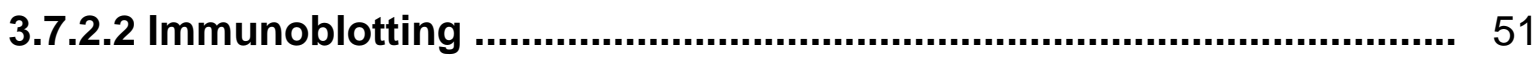

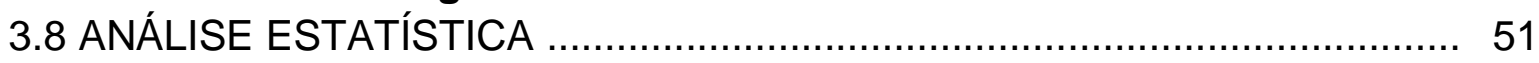

4 RESULTADOS …........................................................................... 52

4.1 Efeito de um oxidante de tióis na contração induzida pela Angiotensina II 53

4.2 Expressão de PDI e NOX-1 em aortas isoladas....................................... 53

4.3 Efeito da inibição da PDI e da NADPH oxidase na geração de EROs induzida por Angiotensina II e Noradrenalina . ............................................. 53

4.4 Efeito de inibidores da PDI na resposta contrátil à Angiotensina II .............. 54

4.4.1 Papel do endotélio ........................................................................ 54

4.5 Papel de EROs na inibição da resposta contrátil à Angiotensina II induzida pela bacitracina ........................................................................... 55

4.6 Papel da NADPH oxidase na inibição da resposta contrátil à Angiotensina II e Noradrenalina .............................................................................. 55

4.7 Efeito da inibição da PDI sobre a mobilização e o influxo de cálcio durante a contração por Noradrenalina ................................................................. 56

4.8 Efeito da inibição da PDI sobre a fosforilação da ERK 1/2 após estímulo com Angiotensina II e Noradrenalina ......................................................... 57

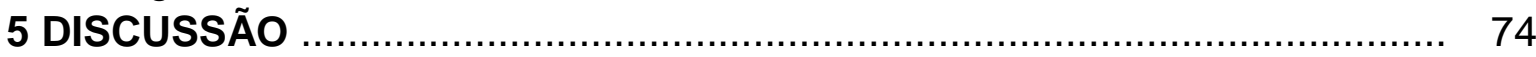

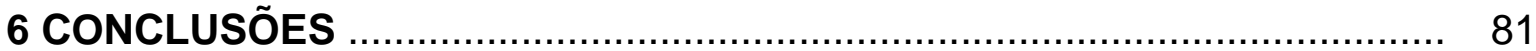

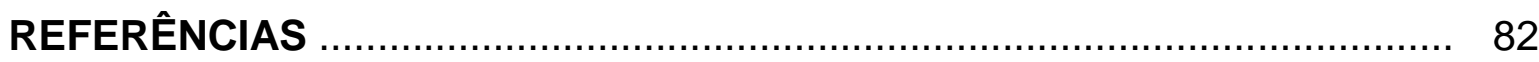




\section{INTRODUÇÃO}

\subsection{Mecanismos envolvidos na regulação do tônus vascular}

No sistema vascular as artérias de pequeno calibre são responsáveis pela regulação do fluxo sanguíneo na circulação sistêmica. O fluxo laminar, a liberação de hormônios e fatores derivados do endotélio participam da regulação do tônus vascular ajustando o diâmetro do lúmen que em última instância controla a pressão arterial e distribui o fluxo sanguíneo através dos diferentes órgãos (Wynne et al., 2009). O sistema cardiovascular é formado por componentes celulares (endotélio, células de músculo liso vascular e fibroblasto) e por matriz extracelular. Os componentes deste sistema são ativos, dinâmicos e capazes de reorganizarem-se em resposta a estímulos fisiológicos ou patológicos (Schiffrin, 1992; Dubey, 1997).

As artérias são compostas de três camadas: túnica adventícia, túnica média e túnica íntima. Enquanto as camadas externa e interna são formadas essencialmente por tecido conectivo e células endoteliais, a túnica média é composta por células musculares lisas. O endotélio compõe a camada íntima dos vasos sanguíneos e é importante na regulação do tônus vascular, exercendo papel na regulação do fluxo sanguíneo e na prevenção da formação de trombos. A regulação do tônus vascular pelo endotélio ocorre através da liberação de fatores vasoconstritores como endotelina e vasodilatadores como óxido nítrico (NO), prostaglandinas $\left(\mathrm{PGI}_{2}\right)$ e fatores hiperpolarizantes do endotélio (EDHF) (Galley e Webbster, 2004; Wrzosek, 2009).

A camada média dos vasos sanguíneos é composta por células de músculo liso vascular (CMLV) e matriz extracelular e está associada ao controle do tônus vascular. Em situações de lesão vascular, esta camada sofre proliferação e remodelamento (Mulvany e Aalkjaer, 1990; Schiffrin, 1994). Diversos fatores locais e sistêmicos podem regular as funções das CMLV como agentes vasoativos como endotelina-1, angiotensina II (Ang II) e vasodilatadores como NO e prostaciclina. A principal função das CMLV é a contração vascular, o que requer a ativação de vias de sinalização especifica e geração de segundos mensageiros. A contração vascular inicia-se com a interação de agentes vasoconstritores como noradrenalina (NOR) e Ang II com seus receptores, $\alpha-1$ e $A T_{1}$ respectivamente, nas membranas das CMLV. 
Estes receptores são denominados receptores acoplados à proteína G ou GCPR. Em resposta ao estimulo de um agente vasoconstritor, as CMLV se contraem rapidamente. Contudo, a exposição continua à vasoconstritores como Ang II, por exemplo, pode levar à proliferação e migração das CMVL para a camada íntima, o que culmina no espessamento da camada média e formação de uma nova camada vascular denominada neoíntima. Este evento resulta no remodelamento do vaso e está relacionado à disfunção vascular e patologias como a hipertensão arterial sistêmica (Fyhrquist e Saijonmaa, 2008; Nguyen e Touyz, 2011).

\subsubsection{Angiotensina Il e Noradrenalina como fatores vasoconstritores}

A ligação Ang II e NOR ao seu receptor específico, $A T_{1}$ e $\alpha-1$, resulta na ativação de proteínas $\mathrm{G}$ do tipo $\mathrm{Gq} / 11, \mathrm{Gi}, \mathrm{G} 12$ ou $\mathrm{G} 13$. Os receptores $A T_{1}$ e $\alpha-1$ podem sinalizar por 3 vias principais: i) ativação de fosfolipase $C(P L C)$ e formação de inositol trifosfato $\left(\mathrm{IP}_{3}\right)$ e diacilglicerol (DAG) ii) ativação de fosfolipase $\mathrm{D}$ e formação de DAG a partir do ácido fosfatídico e iii) ativação de fosfolipase $A_{2}$ e formação de ácido araquidônico e eicosanóides. A regulação da contração vascular pela Ang II e NOR é mediada via ativação de fosfolipase $C$ e formação de $\mathbb{I P}_{3}$ e DAG. O IP 3 e DAG são os intermediários na regulação do aumento de cálcio $\left(\mathrm{Ca}^{+2}\right)$ intracelular e fosforilação da cadeia leve de miosina (MLC) (Wynne et al., 2009) necessários para a contração $C M L V$. $O \mathbb{I P}_{3}$ se liga ao seu receptor $\left(\mathrm{IP}_{3} \mathrm{R}\right)$ presente na membrana do retículo sarcoplasmático (RS). Esta interação promove a saída do $\mathrm{Ca}^{+2}$ do RS e produz uma rápida elevação da concentração deste íon no citosol. $\mathrm{O}$ alvo primário do $\mathrm{Ca}^{+2}$ é a calmodulina, um dímero com quatro sítios de ligação ao $\mathrm{Ca}^{+2}$ capaz de ativar a quinase de cadeia leve de miosina (MLCK).

Por sua vez, o DAG e as altas concentrações de cálcio $\left(\mathrm{Ca}^{+2}\right)$ ativam a proteína quinase $C$ (PKC). As células musculares lisas vasculares possuem 3 isoformas de PKC: $\mathrm{PKC} \alpha, \mathrm{PKC} \beta$ que são cálcio e DAG dependentes e a $\mathrm{PKC} \varepsilon$ que só depende de DAG para sua ativação. Além da fosforilação da MLCK a PKC pode ainda ativar outras proteínas envolvidas com a contração como quinases 1 e 2 reguladas por sinais extracelulares (ERK 1/2), Rho quinase e a proteína quinase dependente de calmodulina II. Uma vez ativada, via PKC ou pelo complexo $\mathrm{Ca}^{+2}$ calmodulina, a MLCK fosforila a MLC. A fosforilação da MLC possibilita a interação 
entre os filamentos de actina e miosina. A energia liberada do ATP pela atividade intrínseca de uma ATPase localizada na cabeça da miosina leva a formação de pontes cruzadas entre os filamentos de actina e miosina resultando na contração. Desta forma, a contração é determinada essencialmente pelo estado de fosforilação da MLC. Em algumas CMLVs, a fosforilação da MLC é mantida em níveis reduzidos capazes de manter a contração ainda que na ausência de estímulos mecânicos ou da ativação de receptores e esta atividade resulta no tônus do músculo liso (Webb, 2003).

\subsubsection{Mecanismos de contração vascular dependentes de cálcio}

Os mecanismos que modulam a concentração de $\mathrm{Ca}^{+2}$ intracelular também regulam a contração da musculatura lisa vascular. As CMLV possuem um nível intracelular de cálcio muito inferior em comparação aos níveis extracelulares. A liberação de $\mathrm{Ca}^{+2}$ do $\mathrm{RS}$ induzida por agonistas produz uma elevação rápida e transitória suficiente para iniciar a contração. Contudo, os estoques de $\mathrm{Ca}^{+2}$ do RS são finitos e torna-se necessário o influxo de $\mathrm{Ca}^{+2}$ através dos canais de cálcio presentes na membrana plasmática para a manutenção da contração. As modificações no influxo de $\mathrm{Ca}^{+2}$ em CMLVs dependem essencialmente da mobilização das reservas intracelulares e do cálcio presente no meio extracelular derivado dos canais de cálcio localizados na membrana plasmática. Existe uma ampla variedade de canais iônicos implicados neste processo e seu papel depende do tipo do leito vascular e da natureza do estimulo envolvido. Está claramente estabelecido que os canais de $\mathrm{Ca}^{+2}$ operados por voltagem (VOC) exercem função essencial no aumento intracelular de $\mathrm{Ca}^{+2}$ durante a contração de CMLV (Berridge, 2008). Além dos VOC, os canais de $\mathrm{Ca}^{+2}$ operados por receptor (ROC), canais de $\mathrm{Ca}^{+2}$ operados por estoque (SOC), canais não seletivos permeáveis à cátions (NCSS) e os canais de potencial transiente associados a receptor (TRP) são importantes canais envolvidos com o influxo de $\mathrm{Ca}^{+2}$ nas CMLV (Trebak et al., 2010).

Os canais de $\mathrm{Ca}^{+2}$ operados por voltagem (VOC) representam a principal via de entrada de $\mathrm{Ca}^{+2}$ nas CMLV e sua função é regulada pelo potencial de membrana, 
de forma que a despolarização das células promove a abertura do canal e o influxo de $\mathrm{Ca}^{+2}$. Os canais sensíveis a dihidropiridina (DHPR) ou canais do tipo $L$ são regulados por vasoconstritores como NOR e Ang II via ativação de PKC, que fosforila estes canais, ativando-os. Estes canais também podem ser ativados pelo estiramento que leva à despolarização da membrana reforçando o papel de destes canais na resposta miogênica e no controle do tônus vascular (Berridge, 2008). A ativação dos canais do tipo VOC pode ainda ser induzida pela ação de PLC, PKC ou tirosina quinases mediadas pela angiotensina intracelular de modo independente da interação da Ang II com seu receptor AT ${ }_{1}$ (Eto et al., 2002). A inibição de VOC ocorre inicialmente em resposta ao aumento da concentração de $\mathrm{Ca}^{+2}$ intracelular e ativação da proteína quinase dependente de GMP cíclico (PKG) o que diminui o influxo de $\mathrm{Ca}^{+2}$ (Hughes, 1995; Jackson, 2000; Chitaley et al., 2001; Wynne et al., 2009). Além disso, o aumento da concentração de cálcio induzido pela abertura dos VOC pode levar a liberação do cálcio das reservas intracelulares num fenômeno denominado liberação de cálcio induzida por cálcio. Este mecanismo é mediado pelos canais de cálcio modulados pelo $\mathrm{IP}_{3}$ e garante a saída de cálcio do retículo sarcoplasmático aumentando os níveis de cálcio intracelular e despolarização o que promove a abertura de mais canais do tipo VOC (Zhang e Li, 2006).

A interação de um agente vasoconstritor com seu receptor acoplado à proteína $G$ e formação de segundos mensageiros como $\circ \mathrm{IP}_{3}$ e $\circ \mathrm{DAG}$ pode ainda ativar os canais de $\mathrm{Ca}^{+2}$ operados por receptor, ROC (Morris et al., 1987; Kuno e Gardner, 1987, Miwa et al., 2005) e também dos canais de cálcio do tipo transiente TRPC3, TRPC6 e TRPC7 aumentando o influxo de cálcio nas CMLV. A depleção de $\mathrm{Ca}^{+2}$ do RS por sua vez, pode ativar outro tipo de canal, o canal de $\mathrm{Ca}^{+2}$ operado por estoque (SOC). Este canal foi inicialmente descrito por Putney e colaboradores (1986) que demonstraram que a entrada de $\mathrm{Ca}^{+2}$ mediada por agonistas ocorria como uma resposta à depleção do estoque intracelular deste íon, mesmo na ausência da ativação do receptor e formação de $\mathrm{IP}_{3}$. Desta forma, a ativação e abertura de SOC na membrana plasmática ocorre em resposta à depleção do estoque de $\mathrm{Ca}^{+2}$ do RS. Assim, o influxo de $\mathrm{Ca}^{+2}$ por estes canais é direcionado para reposição dos estoques do RS. Quando os níveis de $\mathrm{Ca}^{+2}$ intracelular estão elevados, ocorre inibição deste canal e desta forma, redução do influxo de $\mathrm{Ca}^{+2}$ pela membrana plasmática (Putney et al., 1986; Wynne et al., 2009). Além do seu papel 
na contração, $\mathrm{SOC}$ tem sido implicado no aumento de $\mathrm{Ca}^{+2}$ intracelular durante a apoptose e proliferação de CMLV (Wamhoff et al., 2006). A bomba Cálcio-ATPase do retículo sarcoplasmático (SERCA) é responsável por promover a reposição dos estoques de $\mathrm{Ca}^{+2}$ no $\mathrm{RS}$, reduzindo a concentração de $\mathrm{Ca}^{+2}$ intracelular. De fato, a inibição da SERCA pelo ácido ciclopiazônico e tapsigargina resulta na manutenção de níveis elevados de cálcio intracelular o que promove a entrada de $\mathrm{Ca}^{+2}$ do meio extracelular através de canais do tipo SOC aumentando a contração (Wynne et al., 2009).

Em resumo a ativação de receptores acoplados a proteína G por NOR e Ang II ativa dois mecanismos responsáveis pelo aumento do cálcio intracelular e contração de CMLV: i) um aumento inicial através da liberação dos estoques de cálcio intracelulares (RS) ii) seguido de uma entrada lenta e gradativa de cálcio do meio extracelular resultante da abertura de canais de cálcio na membrana plasmática (estoque extracelular) (Figura 1).

\subsubsection{Mecanismos independentes de cálcio: papel da Rho quinase}

O processo de geração da força contrátil em CMLV é dependente de $\mathrm{Ca}^{+2}$, porém a manutenção desta contração decorre de mecanismos independentes de cálcio que dependem essencialmente da modulação da atividade da fosfatase de cadeia leve de miosina (MLC fosfatase) cuja função é remover o grupamento fosfato da cadeia de miosina levando ao relaxamento da CMLV. A MCL fosfatase é uma enzima constituída por três subunidades: uma subunidade pequena não catalítica cuja função é desconhecida, uma subunidade alvo da miosina (MYPT), e a subunidade catalítica, PP1c. A interação entre MYPT e PP1c inibe a atividade catalítica da MLC fosfatase, e resulta na manutenção da MLC no estado fosforilado, favorecendo a contração (Ishikawa et al., 1996, Brozovich, 2002). Esta modulação da atividade da fosfatase depende de uma proteína GTPase denominada RhoA. A RhoA é uma proteína regulada por GTP cuja ligação ao GTP é facilitada por GEF (fatores ativadores da troca GDP/GTP) que por sua vez ativam a RhoA. Uma vez ativada, o complexo RhoA-GTP ativa uma serina/treonina quinase denominada Rho 
kinase que fosforila a subunidade MYPT da miosina fosfatase, inativando-a. A interação da NOR ou Ang II com seu receptor, leva a ativação de proteínas $G$ do tipo $\mathrm{G}_{12 / 13}$ que ativam estes fatores de troca GDP/GTP (GEF) resultando na ativação da via $R h o A / R h o$ quinase (Figura 1). De fato inibidores da Rho quinase como Y-27632 e fasudil induzem ao relaxamento em segmentos de aorta contraídos por fenilefrina (Chintaley et al., 2001) e Ang II (Hilgers e Webb, 2005).

A diminuição da contratilidade da CMLV ou vasodilatação é mediada por mecanismos que limitam a entrada de $\mathrm{Ca}^{+2}$ pela membrana plasmática em combinação com a redução de $\mathrm{Ca}^{+2}$ intracelular. A hiperpolarização da membrana fecha os canais do tipo $L$ e favorece o influxo de $\mathrm{K}^{+}$. No citoplasma, a ação da SERCA bombeia $\circ \mathrm{Ca}^{+2}$ de volta para o retículo, favorecendo a reposição do estoque no RS e a Cálcio - ATPase da membrana plasmática (PMCA) bombeia $\mathrm{Ca}^{+2}$ para fora da célula. 
Figura 1 - Regulação da contração vascular: mecanismos que envolvem a mobilização e influxo de cálcio e inativação da MLC fosfatase

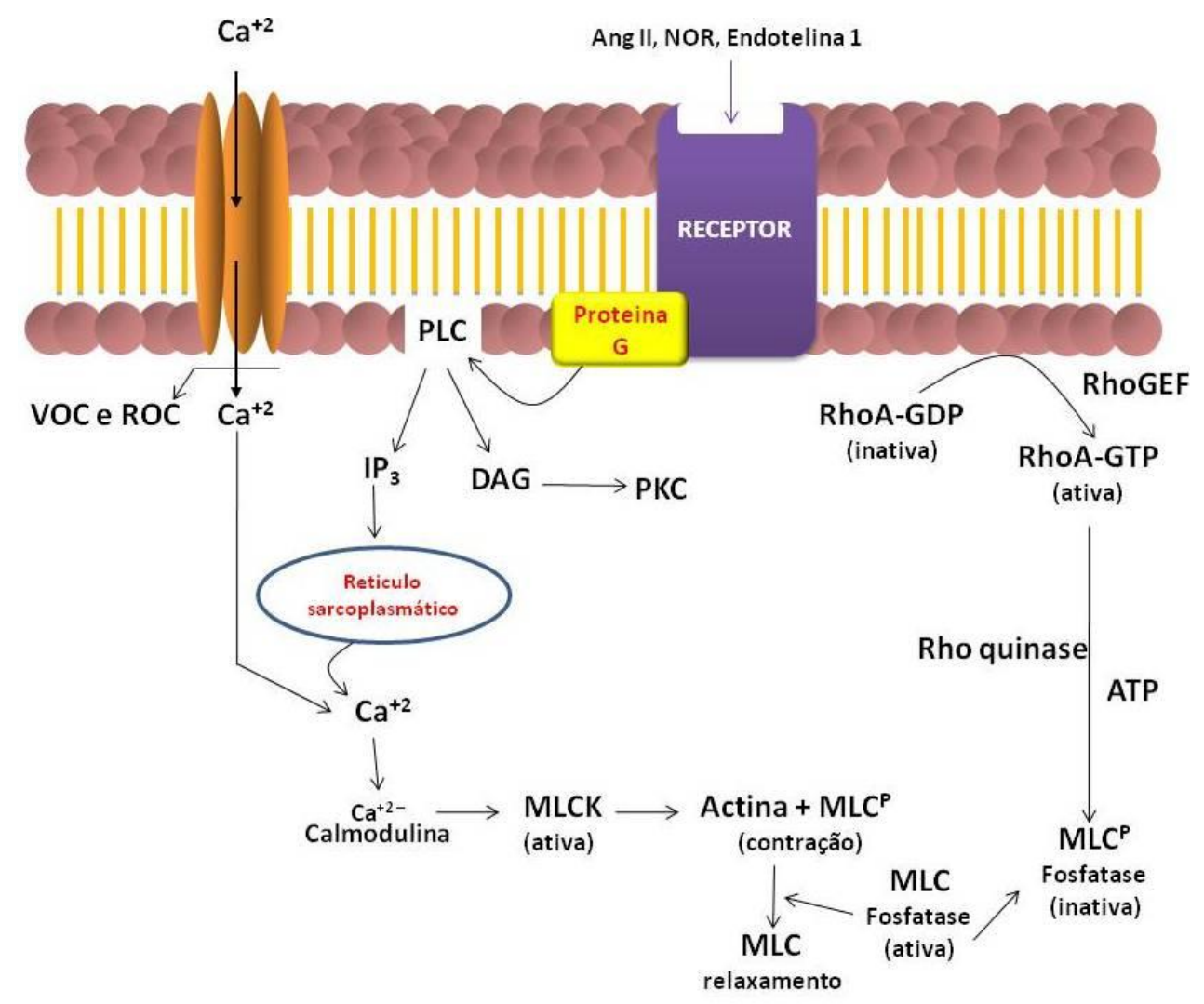

Regulação da contração do músculo liso. Vários agonistas como angiotensina II (Ang II), noradrenalina (NOR) e endotelina-1 se ligam ao seu receptor especifico para ativar a contração no músculo liso. Subsequente a esta ligação, ocorre aumento da atividade da fosfolipase $C$ (PLC) devido a ligação do agonista ao receptor acoplado à proteína G. A PLC induz a formação de dois segundos mensageiros: o diacilglicerol (DAG) e o trifosfato inositol $\left(\mathrm{IP}_{3}\right)$. $\mathrm{O} \mathrm{IP}_{3}$ se liga ao seu receptor especifico $\left(\mathrm{IP}_{3} \mathrm{R}\right)$ no retículo sarcoplasmático (RS) causando liberação de cálcio $\left(\mathrm{Ca}^{+2}\right)$. O DAG ativa proteína quinase $C(P K C)$ que causa fosforilação de proteínas alvo especificas. Na maioria das células de músculo liso, a PKC promove a contração devido a fosforilação de canais de $\mathrm{Ca}^{+2}$ e de outras proteínas que regulam o ciclo de pontes cruzadas. $\mathrm{O} \mathrm{Ca}^{+2}$ se liga a calmodulina causando ativação da cadeia leve de miosina quinase (MLCK). Esta quinase fosforila a cadeia leve de miosina (MLC) e associada à actina, formam as pontes cruzadas. Entretanto, a elevação do $\mathrm{Ca}^{+2}$ é transitória e a resposta contrátil é mantida por mecanismos que envolvem a sensibilização ao $\mathrm{Ca}^{+2}$, inibindo a fosfatase de cadeia leve de miosina (MLC fosfatase) pela atividade da Rho quinase. Este mecanismo de sensibilização ao $\mathrm{Ca}^{+2}$ é iniciado quando a PLC é ativada e envolve a ativação da RhoA ligada ao GTP. O mecanismo preciso da ativação de RhoA pelos receptores acoplados a proteína G não é completamente esclarecido mas envolve os fatores de guanina ativadores de troca (RhoGEF) e migração de RhoA para membrana plasmática. Após a ativação, RhoA induz a ativação Rho quinase, levando a inativação de MLC fosfatase, o que leva a estado contrátil, uma vez que a MLC não pode ser desfosforilada.

Fonte: Ilustração adaptada de Webb, 2003 


\subsubsection{Papel de EROs na regulação da concentração de cálcio intracelular}

Os efeitos diretos de EROs na ativação da sinalização por $\mathrm{Ca}^{+2}$ tem sido observados em CMLV. Diversos estudos empregando EROs exógeno ou produzido via sistema xantina/hipoxantina $(\mathrm{XO} / \mathrm{HX})$ tem relatado um aumento de $\mathrm{Ca}^{+2}$ intracelular nestas células (Touyz, 2005; Hildago e Donoso, 2008). Os principais efeitos das EROs que contribuem para este aumento da concentração de $\mathrm{Ca}^{+2}$ intracelular são decorrentes da inibição da SERCA e/ou ativação de canais de cálcio na membrana (Ermak e Davies, 2002). Dentre os possíveis mecanismos envolvidos, o fato de reagentes que se ligam a grupamento sulfidrílicos inibirem a atividade da SERCA (Scherer e Deamer, 1986) e a reversão deste efeito por agentes redutores sugerem que EROs poderiam inibir a SERCA através da oxidação irreversível dos grupamentos sulfídrilicos presentes no sitio ativo desta ATPase (Grover et al., 2003)

As proteínas transportadoras de cálcio também são alvo de EROs. Assim proteínas como a) canais de cálcio do tipo $L$ e $T$, canais de cálcio ligados ao receptor de RyR, canal de $\mathrm{K}^{+}$ativado por $\mathrm{Ca}^{+2}$; b) trocadores iônicos como trocadores de $\mathrm{Na}^{+} / \mathrm{Ca}^{+2}$ e de $\mathrm{Na}^{+} / \mathrm{H}^{+}$; c) co transportadores de $\mathrm{Na}^{+} / \mathrm{Cl}^{-}$e $\mathrm{Na}^{+} / \mathrm{K}^{+} / \mathrm{Cl}^{-}$tem sua atividade modulada pela Ang II (Kourie, 1998). Desta forma, a geração de EROs induzida pela Ang II nas células vasculares poderia modular também o influxo de cálcio através da membrana celular. De fato, estudos realizados por Tabet e colaboradores (2004) demonstraram que $\mathrm{H}_{2} \mathrm{O}_{2}$ e $\mathrm{O}_{2}{ }^{-}$estimulam o influxo de $\mathrm{Ca}^{+2}$ por canais do tipo $L$ e $T$ nas CMLV. Este influxo encontra-se aumentado em células de animais hipertensos, o que foi atribuído ao aumento da expressão canais do tipo $L$ nestas células (Tabet et al., 2004). Entre os mecanismos envolvidos, a ação de EROs poderia levar a modificações no transporte iônico devido a oxidação dos grupamentos sulfidrílicos localizados nas proteínas transportadoras (Kourie, 1998). De fato, a aplicação de um peptídeo vasoconstritor em conjunto com EROs potencializa a sinalização dependente de cálcio (Touyz, 2005). Isto é particularmente importante na sinalização redox pois, a Ang II induz a formação de EROs que por sua vez, aumentam a sinalização dependente de cálcio ao mesmo tempo em que 
aumenta a expressão de receptores $A T_{1}$, amplificando a ativação de vias de sinalização de cálcio dependentes de EROs (Yermolaieva et al., 2000).

Além da regulação da sinalização dependente de $\mathrm{Ca}^{+2}$, as EROs modulam também vias independente de $\mathrm{Ca}^{+2}$ através da ativação de vias como RhoA e Rho quinase (Mukai et al., 2001). De fato, em situações patológicas como na hipertensão arterial, o aumento da reatividade vascular é também decorrente do aumento da sensibilização ao $\mathrm{Ca}^{+2}$ devido a maior atividade da RhoA, Rho quinase e EROs, como $\mathrm{O}_{2}^{-}$tem sido implicados neste processo (Matsumoto et al., 2001; Kataoka et al., 2002; Kobayashi et al., 2002).

Figura 2 - Mecanismos de regulação de cálcio pelas EROs nas células vasculares

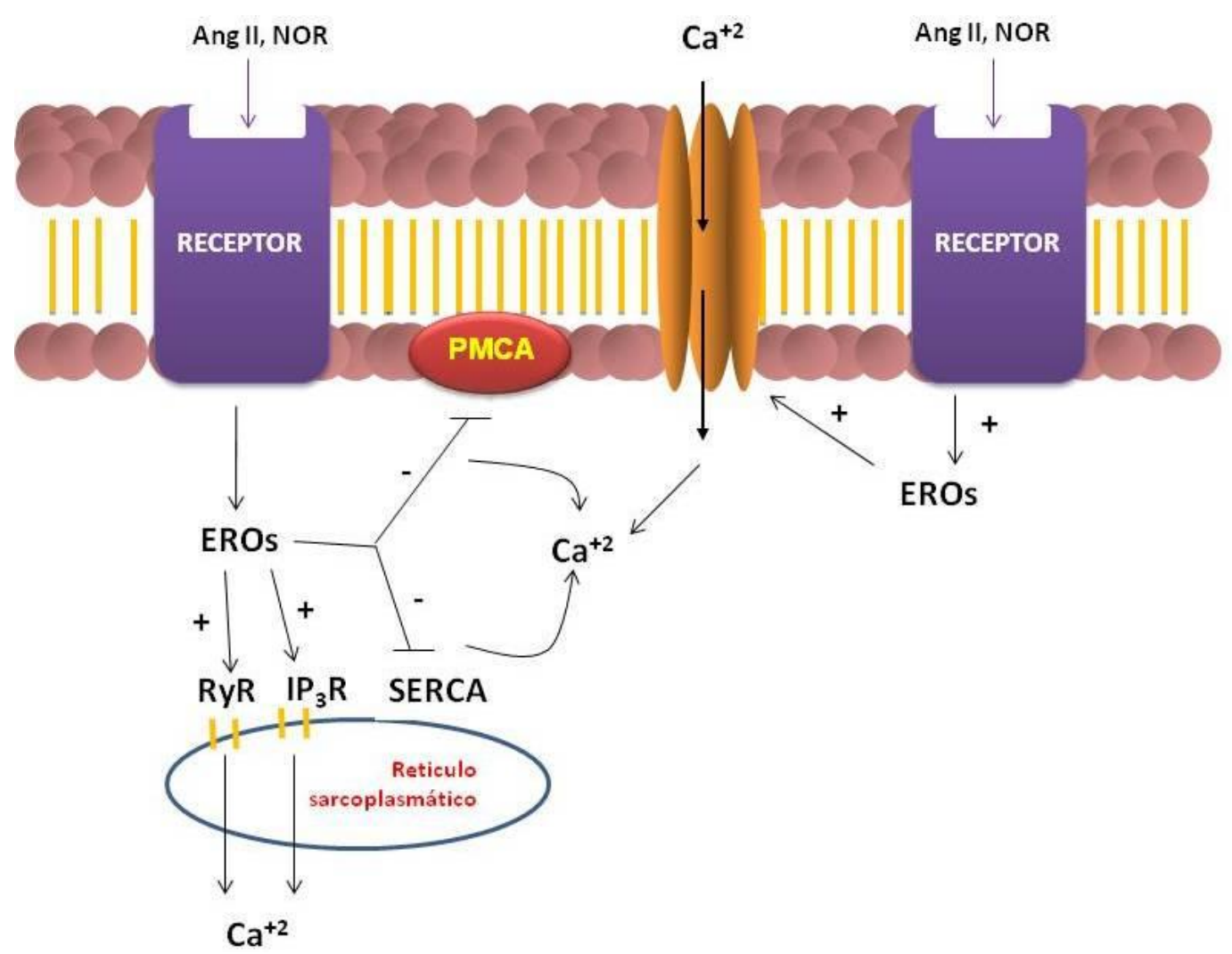

As espécies reativas de oxigênio (EROs) aumentam mobilização e influxo de $\mathrm{Ca}^{+2}$. O estimulo do receptor do trifosfato inositol $\left(\mathrm{IP}_{3} \mathrm{R}\right)$ ou da rianodina (RyR) por EROs induzem a mobilização de $\mathrm{Ca}^{+2}$. $\mathrm{A} \mathrm{Ca}^{+2}$-ATPase do retículo sarcoplasmático/endoplasmático (SERCA) e $\mathrm{Ca}^{+2}$-ATPase da membrana plasmática (PMCA) reduzem a concentração de $\mathrm{Ca}^{+2}$ intracelular e a atividade destas bombas é inibida pelas EROs, favorecendo o aumento de $\mathrm{Ca}^{+2}$ intracelular. +: efeito estimulatório; -: efeito inibitório.

Fonte: Ilustração adaptada de Touyz, 2005 
1.2 NADPH OXIDASE: Principal sistema enzimático gerador de EROs no sistema vascular

As espécies reativas de oxigênio contribuem para vários aspectos presentes em doenças vasculares, incluindo lesões por isquemia-reperfusão, inativação de NO e estímulo de processos inflamatórios e de hipertrofia (Brandes et al., 2010).

A geração de EROs pode ocorrer como subproduto de reações biológicas em mitocôndrias, peroxissomos, citocromo P-450 e em outros elementos celulares. No entanto, as NADPH oxidases, da família NOX, constituem a única fonte enzimática especificamente dedicada à geração de EROs, que através da transferência de elétrons reduzem oxigênio a superóxido, utilizando NADPH como doador de elétrons (Bedard e Krause, 2007).

A NADPH oxidase compreende, na verdade, uma família de enzimas denominadas de NOX que catalisam a redução do oxigênio molecular gerando superóxido a partir da NADPH. A NADPH oxidase presente em fagócitos (conhecida também como NOX-2) foi o primeiro exemplo identificado de um sistema gerador de ROS, estando envolvida com a atividade microbicida deste tipo celular (Babior, 1999). Posteriormente, seis homólogos da subunidade gp $91^{\text {phox }}$ da NADPH oxidase fagocítica foram descobertos em diferentes tipos celulares e foram denominados de NOX-1, NOX-3, NOX-4, NOX-5, DUOX-1 e DUOX-2. Os seis homólogos juntamente com a própria NADPH oxidase fagocítica (NOX-2) compõem a família NOX das NADPH oxidases (Bedard e Krause, 2007). A NADPH oxidase presente em células vasculares, constitui a principal fonte enzimática de geração de EROs em células no sistema cardiovascular (Lassegue e Clempus, 2003; Nguyen e Touyz, 2011).

A estrutura do complexo NADPH oxidase é relativamente complexa, composta por uma subunidade catalítica associado à membrana e, também por subunidades regulatórias, as quais se associam para formar o complexo enzimático ativo e produzir EROs. A expressão destas subunidades varia de acordo com o tipo de célula vascular, então o termo "NADPH oxidase vascular" se refere às diferentes isoformas da enzima expressas no sistema vascular, pertencentes a cada tipo celular (Laurindo et al., 2008). A Tabela 1 resume as principais subunidades catalíticas e reguladoras das diferentes isoformas da NADPH oxidase presentes em células do sistema vascular, e os seus principais efeitos celulares. A figura 3 ilustra 
modelos de ativação e os produtos gerados por diferentes isoformas da NADPH oxidase presentes no sistema vascular.

Tabela 1- NADPH oxidase vascular.

\begin{tabular}{|c|c|c|c|c|c|}
\hline & \multicolumn{3}{|c|}{$\begin{array}{c}\text { SUBUNIDADES CATALÍTICAS } \\
\text { (expressão basal) }\end{array}$} & \multirow{2}{*}{$\begin{array}{l}\text { SUBUNIDADES } \\
\text { REGULATORIAS } \\
\text { ASSOCIADAS }\end{array}$} & \multirow{2}{*}{$\begin{array}{l}\text { PRINCIPAIS } \\
\text { EFEITOS } \\
\text { CELULARES }\end{array}$} \\
\hline & CE & CMLV & Fib & & \\
\hline NOX-1 & + & ++ & $0 /+$ & $\begin{array}{c}{\mathrm{p} 22^{\text {phox }}} \\
\text { NOXO1 } \\
\text { NOXA1 } \\
\text { p47 }\end{array}$ & $\begin{array}{l}\text { Proliferação } \\
\text { Migração }\end{array}$ \\
\hline NOX-4 & ++ & ++ & +++ & $\begin{array}{c}\mathrm{p} 22^{\text {phox }} \\
\mathrm{p} 47^{\text {phox }} \\
\mathrm{p} 67^{\text {phox }} \\
\mathrm{p} 40^{\text {phox }}(?) \\
\mathrm{p} 22^{\text {phox }}\end{array}$ & $\begin{array}{c}\text { Proliferação } \\
\text { Migração } \\
\text { Inflamação } \\
\text { Diferenciação } \\
\text { Apoptose }\end{array}$ \\
\hline NOX-5 & + & ++ & (?) & $\mathrm{p} 22^{\mathrm{phox}}$ & $\begin{array}{c}\text { Respostas } \\
\text { mediadas por } \\
\mathrm{Ca}^{+2}\end{array}$ \\
\hline
\end{tabular}

Principais subunidades catalíticas e reguladoras dos homólogos da NAPDH oxidase presentes em células do sistema vascular (adaptado de Laurindo, 2008) Abreviações: CE=célula endotelial, CMLV = célula muscular lisa vascular, Fib=fibroblasto. As quantidades relativas $(+\mathrm{a}+++)$ representam estimativas semi-quantitativas. Rac 1 regula a atividade dos complexos Nox1 e Nox2, enquanto seu papel para NOX-4 e NOX-5 ainda não foi esclarecido 
Figura 3- Modelo de ativação das proteínas NOX.
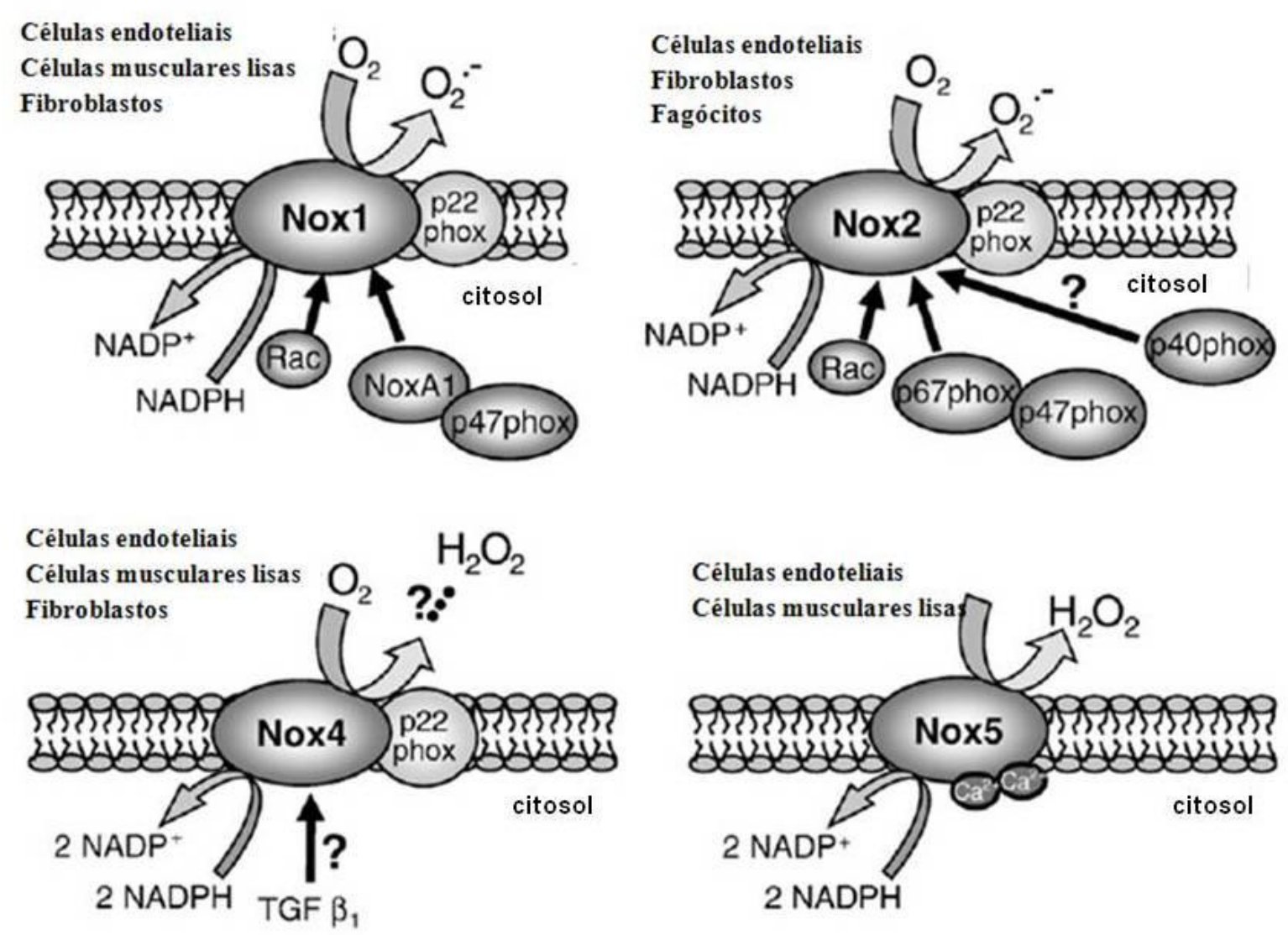

Com exceção da NOX-4, todos os homólogos da NOX são inativos no estado basal. Interações com proteínas doCitosol ou aumento na concentração de cálcio são necessários para ativar NOX-1, NOX2 e NOX-5.

Fonte: Ilustração adaptada de Brandes et al., 2010.

A geração de EROs pela NADPH oxidase vascular, é constitutivamente ativa, produzindo uma baixa concentração de EROs intracelular de maneira contínua (Li e Shah, 2002). Nas CMLV, NOX-1 está localizada na caveola e na membrana plasmática (Hilenski et al.,2004) e possui a capacidade de gerar $\mathrm{O}_{2} \cdot \mathrm{A}$ geração de $\mathrm{O}_{2}^{-}$por esta NOX requer a ativação e migração das subunidades regulatórias presentes no citosol; p47 $7^{\text {phox }}$, NOXA1, e Rac1 (Garrido e Griendling, 2009). Fatores humorais, assim como fatores de crescimento, agentes vasoativos e físicos tais como estiramento e atrito regulam a atividade da NADPH oxidase vascular (Lassegue e Clempus, 2003).

A Ang II constitui um forte estímulo para a produção de EROs pela NADPH oxidase vascular que ocorre em duas fases: uma fase rápida e outra lenta e 
sustentada. O primeiro pico ocorre poucos segundos após ativação da oxidase pela Ang II e como conseqüência há fosforilação de p47 $7^{\text {phox }}$ e migração da Rac. Esta fase de ativação da oxidase inicial gera EROs capazes de aumentar ainda mais a ativação da enzima e, assim resulta na geração de EROs sustentada que pode se manter por horas. Para manter a ativação da NOX-1 requer é necessário a transativação do fator epitelial de crescimento (EGFR), ativação da Src que leva a ativação da Rac e conseqüente ativação da NADPH oxidase em um ciclo de retroalimentação positivo dependente de EROs (Seshiah et al., 2002). A ativação sustentada da NOX-1 está relacionada com os efeitos hipertróficos da Ang II resultando em alterações vasculares como o remodelamento vascular observado na hipertensão arterial (Touyz e Schiffrin, 2004) (Figura 4). A influência da Ang II no aumento da geração de EROs, via NADPH oxidase, também inclui o aumento da atividade via de sinalização da ERK (ERK 1/2-MAPK), fato observado em experimentos realizados com anéis isolados de aorta de ratos espontaneamente hipertensos (SHR) infundidos com Ang II (Ding et al., 2007).

A transativação de EGFR também está parcialmente envolvida na contração de segmentos de aortas torácicas de ratos Wistar, mediada por a1-adrenoceptores, via PI3-kinase e ERK1/2 (Ulu et al., 2010). 
Figura 4- Via de ativação da NADPH oxidase mediada por Angiotensina II em CMLV.

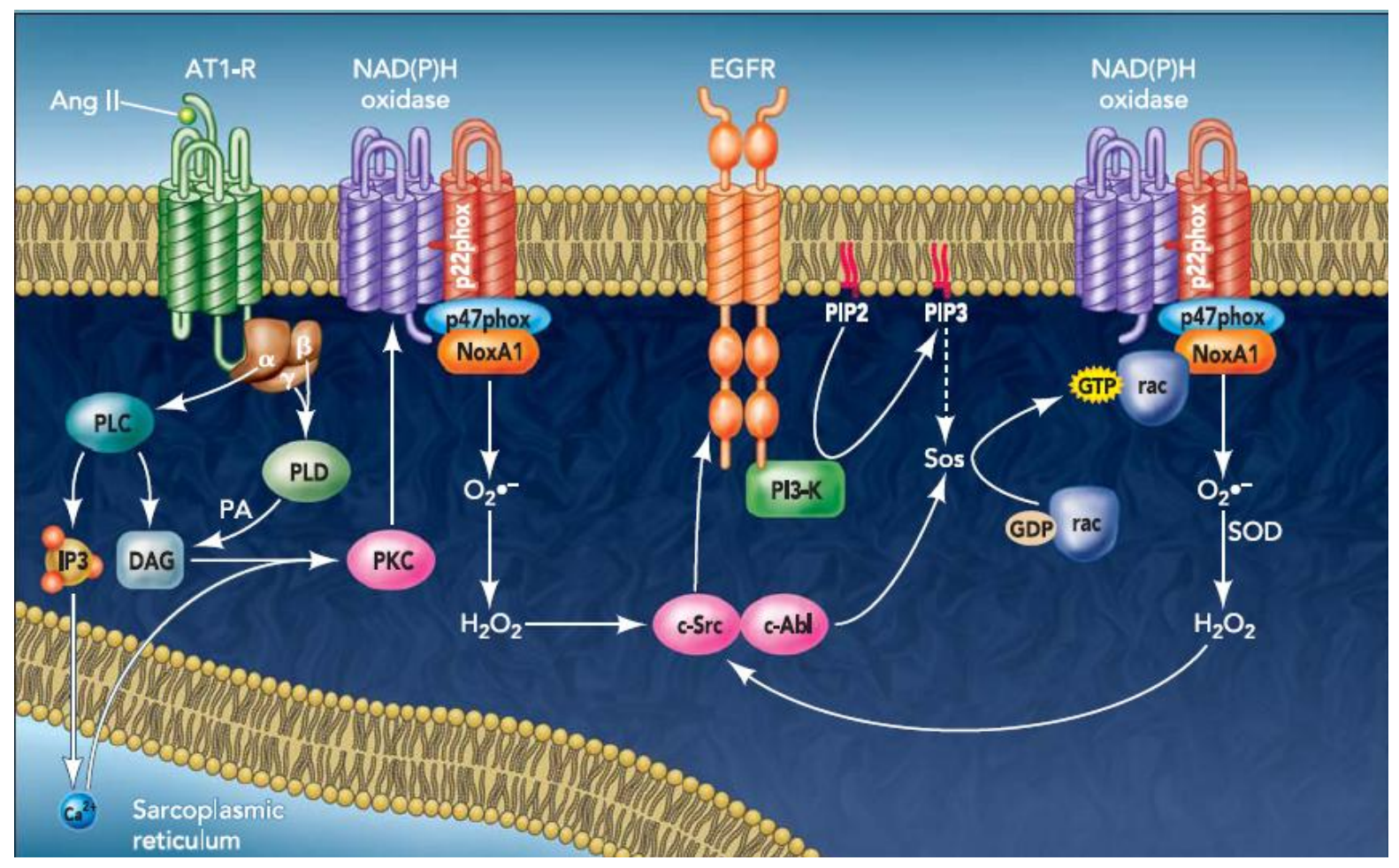

O estímulo do receptor $\mathrm{AT}_{1}$ por Ang II leva a uma rápida geração de EROs através da ativação da PKC. A subunidade Gq (da proteína G heterotrimérica) ativa a PLC, o qual produz IP ${ }_{3}$ e DAG. DAG pode também ser produzido em resposta ao estímulo da PLD mediado por $\beta$ e $\gamma$, produzindo ácido fosfatídico (PA), o qual é convertido em DAG. A PLA2 também pode estar envolvida no processo de ativação da PKC. A liberação de cálcio a partir do retículo sarcoplasmático (mediada por IP 3 ) e o DAG contribuem para ativação da PKC. Mediante ativação, a PKC fosforila a subunidade p47 ${ }^{\text {phox }}$, ativando então a NADPH oxidase, o que leva a geração de superóxido $\left(\mathrm{O}_{2}{ }^{-{ }^{-}}\right)$intracelular, o qual é convertido a $\mathrm{H}_{2} \mathrm{O}_{2}$ pela ação da superóxido dismutase (SOD). $\mathrm{H}_{2} \mathrm{O}_{2}$, por sua vez, ativa c-Src, levando a transativação de EGFR. O EGFR é upstream a $\mathrm{Pl}_{3}$-kinase e Rac. $\mathrm{Pl}_{3}$-kinase produz $\mathrm{PIP}_{3}$, ativando Sos-1 (um fator de troca do nucleotídeo guanina) que por sua vez, atua sobre a Rac, trocando GDP por GTP na Rac, ativando-a então. A Rac ativada se liga ao complexo NADPH oxidase, levando à geração de $\mathrm{O}^{-}$e $\mathrm{H}_{2} \mathrm{O}_{2} \cdot \mathrm{H}_{2} \mathrm{O}_{2}$ cria uma alça de feedback positivo para ativação de c-Src, o qual posteriormente amplifica a atividade da NADPH oxidase. Outro mediador importante para a forsforilação da $\mathrm{p} 47^{\text {phox }}$ é a Src, embora não esteja claro se a Src atua diretamente sobre a p47phox ou pelas sua ações no citoesqueleto via cortactina (vias não mostradas). A geração de sinal prolongado requer 'upregulation' das subunidades da NADPH oxidase: $p 47^{\text {phox }}$ e p22 ${ }^{\text {phox }}$. As setas pontilhadas indicam vias hipotéticas.

Fonte: Ilustração de Lyle e Griendling, 2006. Atualizada conforme revisão de Garrido e Griendling, 2009.

Outra isoforma encontrada nas CLMV, NOX-4, foi inicialmente caracterizada como um homologo do gp9 $1^{\text {phox }}$ encontrada no rim, denominada de Renox (Geiszt et al., 2003). Atualmente, está claro que é expressa em diversos tipos celulares e possui estrutura distinta das demais isoformas, pois, não requer subunidades citossólicas para a geração de EROs, apenas p22 $2^{\text {phox }}$ como subunidade regulatória (Martyn et al., 2006) (figura 3). A NOX-4 tem sido descrita como constitutivamente ativa e seu produto primário é o $\mathrm{H}_{2} \mathrm{O}_{2}$. A bioquímica que envolve a geração de $\mathrm{EROs}$ 
por esta NOX não está bem esclarecida. Contudo, sabe-se que a dismutação de $\mathrm{O}_{2}{ }^{-}$ em $\mathrm{H}_{2} \mathrm{O}_{2}$ ocorre rapidamente o que torna difícil sua detecção e por isso, no estudo realizado por Dikalov e colaboradores (2008) não foi possível mensurar $\mathrm{O}_{2}{ }^{-}$a partir de NOX-4. A localização de NOX-4 também é variável nos compartimentos intracelulares, é possível encontrá-la no núcleo (Pedruzzi et al., 2004; Chen et al., 2008), zonas de adesão focal (Hilenski et al.,2004; Clempus et al., 2007; Lyle et al., 2006) e retículo endoplasmático. Estudos recentes indicam um papel benéfico da NOX-4 na vasodilatação e regulação da pressão arterial (Brandes et al., 2010, Ray et al., 2011).

Embora o processo de ativação da NADPH oxidase tenha sido amplamente estudado, os mecanismos de regulação fina desta oxidase na geração de EROs ainda precisam ser elucidados.

Reconhecidamente, a ativação do complexo NADPH oxidase em fagócitos é inibida por reagentes oxidantes ou alquilantes de tióis. A inibição da NADPH oxidase fagocítica com um alquilante de ditióis, o óxido de fenilarsina, indicou um papel crítico de um ditiol (ou ditióis) na ativação da enzima, que foi atribuído às cisteínas presentes na subunidade $\mathrm{gp} 91^{\text {phox }}$, acessíveis em neutrófilos em repouso, mas inacessíveis quando o neutrófilo é ativado. Nosso grupo de pesquisa estendeu essas observações para a NADPH oxidase vascular. Janiszewski et al. (2000) demonstraram que a incubação de homogenatos de membrana celular com o oxidante de tióis diamida e o DTNB (ácido 5,5-ditiobis(2-nitrobenzóico)), ou o alquilante pCMPS ( $p$-cloro mercúrio-fenil-sulfonato) promove uma forte inibição da NADPH oxidase. Vários outros compostos também foram utilizados, demonstrando que a presença ou o grau do efeito inibidor da enzima não é proporcional à redução dos níveis intracelulares de glutationa total, reduzida e oxidada. Estes resultados combinados levaram à hipótese de que não apenas o estado redox celular estaria influenciando na atividade da enzima, mas que também um importante mecanismo modulador da NADPH oxidase seria mediado por uma óxido-redutase de tióis críticos (Laurindo et al., 2008) 
1.3 Proteína dissulfeto isomerase (PDI)

As oxidoredutases ditiólicas, especialmente aquelas pertencentes à superfamília das tiorredoxinas, são enzimas reconhecidamente importantes na ativação de vias de sinalização redox (Ebrahimian e Touyz, 2008). Os membros desta família têm como característica principal a presença do motivo catalítico CxxC, cuja natureza redox é a principal responsável pela variedade de funções atribuídas aos membros desta família (Laurindo et al., 2008). As cisteínas do sítio ativo da enzima atuam tanto como aceptores de elétrons, quando estão na forma dissulfeto (S-S, oxidada), quanto doadores de elétrons, quando estão na forma reduzida (-SH, reduzida). Desta forma, o sítio redox $\mathrm{CxxC}$ cicla reversivelmente entre um e outro estado redox durante reações ou interações que envolvam trocas tiol/dissulfeto (Gruber et al, 2006). Os resíduos "x" podem ser representados por distintos aminoácidos, embora a natureza química das cadeias laterais exerça importância capital na determinação do potencial redox das cisteínas do sítio ativo (Ellgard et al., 2005).

Dentre os membros da superfamília das tiorredoxinas, encontra-se a Proteína Dissulfeto Isomerase (PDI, EC 5.3.4.1), uma chaperona-redox oriunda do retículo endoplasmático. A PDI e as suas análogas são as únicas capazes de catalisar reações de isomerização, ou seja, re-organizam o posicionamento de pontes dissulfeto através de ciclos repetidos de oxidação e redução.

\subsubsection{Estrutura e funções da PDI}

Dentre as funções da PDI, podemos citar a catálise da oxidação de cisteínas para a formação de pontes dissulfeto, processo que auxilia o enovelamento de proteínas destituídas de pontes dissulfeto (função chaperona), bem como a redução e re-arranjo de pontes dissulfeto em proteínas, ou seja, re-organização do posicionamento de pontes dissulfeto. Ambas as funções são independentes do potencial redox do meio em que a PDI se encontra (Figura 5). 
Figura 5- Reações realizadas pela PDI em substratos protéicos portadores de dissulfetos ou ditióis.

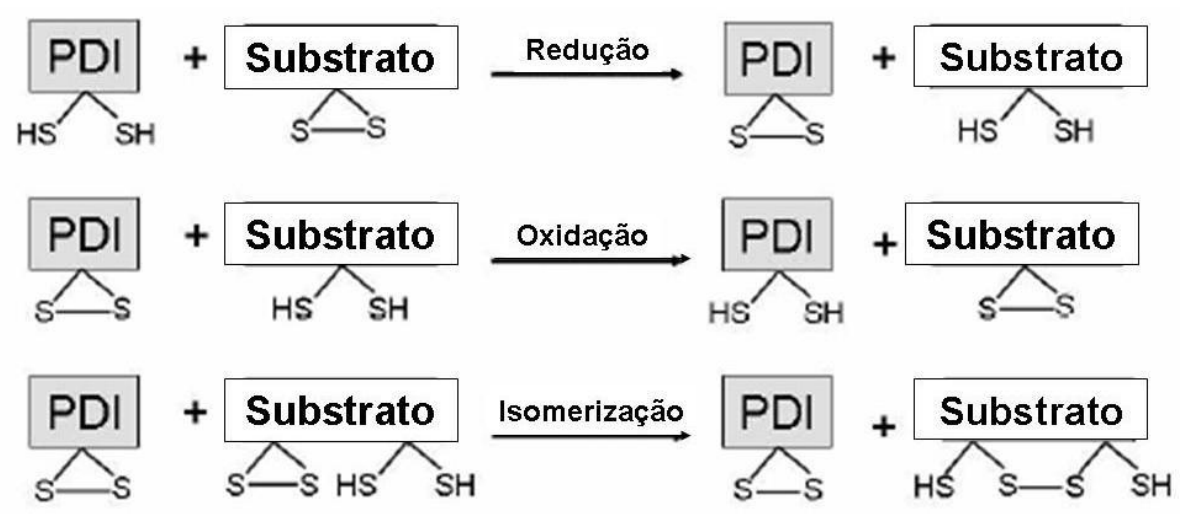

A PDI catalisa reações de redução de dissulfetos em ambientes onde o potencial redox local é mais redutor. Entretanto, naqueles menos redutores, como o RE, a PDI tende a intermediar reações de oxidação e ou isomerização, reações essenciais ao correto enovelamento protéico.

Fonte: llustração de Laurindo et al., 2008 adaptada por Paes, 2009.

A PDI é uma proteína de peso molecular aproximado de $55 \mathrm{kDa}$ e sua organização compreende cinco domínios semelhantes à tiorredoxina: $a, a^{\prime}, b$ e b' . A PDI também apresenta um domínio carboxi-terminal denominado de $c$ (figura 6 ). Nos domínios a e a' localizam-se os dois sítios catalíticos independentes da enzima, cujas cisteínas reativas localizam-se na seqüência Trp-Cys-Gly-His-Cys (WCGHC) (Noiva, 1999). As diferentes atividades exercidas pela PDI são realizadas nos diferentes estados redox destes motivos catalíticos, os quais podem se encontrar no estado reduzido ditiol ou no estado oxidado dissulfeto (Laurindo et al., 2008). Os domínios $b$ não são catalíticos, entretanto, o domínio b' apresenta uma larga superfície hidrofóbica, que foi identificada como principal responsável pelo reconhecimento e ligação da PDI ao seu substrato (Denisov, 2007; Byrne, 2009). Finalmente, o domínio carboxi-terminal c, apresenta a seqüência KDEL de retenção no retículo endoplasmático e, tem sido considerado um sítio de ligação ao cálcio (Laurindo et al., 2008). 
Figura 6 - Representação esquemática da estrutura da PDI.

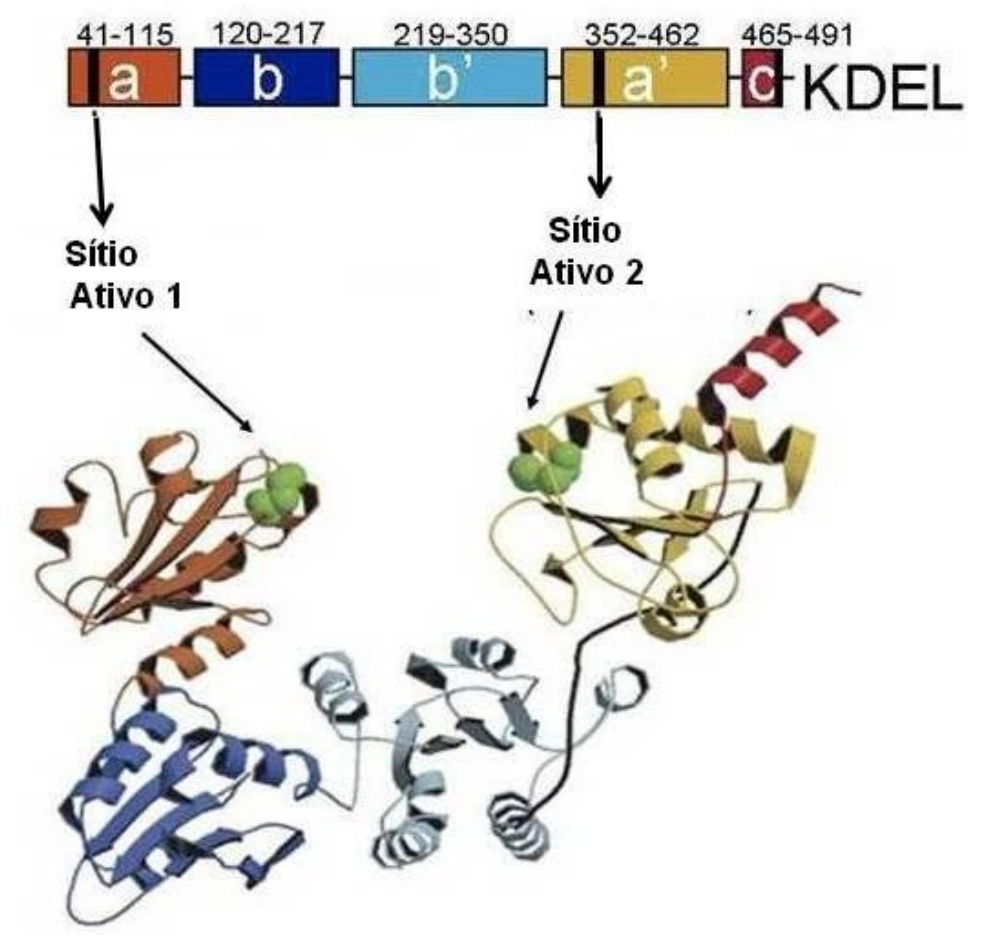

No diagrama superior $(\mathrm{A})$ a organização da PDI é vista como uma seqüência de 5 domínios: $a, b, b$, a', e $c$, aonde os sítios ativos redox (WCGHC) estão localizados nos domínios a e a'. Os domínios be b' constituem o principal sítio de ligação de substratos e o domínio $C$ possui a seqüência KDEL de retenção no RE. O diagrama inferior (B) representa a estrutura cristalizada da PDI de levedura, demonstrando a forma de $U$ da molécula; as setas indicam o início de cada domínio. Os sítios tióis ativos são apresentados no modelo de preenchimento espacial.

Fonte: llustração adaptada de Laurindo et al., 2008

\subsubsection{Papel fisiológico da PDI}

A PDI é uma proteína abundante, podendo atingir níveis milimolares no RE de hepatócitos, e sua expressão relaciona-se a sobrevivência celular. Em leveduras, a PDI é uma proteína vital, uma vez que qualquer redução substancial de sua expressão pode comprometer sua viabilidade. Em células de mamíferos, a expressão de PDI mantém a sobrevivência celular e o aumento de sua expressão melhora a resistência celular pós-hipóxia em astrócitos ou células endoteliais (Tanaka et al., 2000; Graven et al., 2002; Sullivan et al., 2003). Além disso, a PDI constitui um importante mediador da agregação plaquetária, sendo que a adesão plaquetária é inibida por seus antagonistas (Essex et al., 1999, 2001 e 2006).

A PDI realiza tráfego intracelular e é encontrada na superfície de diversas células procarióticas e eucarióticas, constituindo aproximadamente $25 \%$ dos tióis 
encontrados em superfícies celulares. Outras funções extracelulares têm sido atribuídas à PDI como reconhecimento da superfície celular no contato célula-célula, expressão de integrinas em leucócitos e internalização do vírus HIV (Barbouche et al., 2003). Há relatos da presença de PDI em tecidos como rins, tecido adiposo, coração e músculos (Mikami et al., 1998) e na membrana celular de inúmeros tipos celulares tais como linfócitos (Tager et al.,1997), neutrófilos (Bennet et al., 2000) e hepatócitos (Terada et al., 1995). A função desta PDI de membrana ainda não está clara, mas estudos sugerem que ela poderia agir como uma enzima redutora de tióis (Jiang et al., 1999) e mediar a reação de trans-nitrosação que favorece a internalização do NO de S-nitrosotióis extracelulares (Ramanchandran et al., 2001; Brandes e Kreuzer, 2005).

O envolvimento da PDI nas trocas tiol/dissulfeto e a versatilidade na interação com diferentes substratos sugerem um papel desta chaperona na geração de EROs pela NADPH oxidase. Estudos prévios realizados pelo nosso grupo de pesquisa demonstraram que a NADPH oxidase de neutrófilos bem como as isoformas vasculares da enzima são reguladas pela PDI (Laurindo et al., 2008; Paes et al., 2011).

\subsubsection{PDI como reguladora da atividade da NADPH oxidase}

Recentemente, nosso grupo demonstrou que a PDI pode estar associada com NADPH oxidase em diferentes tipos celulares, como células endoteliais, macrófagos, neutrófilos (Laurindo et al., 2008) e CMLV (Janiszewski et al., 2005).

A inibição da PDI por meio de intervenções moleculares, com o emprego da bacitracina (conhecido inibidor da atividade da PDI), SCRNase (um substrato competitivo para PDI), e com a utilização de um anticorpo neutralizante anti-PDI (inibidor do sítio redox ativo da enzima), levaram a diminuição da atividade da NADPH oxidase induzida por Ang II em CMLV (Janiszewski et al., 2005). Além disso, demonstramos através de ensaios de co-imunoprecipitação e de co-localização (por microscopia confocal), a interação física entre PDI e as subunidades da NADPH 
oxidase: p22 ${ }^{\text {phox }}$, NOX-1, NOX-2 e NOX-4 em CMLV e em células HEK293 (transfectadas com as diferentes isoformas de NOX) (Janiszewski et al., 2005).

Outras evidências obtidas pelo nosso grupo demonstraram que a superexpressão de PDI em CMLV induz a ativação espontânea da NADPH oxidase de forma independente de Ang II, possivelmente devido ao aumento da expressão gênica de NOX-1 e aumento da atividade da oxidase. Analisados em conjunto, estes resultados demonstram um papel regulatório da PDI na geração de EROs pela NOX1 (Fernandes et al., 2009).

Em macrófagos e células endoteliais esta associação PDI-NADPH oxidase também tem sido observada (Laurindo et al., 2008). Recentemente demonstramos que a PDI presente em neutrófilos pode atuar como organizador do complexo da NADPH oxidase através da interação redox- dependente com a subunidade regulatória $p 47^{\text {phox }}$ (Paes et al., 2011). Nos estudos conduzidos com a NADPH oxidase de neutrófilos, modelo considerado como um protótipo para o estudo das outras isoformas da enzima, a utilização de inibidores da PDI, Scrambled RNAse ou bacitracina, praticamente aboliram a geração de superóxido, indicando uma associação funcional da PDI e a NOX fagocítica. Dados de co-localização e experimentos de 'pull- down' demonstraram a interação da PDI com a subunidade regulatória $\mathrm{p} 47^{\mathrm{phox}}$. Além disso, nossos estudos revelaram que esta interação só ocorria após estímulo com PMA, confirmando a associação física entre essas proteínas durante o processo de ativação da enzima. Nossos dados revelaram também que modificações no estado redox da PDI modulam a interação com o p $47^{\text {phox }}$ e que ativação da NADPH oxidase favoreceria a formação de uma ponte dissulfeto entre as duas proteínas.

O mecanismo pelo qual a PDI regula a atividade da NADPH oxidase ainda não está totalmente esclarecido. Dentre os possíveis mecanismos está a estabilização do complexo das subunidades da oxidase, uma reconhecida função da PDI como chaperona, ou ainda, a distribuição, estabilização da ligação ou remoção das subunidades especificas da NOX, o que permite o controle de produção localização de EROs (Laurindo et al., 2008).

Contudo, apesar dos recentes avanços na compreensão da interação entre PDI e NADPH oxidase, a participação da PDI em efeitos biológicos relacionados 
com as EROs, como a regulação de vias de sinalização dependentes e independentes de cálcio na contração vascular induzida pela Ang II ainda não estão esclarecidos. Desta forma, mais estudos se fazem necessários para elucidar o papel da PDI em efeitos biológicos redox-dependentes como a contração vascular. 


\section{OBJETIVO}

\subsection{Objetivo Geral}

Avaliar o papel da proteína dissulfeto isomerase (PDI) na resposta contrátil à Angiotensina II e Noradrenalina em aortas isoladas.

\subsection{Objetivos Específicos}

Em aorta isoladas de ratos Wistar avaliamos:

- A expressão da PDI nas camadas íntima, média e adventícia.

- O efeito da inibição da PDI na resposta contrátil à Angiotensina II e Noradrenalina na presença e ausência do endotélio.

- Participação da NADPH oxidase e EROs na modulação da resposta contrátil pela PDI.

- O efeito da inibição da PDI na mobilização e influxo de cálcio na resposta vasoconstritora à Noradrenalina.

- O efeito da inibição da PDI sobre a fosforilação da ERK 1/2 após estímulo com Angiotensina II e Noradrenalina. 


\section{MATERIAL E METODOS}

\subsection{Animais}

Para os experimentos foram utilizados ratos Wistar, com 12-16 semanas de idade, com peso entre 180 a 210 g, provenientes do Biotério Central do Instituto de Ciências Biomédicas da Universidade de São Paulo. Os animais foram mantidos em temperatura controlada, ciclo claro/escuro, $60 \%$ de umidade e alimentados com ração padrão e água ad libitum. Todos os procedimentos realizados neste trabalho estão de acordo com as normas do Comitê de Ética em Experimentação Animal do Instituto de Ciências Biomédicas da Universidade de São Paulo (Protocolo $\mathrm{n}^{\circ}$ 157/2007).

3.2 Determinação da localização da proteína dissulfeto isomerase na aorta de ratos Wistar

\subsubsection{Obtenção do material}

Os animais foram anestesiados com solução de pentobarbital sódico (45 $\mathrm{mg} / \mathrm{kg}$ de peso corporal) por via intraperitoneal (ip) e após toracotomia a aorta torácica foi dissecada, removendo-se todo o tecido conectivo e adiposo. Os segmentos de aorta foram imersos na solução fixadora paraformaldeído 4\% (PFA) por 6 horas. Após a fixação, as aortas foram crioprotegidas em solução de sacarose $30 \%$ e emblocados em meio para congelamento (Leica Instruments, Austrália), congeladas em nitrogênio liquido e mantidas a $-70{ }^{\circ} \mathrm{C}$. Para garantir que os cortes usados abrangessem uma porção significativa da aorta, foram feitos cinco cortes não seriados de $10 \mu \mathrm{m}$ a $-25^{\circ} \mathrm{C}$ em criostato Leica CM 1850 (Leica Instruments, 
Austrália) e estes foram colocados em lâminas com poli-L-Lisina (Sigma-Aldrich, EUA).

\subsubsection{Imunohistoquímica}

Os animais foram anestesiados com solução de pentobarbital sódico (45 $\mathrm{mg} / \mathrm{kg}$ de peso corporal) por via intraperitoneal (ip) e após toracotomia a aorta torácica foi dissecada, removendo-se todo o tecido conectivo e adiposo. Os segmentos de aorta foram imersos na solução fixadora paraformaldeído 4\% (PFA) por 6 horas. Após a fixação, as aortas foram crioprotegidas em solução de sacarose $30 \%$ e congeladas em nitrogênio liquido e mantidas a $-70{ }^{\circ} \mathrm{C}$. Para garantir que os cortes usados abrangessem uma porção significativa da aorta, foram feitos cinco cortes não seriados de $10 \mu \mathrm{m}$ a $-25{ }^{\circ} \mathrm{C}$ em criostato Leica CM 1850 (Leica Instruments, Austrália) e estes foram colocados em lâminas com poli-L-Lisina (Sigma-Aldrich, EUA).

O anticorpo primário anti-PDI (IgG de camundongo, Afinity Bioreagents, EUA) foi diluído em tampão fostafato (PB $0,1 \mathrm{M}$ contendo $0,3 \%$ Triton $-\mathrm{X}$ ) na proporção 1:1000 e incubado com o corte de aorta por um período de aproximadamente 18 horas a $4^{\circ} \mathrm{C}$. O controle negativo foi realizado na ausência de anticorpo primário.

Após o período de incubação, os cortes foram submetidos a três lavagens de 10 minutos cada com PB. Em seguida os cortes foram incubados durante uma hora à temperatura ambiente, com anticorpo secundário biotinilado, diluído a 1:200 em PB contendo $0,3 \%$ de Triton X-100; após este período, foram submetidos a três lavagens de 10 minutos em PB; e incubados novamente com um complexo avidina-biotinaperoxidase (ABC-Elite, Vector, EUA) preparada com $10 \mu \mathrm{L}$ da solução A e $10 \mu \mathrm{L}$ da solução $B$ por $\mathrm{mL}$ de $\mathrm{PB}$ contendo $0,3 \%$ de Triton $\mathrm{X}-100$ e $\mathrm{NaCl}(0,3 \mathrm{M}-0,5 \mathrm{M})$ durante 1 hora à temperatura ambiente. Em seguida os cortes foram submetidos a três lavagens com PB durante 10 minutos cada.

A marcação com peroxidase foi realizada utilizando o cromógeno 3,3'diaminobenzidina (DAB) dissolvido em PB durante 3 minutos, e em seguida foi adicionada uma solução de $0,3 \%$ de peróxido de hidrogênio em água destilada. Após o desenvolvimento da cor, os cortes foram lavados três vezes com PB de 10 
minutos cada. Após lavagem, secar as laminas à $37^{\circ} \mathrm{C}$ por aproximadamente 18 horas.

Logo após, as lâminas foram submetidas a 3 lavagens de 10 minutos cada em PB e submetidas a uma bateria de desidratação, que consiste em uma série crescente de álcool e por um solvente clareador (Hemo-De, Fisher, EUA) com duração de 5 minutos para cada estágio. Após este processo, os cortes foram imersos em água destilada, em solução de Hematoxilina e, posteriormente em tampão PB. Para fixação da coloração os mesmos foram imersos em solução de molibdato de amônia 1\% e submetidos a uma nova bateria de desidratação. As lâminas foram então cobertas com lamínulas usando Permount (Fisher, EUA) como meio de montagem.

A análise qualitativa da imunoreatividade foi realizada em microscópio ótico equipado com câmera fotográfica, utilizando uma objetiva com aumento de 40x. As análises foram determinadas em três aortas por grupo experimental.

3.3 Análise da co-localização da proteína dissulfeto isomerase e NOX-1 na aorta de ratos Wistar

\subsubsection{Obtenção do material}

As amostras foram obtidas de acordo com o item 3.2.1

\subsubsection{Imunofluorescência}

Os cortes foram incubados durante 18 horas com anticorpos específicos para PDI (anti-mouse anti-PDI; ABR, 1:1000) e a subunidade da NADPH oxidase (antirabbit anti-Nox1, ABR, 1:1000) e anticorpos secundários goat anti-mouse - FICT (fluoresceína), 1:500 e goat anti-rabbit - TRICT (rodamina). 
A análise qualitativa da fluorescência foi realizada em microscópio óptico equipado com câmera fotográfica, utilizando-se uma objetiva com aumento de 40x utilizando pelo menos sete aortas por grupo experimental.

3.4 Análise da fluorescência derivada dos produtos de oxidação da diihidroetidina em cortes histológicos

As aortas isoladas foram pré incubadas com bacitracina (BAC; $1 \mathrm{mM}$ ), Scrambled RNAse (SCRN, $500 \mu \mathrm{M}$ ), Difenileno-iodônio (DPI; $30 \mu \mathrm{M}$ ) e 5,5-ditio-bis ácido 2-nitrobenzóico (DTNB; $500 \mu \mathrm{M})$ por 30 minutos. Em seguida foram estimuladas com Ang II $(10 \mu \mathrm{M})$ ou NOR $(10 \mu \mathrm{M})$ conforme indicado. Os cortes foram então fixados em lâmina e incubados com DHE $(5 \mu \mathrm{M})$ diluída em tampão fosfato (PB/DTPA $100 \mu \mathrm{M}$ ), em câmara úmida (30 minutos a $37^{\circ} \mathrm{C}$ ) protegida de luz.

Os cortes foram analisados em microscópio óptico equipado com filtro para rodamina, utilizando-se objetiva com aumento de 10X. A geração de EROs foi determinada pela densidade óptica média de fluorescência analisada em oito diferentes áreas da aorta que abrangiam as camadas musculares e o endotélio utilizando o programa de análise de imagens Image $J^{\circledast}$ e a geração de EROs expressa em unidades arbitrárias.

3.5 Estudo da reatividade vascular à Angiotensina II em anéis de aorta de ratos Wistar

3.5.1 Estudo in vitro da reatividade de anéis de aorta torácica isolada de ratos Wistar

Os animais foram anestesiados com solução de pentobarbital sódico (45 $\mathrm{mg} / \mathrm{kg}$ de peso corporal), por via ip e em seguida exsanguinados. A artéria aorta torácica foi cuidadosamente dissecada, o tecido conjuntivo foi removido e imersa em solução nutriente de Krebs Henseleit em mM: cloreto de sódio ( $\mathrm{NaCl}$ ) 130; cloreto de potássio ( $\mathrm{KCl}$ ) 4,7; ácido tetracético-etilenediamino (EDTA) 0,026; 
monofosfato de potássio $\left(\mathrm{KH}_{2} \mathrm{PO}_{4}\right)$ 1,18; sulfato de magnésio $\left(\mathrm{MgSO}_{4}\right)$ 1,17; cloreto de cálcio $\left(\mathrm{CaCl}_{2}\right)$ 1,6; Glicose 10). A artéria foi seccionada em anéis transversais de $4 \mathrm{~mm}$. Os anéis foram suspensos por um par de ganchos de aço inoxidável, um fixado à base da cuba de vidro para órgãos isolados, contendo $15 \mathrm{~mL}$ de solução de Krebs Henseleit, e o outro conectado a um transdutor de pressão de sinal (ML T001 transdutor isométrico de tensão, Power Lab/8S, AD Instruments, Austrália) acoplado a um computador. A solução nutriente foi gaseificada com mistura de $95 \%$ de $\mathrm{O}_{2} \mathrm{e}$ $5 \%$ de $\mathrm{CO}_{2}$ para manter $\mathrm{opH} 7,4$ e mantida aquecida à temperatura de $37{ }^{\circ} \mathrm{C}$ durante todo o protocolo experimental segundo protocolo descrito por Carvalho e colaboradores, 1990.

As preparações permaneceram por um período de 60 minutos, para a estabilização, sob tensão de $1,5 \mathrm{~g}$, com trocas de solução nutriente e ajuste de tensão a cada 30 minutos. Após esse período as peças sofreram contração com $\mathrm{KCl}$ (90 $\mathrm{mM}$ ) para que fosse verificada a integridade funcional do tecido. Foram realizadas duas contrações com $\mathrm{KCl}$ e após cada estabilização da contração, houve troca da solução nutriente a cada dez minutos, totalizando 30 minutos para que houvesse retorno da tensão aos níveis basais.

Após este preparo, foram realizadas curvas concentração-efeito (CCE) à Ang II $(0,1 \mathrm{nM}$ a $10 \mu \mathrm{M})$ nos anéis de aorta com e sem endotélio. Outro agente vasoconstritor utilizado neste estudo foi a NOR $(0,1 \mathrm{nM}$ a $10 \mu \mathrm{M})$, na presença e ausência do endotélio.

O endotélio foi removido através de leve fricção da superfície interna do vaso com fio de inox envolvido com algodão. A eficácia da remoção do endotélio foi verificada através da ausência de relaxamento induzido por $30 \mu \mathrm{M}$ de acetilcolina após contração com $30 \mu \mathrm{M}$ de noradrenalina, da mesma maneira integridade do endotélio foi testada pela capacidade da acetilcolina produzir relaxamento de 80 a $90 \%$ em relação à contração produzida pela noradrenalina. 
3.5.2 Análise do papel de inibidores da PDI na resposta contrátil induzida pela Angiotensina II e Noradrenalina

Para avaliar o papel da PDI na reatividade vascular à Ang II utilizamos a bacitracina e Scrambled RNAse (SCRN), inibidores desta tiol oxido redutase. Com intuito verificar a concentração de bacitracina que produzia a inibição da resposta contrátil à Ang II incubamos os anéis de aorta previamente com concentrações diferentes $(0,01 ; 0,1,1$ e $5 \mathrm{mM}), 15$ minutos antes da CCE. Após a Análise da CCE à Ang II em que as diferentes concentrações de bacitracina foram utilizadas, foi determinado que a dose de $1 \mathrm{mM}$ seria utilizada nos experimentos.

Para compreender o papel do endotélio na regulação da PDI na resposta contrátil foi realizada CCE à Ang II e à Noradrenalina na presença de inibidores da PDI. A bacitracina (BAC;1 mM) foi incubada 15 minutos antes da CCE à Ang II em anéis de aorta com e sem endotélio. A Scrambled RNase (SCRN; $500 \mu \mathrm{M}$ ), inibidor competitivo da PDI, foi incubado 30 minutos antes do inicio da CCE à Ang II no intuito de avaliar se compostos com mecanismos diferentes de inibição da PDI teriam efeitos diferentes na reatividade vascular. Após a Análise de CCE a Ang II incubadas previamente com bacitracina e Scrambled RNase e observado que o endotélio não participa da regulação da PDI na resposta contrátil à este peptídeo. Desta forma, os experimentos posteriores de CCE à Ang II foram realizados na ausência do endotélio.

3.5.3 Análise da participação de proteínas contendo grupos tióis na resposta vascular induzida pela Angiotensina II

Para verificar qual a participação de proteínas contendo grupos tióis na reatividade vascular à Ang II, os anéis de aorta foram incubados com o 5,5-ditio-bis

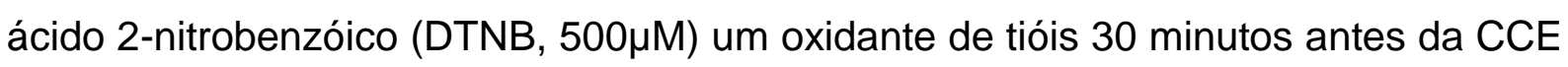
à Ang II. 
3.5.4 Análise da participação da NADPH oxidase na modulação da resposta contrátil pela PDI.

Para verificar qual a participação da NADPH oxidase na modulação da reatividade vascular pela PDI, incubamos os anéis de aorta com bacitracina (1mM) e/ou difenileno-iodônio (DPI, $30 \mu \mathrm{M}$ ), inibidor inespecífico da geração de EROs pela NAPDH oxidase, 30 minutos antes da CCE à Ang II e à NOR.

3.5.5 Análise participação das EROs na modulação da resposta contrátil pela PDI.

Para verificar qual a participação das EROs na modulação da reatividade vascular à Ang II pela PDI, incubamos os anéis de aorta com bacitracina (1 $\mathrm{mM}$ ) e/ou as enzimas superóxido dismutase (SOD; $150 \mathrm{U} / \mathrm{ml}$ ), catalase (CAT; $300 \mathrm{U} / \mathrm{ml}$ ) 30 minutos antes da CCE.

3.6 Análise do papel do cálcio intracelular e extracelular na resposta vasoconstritora à Noradrenalina

Após estabilização de 60 minutos, os anéis de aorta com e sem endotélio foram incubados durante 5 minutos com uma solução de Krebs-Henseleit livre de cálcio $\left(\mathrm{Ca}^{+2}\right)$ e contendo EGTA (ácido tetracético etileno glicol; $1 \mathrm{mM}$ ), em seguida foi adicionada noradrenalina $(10 \mu \mathrm{M})$ ao banho. A adição de noradrenalina induziu uma contração transiente e de pequena magnitude e, após retorno à tensão basal, foi adicionado cloreto de cálcio $\left(\mathrm{CaCl}_{2} ; 2,5 \mathrm{mM}\right)$ ao banho. $\mathrm{O} \mathrm{CaCl}_{2}$ omitido na solução sem cálcio foi substituído por igual concentração de cloreto de sódio, para manutenção da osmolaridade da solução (Figura 7). 
Figura 7 - Registro típico da contração induzida por noradrenalina na presença e ausência de cálcio extracelular.

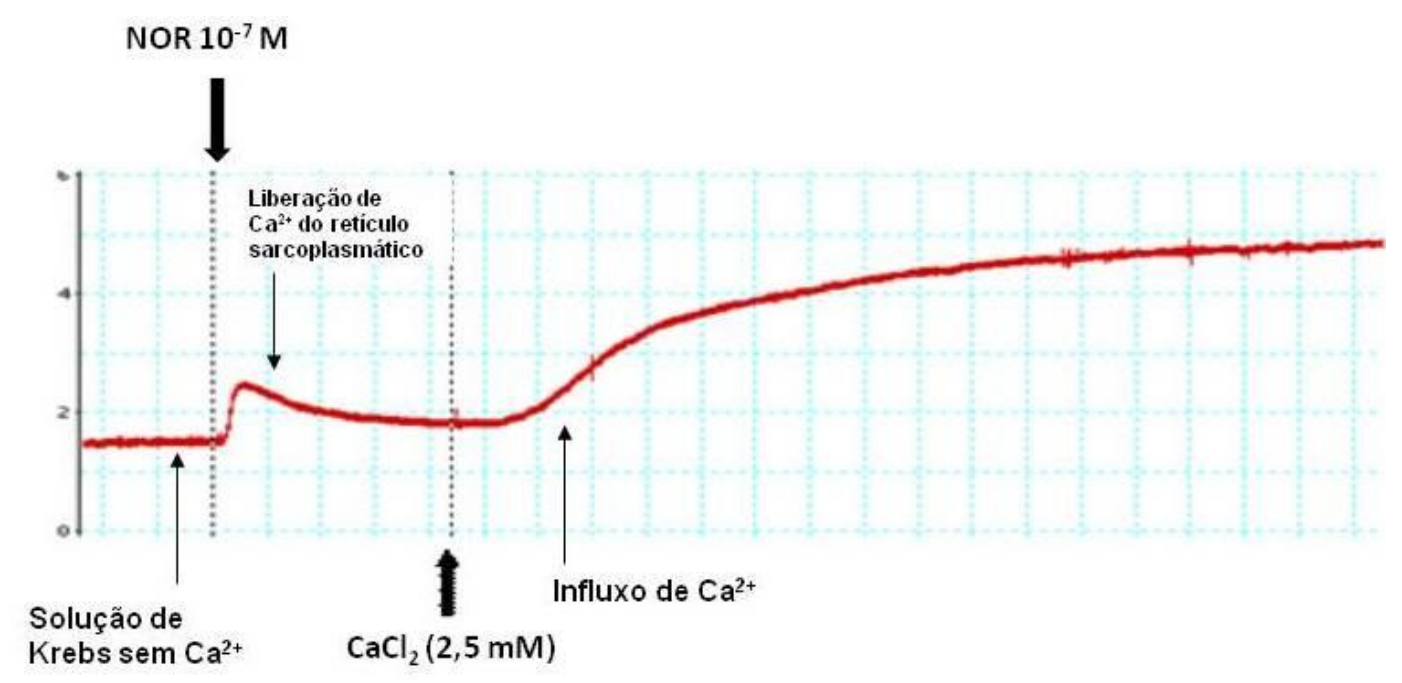

3.6.1 Análise da participação da PDI na mobilização e influxo de cálcio induzida pela NOR

Para verificar o papel da PDI na mobilização de cálcio à NOR incubamos os anéis de aorta com bacitracina (BAC; $1 \mathrm{mM}$; 15 minutos), na presença e ausência de cloreto de cálcio $\left(\mathrm{CaCl}_{2 ;}\right.$ 2,5 mM) na cuba (Figura 8).

Figura 8 - Desenho experimental para Análise do papel da PDI na mobilização e influxo de cálcio durante a contração induzida pela noradrenalina (NOR; $10 \mu \mathrm{M}$ )

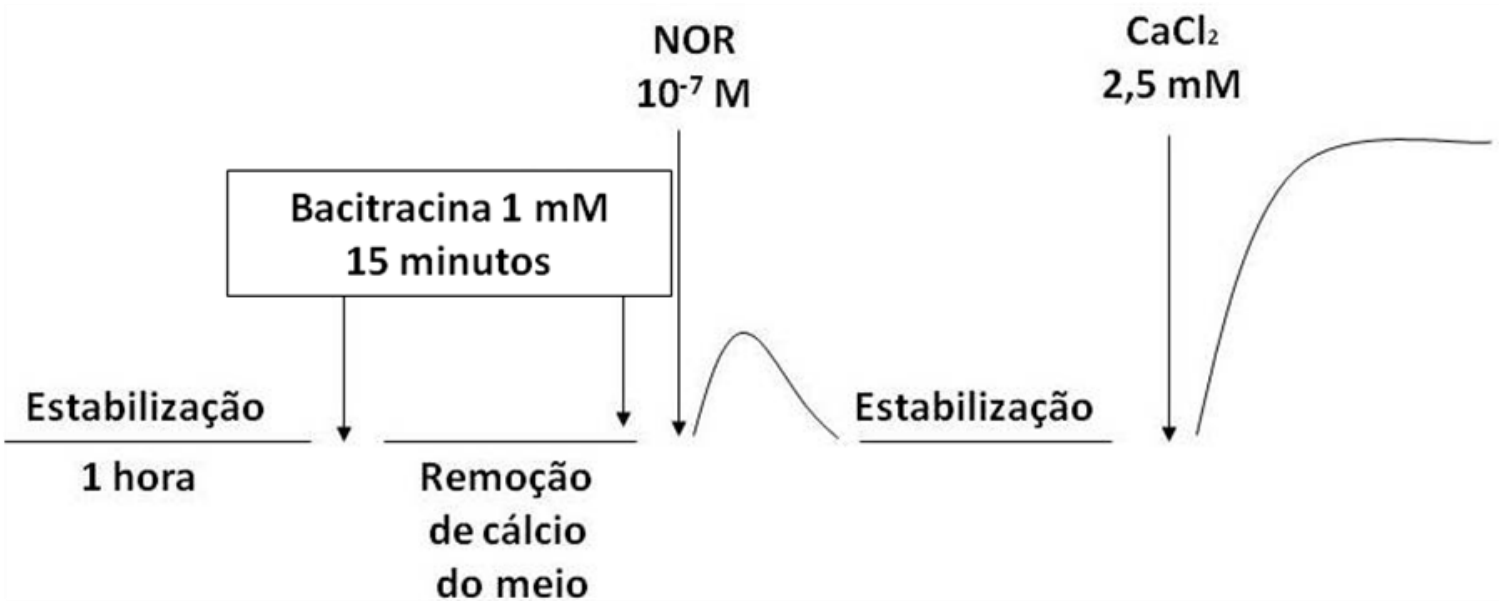


3.7 Análise do papel da PDI na ativação de MAP quinases pela Angiotensina II e Noradrenalina em aortas com endotélio.

3.7.1 Análise da curva temporal de fosforilação da ERK 1/2 em aortas estimuladas com Angiotensina II e Noradrenalina

Os segmentos de aorta incubados em meio Eagle modificado por Dulbecco (DMEM) foram estimulados com Ang II $(10 \mu \mathrm{M})$ ou NOR $(10 \mu \mathrm{M})$ a $37{ }^{\circ} \mathrm{C}$ durante 1, 5,10 e 30 minutos para Análise da fosforilação de ERK1/2.

3.7.2 Análise do papel da PDI na fosforilação de ERK 1/2 em aortas estimuladas com Angiotensina II e Noradrenalina

\subsubsection{Estimulação das aortas}

Para Análise do papel da PDI na fosforilação de ERK 1/2, os segmentos de aorta foram incubados previamente com bacitracina $(1 \mathrm{mM})$ por 30 minutos antes da estimulação com Ang II (10 $\mu \mathrm{M})$ e NOR $(10 \mu \mathrm{M})$.

Após as incubações, os segmentos de aorta foram congeladas em nitrogênio liquido e armazenadas à - $80^{\circ} \mathrm{C}$ para posterior Análise.

\subsubsection{Immunoblotting}

Os segmentos de aorta foram homogeneizadas em tampão contendo TritonX 1\%, Tris $100 \mathrm{mM}(\mathrm{pH} 7,4)$, pirofosfato de sódio $100 \mathrm{mM}$, fluoreto de sódio $100 \mathrm{mM}$, EDTA $10 \mathrm{mM}$, ortovanadato $10 \mathrm{mM}$, fluoreto de fenilmetilsulfonil (PMSF) $2 \mathrm{mM}$ e 
aprotinina $0,01 \mathrm{mg} / \mathrm{ml}$ utilizando um sonicador (Politron PTA 20S, Brinkmann Instrument, EUA).

O homogenato obtido foi centrifugado a 1200 r.p.m. à $4{ }^{\circ} \mathrm{C}$ por 5 minutos para separação do material insolúvel. Após a centrifugação, o conteúdo protéico total obtido foi quantificado utilizando o albumina bovina sérica como padrão e $50 \mu \mathrm{g}$ de proteína total foram submetidas à eletroforese em gel de poliacrilamida (10\%) com SDS (SDS-PAGE).

As proteínas isoladas no gel de poliacrilamida foram trasnferidas para a membrana de nitrocelulose, por meio de sistema semi-seco (BioRad, EUA). Após a transferência, a membrana foi incubada com solução bloqueadora de sítios inespecíficos em temperatura ambiente por 2 horas. As proteínas foram identificadas utilizando anticorpo primário anti-ERK 1/2 fosforilada (p-ERK 1/2; Cell Signaling, EUA) e reveladas utilizando-se o kit de quimioluminescência ECL (Amersham Biosciences, EUA).

A intensidade das bandas reativas foi quantificada por densitometria óptica (Scion Image - Release Beta 3b, EUA) e corrigida pela expressão de ERK total.

\subsection{Análise estatística}

Os resultados foram expressos como média \pm erro padrão da média (EPM). As análises estatísticas foram realizadas utilizando-se análise de variância de uma via (ANOVA) seguida do teste $t$ de Tukey. Valores de $p<0,05$ foram considerados significativos. 


\section{RESULTADOS}

4.1 Efeito de um oxidante de tióis na contração induzida pela Angiotensina II.

Com o intuito de avaliar o envolvimento de proteínas contendo grupos tióis como a PDI e a NADPH oxidase na resposta contrátil à Ang II, utilizamos o 5,5-ditiobis ácido 2-nitrobenzóico (DTNB, $500 \mu \mathrm{M}$ ), um potente oxidante de tióis. Conforme demonstrado na Figura 9 a contração induzida por Ang II foi reduzida na presença de DTNB.

4.2 Expressão de PDI e NOX-1 em aortas isoladas.

Com o objetivo de verificarmos a expressão de PDI em aortas isoladas realizamos uma imunohistoquímica a fim de detectarmos a expressão desta tiol oxido redutase. Na Figura 10, observamos a expressão de PDI nos segmentos de aorta. É possível notar que a PDI é expressa nas camadas média e adventícia e com maior intensidade no endotélio. Para compreender se a expressão de PDI estaria relacionada à expressão de NADPH oxidase investigamos a co-localização destas duas proteínas em aortas isoladas. Conforme pode ser observado na Figura 11, a NOX-1 é expressa principalmente na camada muscular aonde co-localiza com a PDI.

4.3 Efeito da inibição da PDI e da NADPH oxidase na geração de EROs induzida por Angiotensina II e Noradrenalina.

Considerando que demonstramos anteriormente que a PDI associa-se à NADPH oxidase e que esta enzima representa uma fonte de EROs importante na 
contração vascular decidimos investigar o efeito da inibição da NADPH oxidase e da PDI na geração de EROs após estimulação com Ang II e Noradrenalina. Conforme demonstrado na Figura 12, a adição de inibidores da PDI (bacitracina ou Scrambled RNAase) reduziu a geração de EROs em resposta a Ang II. O mesmo efeito inibitório foi observado quando incubamos as aortas com um inibidor da NADPH oxidase (DPI) assim como um oxidante de tióis (DTNB). Estes resultados em conjunto indicam a participação da PDI e da NADPH oxidase na geração de EROs em aortas estimuladas com Ang II.

No entanto, conforme demonstrado na Figura 13, a adição de inibidores da PDI (bacitracina ou Scrambled RNAase) produziu efeitos diferentes na geração de EROs em aortas estimuladas com Noradrenalina. A bacitracina reduziu a geração de maneira semelhante aos inibidores da NADPH oxidase (DPI) e o oxidante de tióis (DTNB). Por outro lado, a incubação das aortas com SCRN não inibiu a geração de EROs em oposição ao efeito obtido após estímulo com Ang II (Figura 13).

4.4. Efeito de inibidores da PDI na resposta contrátil à Angiotensina II.

A Figura 14 apresenta os resultados da resposta contrátil à Ang II na presença de um inibidor da PDI (bacitracina) em aortas isoladas com endotélio. O ensaio foi realizado Com concentrações crescentes de bacitracina $0,01 \mathrm{mM}$ a $5 \mathrm{mM}$. Os resultados demonstram que as concentrações de 0,01, 0,1 e 1mM provocaram uma diminuição da resposta contrátil à Ang II. Entretanto, na concentração de $5 \mathrm{mM}$, observamos um aumento na contração.

\subsubsection{Papel do endotélio}

Considerando-se que a expressão de PDI estava aumentada no endotélio (Figura 14) decidimos investigar o papel desta camada na diminuição da resposta contrátil induzida pela bacitracina. Conforme demonstrado na Figura 15 a resposta 
contrátil à Ang II em anéis de aorta foi maior na ausência do endotélio. No entanto, a inibição da resposta contrátil a Ang II pela bacitracina ocorreu de forma independente do endotélio, uma vez que a redução na resposta foi de $46 \%$ em aortas com endotélio e de $40 \%$ após a sua remoção. Este efeito também foi observado quando utilizamos outro inibidor da PDI, a Scrambled RNAase (SCRN), que diferentemente da bacitracina inibe competitivamente o sítio redox (Figura 16). No intuito de investigarmos se este efeito seria específico para a estimulação por Ang II utilizamos outro agente vasoconstritor: a Noradrenalina. A Figura 17 demonstra que, assim como para Ang II, a inibição da PDI pela bacitracina reduziu a resposta contrátil à NOR de maneira independente do endotélio, embora esta resposta contrátil tenha sido maior na ausência do endotélio.

4.5 Papel de EROs na inibição da resposta contrátil à Ang II induzida pela bacitracina.

A incubação de aortas isoladas com as enzimas antioxidantes superóxido dismutase e catalase isoladamente reduziu a contração após estímulo com Ang II. A incubação das aortas com bacitracina produziu uma inibição da resposta contrátil equivalente (em torno de $20 \%$ ). No entanto, a inibição produzida pela incubação de aortas com bacitracina, superóxido dismutase e catalase conjuntamente aumentou este efeito produzindo uma inibição de aproximadamente de $70 \%$ da resposta contrátil à Ang II (Figura 18).

4.6 Papel da NADPH oxidase na inibição da resposta contrátil à Angiotensina II e Noradrenalina.

Com o intuito de investigar o envolvimento da NADPH oxidase na inibição da resposta contrátil à Ang II e NOR observada nos experimentos anteriores, as aortas foram incubadas com bacitracina e/ou um inibidor de flavoproteínas, o difenilenoiodônio (DPI) (Figuras 19 e 20). 
A inibição da NAPDH oxidase resultou em uma redução de $46 \%$ da resposta contrátil à Ang II, valor semelhante ao efeito da bacitracina. Porém, esta redução foi ainda maior quando as aortas foram incubadas conjuntamente com DPI e bacitracina o que resultou em uma redução da contração à Ang II de aproximadamente $85 \%$ (Figura 19). De modo semelhante, quando estimulamos as aortas com a NOR, a inibição da resposta contrátil pela bacitracina foi maior (redução de $75 \%$ ) do que o efeito do DPI isolado (Figura 20).

4.7. Efeito da inibição da PDI sobre a mobilização e o influxo de cálcio durante a contração por Noradrenalina.

$\mathrm{Na}$ tentativa de compreender o papel da PDI na contração vascular decidimos investigar o efeito de inibidores da PDI na mobilização e influxo de cálcio durante a contração induzida por NOR em anéis de aorta com e sem endotélio incubados com solução de Krebs-Henseleit livre de $\mathrm{Ca}^{+2}$ na presença de um quelante deste íon (EGTA). $\mathrm{Na}$ ausência de $\mathrm{Ca}^{+2}$ extracelular, a NOR causou contração transiente e de pequena magnitude. Quando os anéis de aorta foram incubados com bacitracina, inibidor da PDI houve redução da contração induzida por NOR na ausência de $\mathrm{Ca}^{+2}$ extracelular (Figura 12). Após o acréscimo de $\mathrm{CaCl}_{2}(2,5$ $\mathrm{mM}$ ) no banho observamos que a contração foi de maior magnitude e sustentada nos anéis de aorta com e sem endotélio e a bacitracina, não modificou esta resposta (Figura 21).

4.8 Efeito da inibição da PDI sobre a fosforilação da ERK 1/2 após estímulo com Angiotensina II e Noradrenalina.

No intuito de investigarmos o papel da PDI na ativação de vias de sinalização redox sensíveis ativadas durante a contração vascular analisamos a fosforilação da MAP quinase ERK 1/2. Conforme demonstrado na Figura 22 a estimulação de aortas isoladas com Ang II e Noradrenalina aumentou a fosforilação 
da ERK 1/2. Analisando-se a curva temporal de fosforilação da ERK 1/2 para Ang II e NOR observamos que o pico de fosforilação desta MAP quinase ocorreu aos 5 minutos e diminuiu após 10 minutos mantendo-se reduzida 30 minutos após a estimulação por Ang II. No entanto esta resposta foi diferente quando estimulamos as aortas com NOR (Figura 22). Analisando-se a curva temporal para NOR observamos um aumento na fosforilação da ERK $1 / 2$ a partir de 5 minutos da estimulação que atinge o pico máximo aos 10 minutos e mantém-se ainda ativada 30 minutos após a estimulação. Para compreender o papel da PDI na fosforilação da ERK 1/2 incubamos as aortas com bacitracina, inibidor desta tiol oxido redutase, e estimulamos após 5 minutos com Ang II e, após 10 minutos com NOR. A bacitracina inibiu a fosforilação da ERK1/2 após estímulo com Ang II (Figura 23). Este mesmo efeito não foi observado quando estimulamos as aortas com Noradrenalina (Figura 24). 
Figura 9 - Efeito de um oxidante de tióis (DTNB) na resposta contrátil à Angiotensina II.

A)

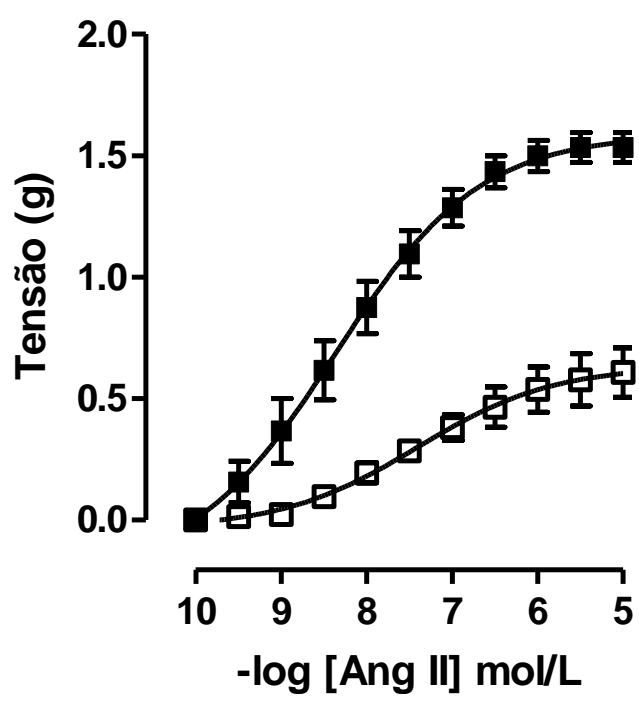

- Ang II

ㅁ Ang II + DTNB

B)

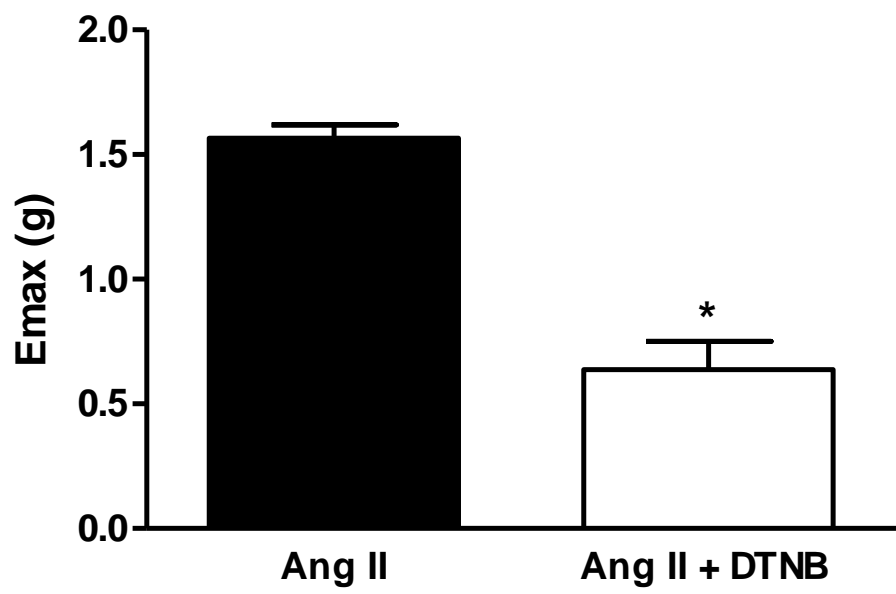

Anéis de aorta (sem endotélio) foram submetidos a tratamento com DTNB (500 $\mu \mathrm{M})$ por 30 minutos previamente ao estímulo com Ang II. Após estimulo, a resposta contrátil foi mensurada e comparada ao grupo também estimulado com Ang II, porém sem tratamento prévio com DTNB. (A) Curva concentração-efeito a Ang II; (B) resposta máxima. Os resultados estão representados como média \pm EPM de no mínimo 5 animais por grupo experimental. ${ }^{*} \mathrm{p}<0.05$ vs Ang II. 

Figura 10 - Determinação da expressão e localização da PDI na aorta por

A)

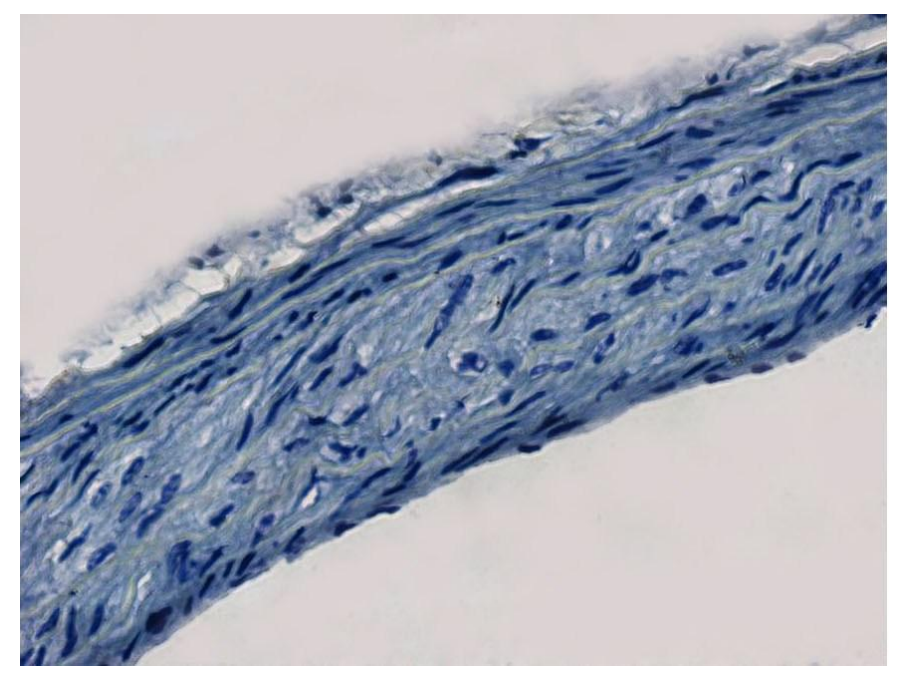

B)

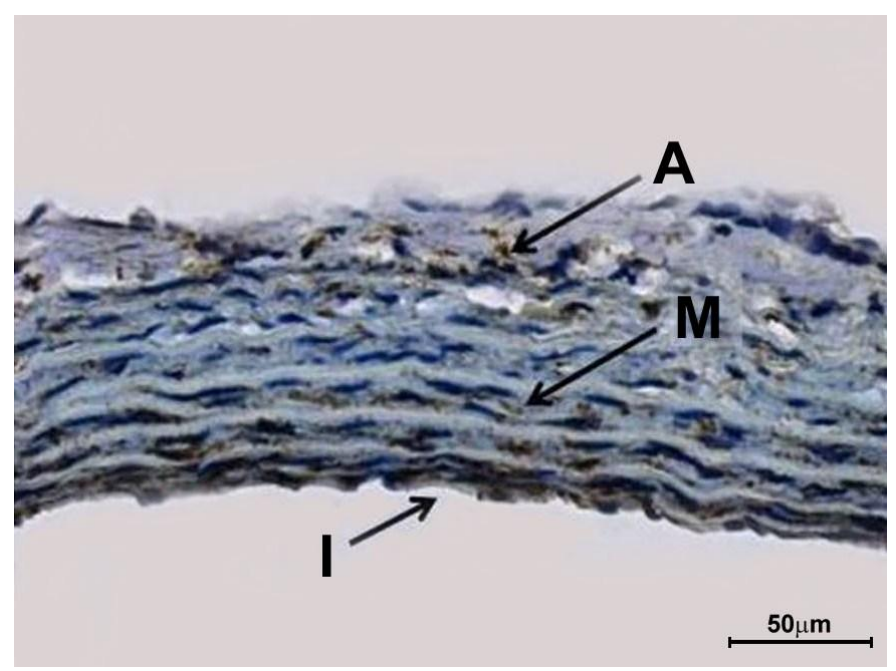

Fotomicrografia de segmento transversal de aorta ilustrando o padrão de marcação para PDI. (A) Controle, amostra sem anticorpo para PDI; (B) amostra incubada com anticorpo para PDI (1:1000), as setas indicam a marcação imunohistoquímica da PDI nas camadas íntima (I), média (M) e adventícia (A). A barra de escala representa $50 \mu \mathrm{m}$. Imagens obtidas com objetiva de 40x. 
Figura 11 - Co-localização entre PDI e NOX-1 por microscopia de fluorescência.

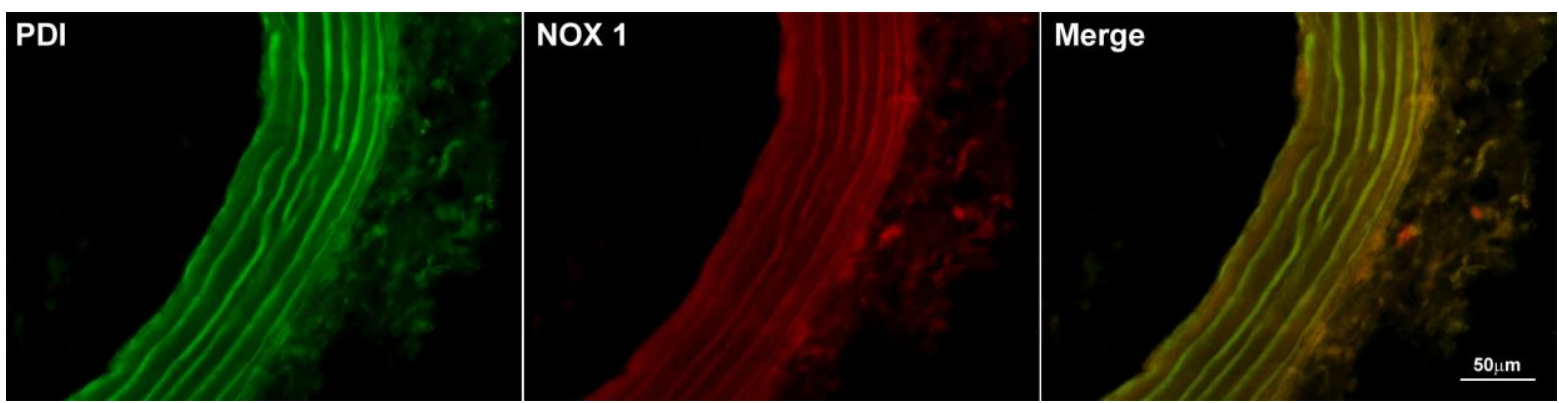

A marcação de PDI (verde) e NOX-1 (vermelho) visualizada em cortes transversais de aorta foi detectada por imunofluorêscencia. A co-localização entre PDI e NOX-1 está demonstrada em Merge (amarelo). As imagens são representativas de no mínimo 4 animais por grupo experimental. 
Figura 12- Papel da PDI na geração de espécies reativas de oxigênio (EROs) pela NADPH oxidase em aortas isoladas estimuladas com Angiotensina II.
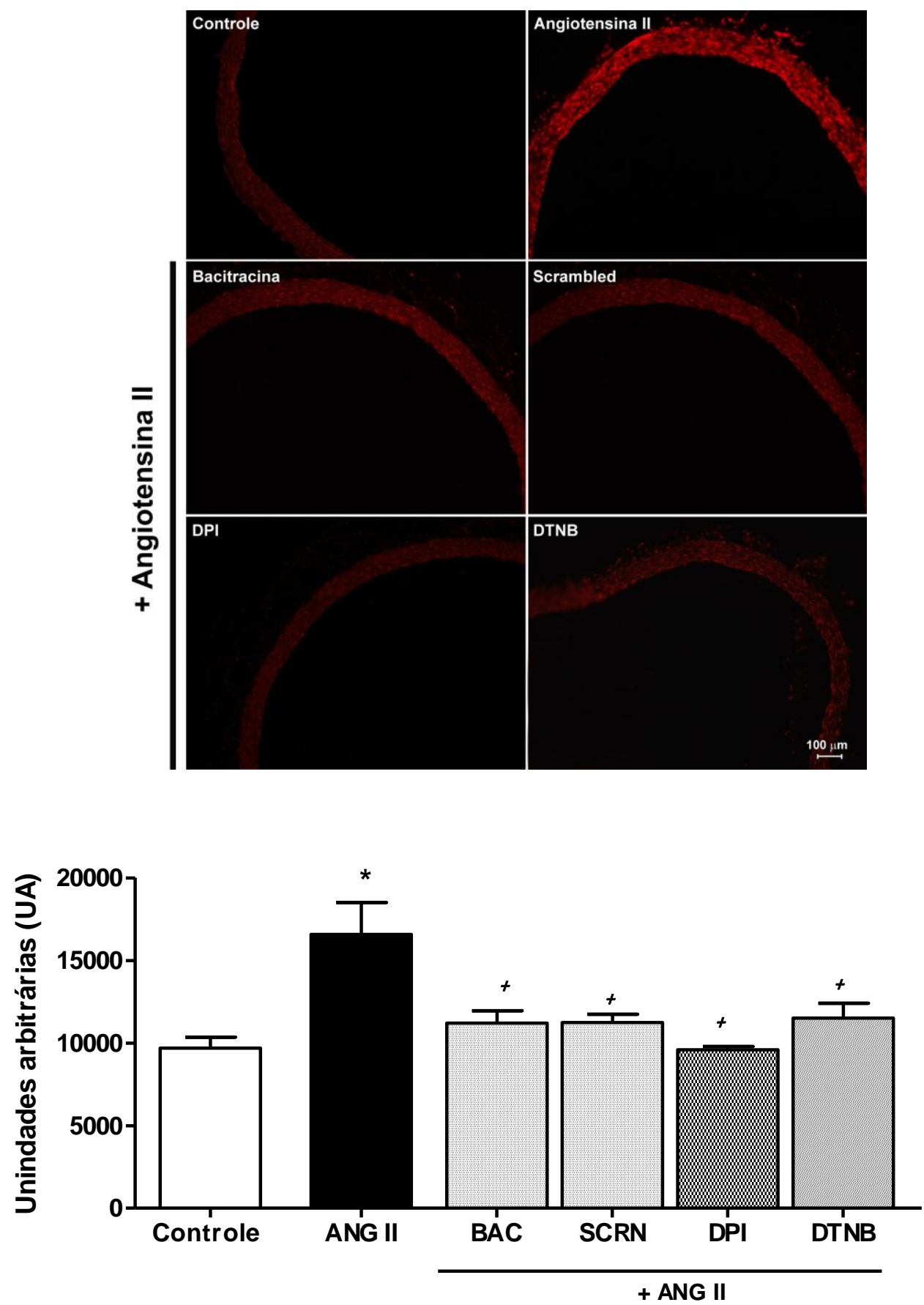

Análise da geração de EROs pelo método da oxidação da dihidrotidina (DHE) em anéis de aorta

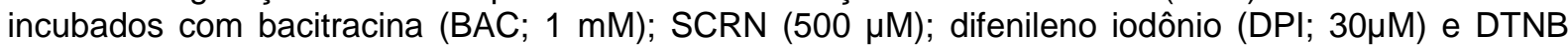
$(500 \mu \mathrm{M})$ por 30 minutos previamente ao estimulo por Ang II (10 $\mu \mathrm{M} ; 30$ minutos). Após o estímulo, a análise da geração de EROs foi quantificada e comparada ao grupo incubado apenas com Ang II e ao grupo sem estímulo por Ang II (Controle). Os resultados estão representados como média \pm EPM de no mínimo 5 animais por grupo experimental. ${ }^{*} p<0.05$ vs Controle; ${ }^{+} p<0.05$ vs Ang II. 
Figura 13 - Papel da PDI na geração de espécies reativas de oxigênio pela NADPH oxidase em aortas isoladas estimuladas com Noradrenalina.
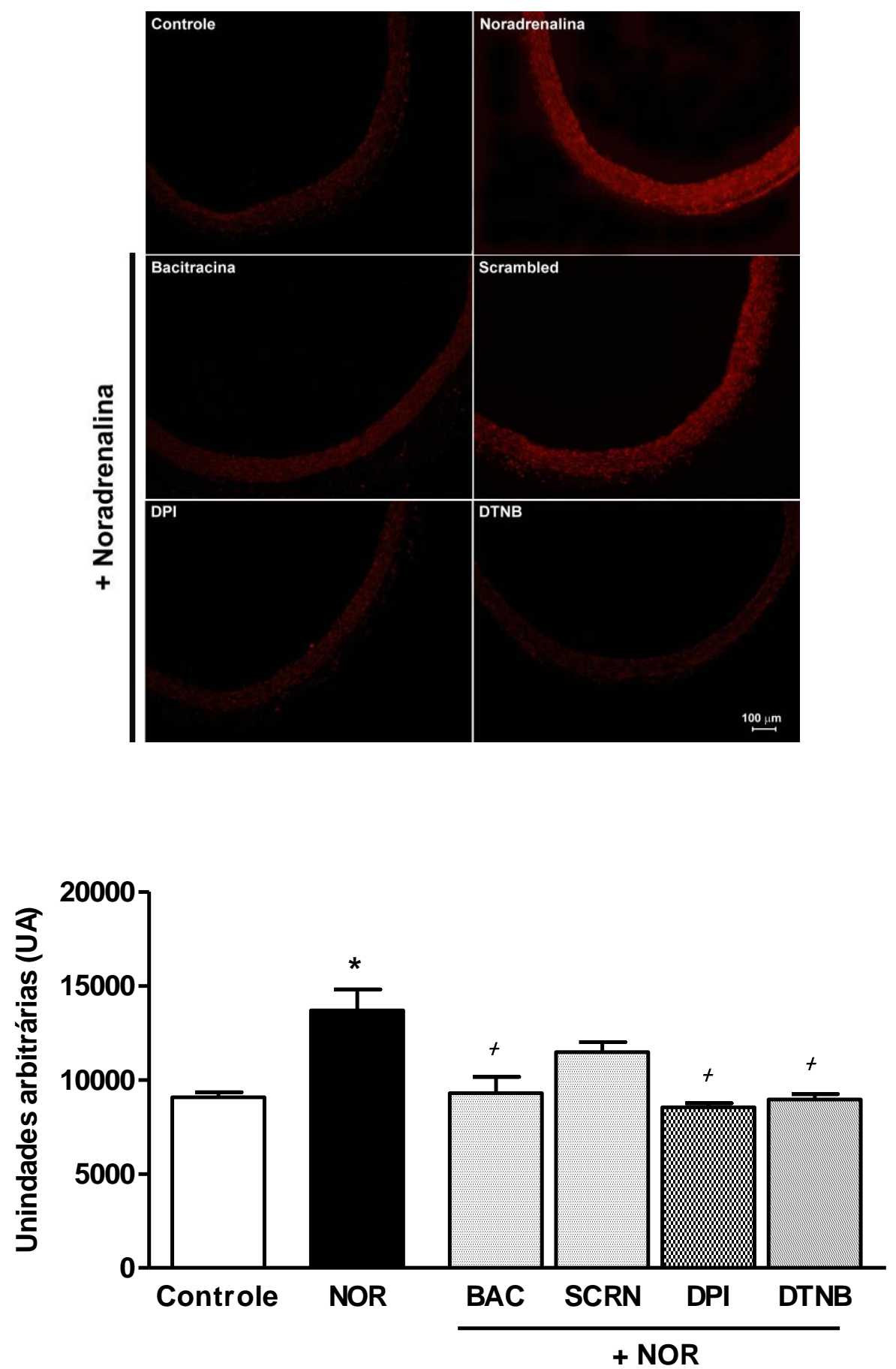

Análise da geração de EROs pelo método da oxidação da dihidrotidina (DHE) em anéis de aorta incubados com bacitracina (BAC; $1 \mathrm{mM})$; SCRN $(500 \mu \mathrm{M})$; DPI $(30 \mu \mathrm{M})$ e DTNB $(500 \mu \mathrm{M})$ por 30 minutos previamente ao estimulo por Noradrenalina (NOR; $10 \mu \mathrm{M} ; 30$ minutos). Após o estímulo, a análise da geração de EROs foi quantificada e comparada ao grupo incubado apenas com NOR e ao grupo sem estímulo por NOR (Controle). Os resultados estão representados como média \pm EPM de no mínimo 5 animais por grupo experimental. ${ }^{*} p<0.05$ vs Controle; ${ }^{+} p<0.05$ vs NOR. 
Figura 14- Efeito da bacitracina na resposta contrátil a Angiotensina II.

A)

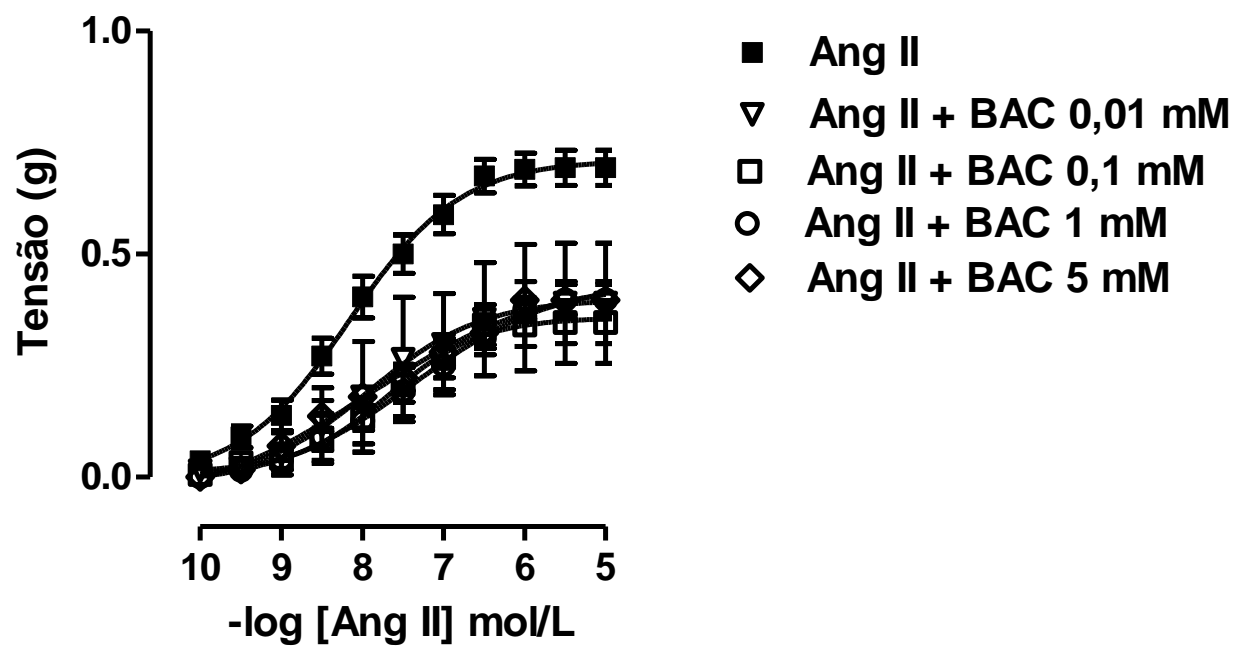

B)

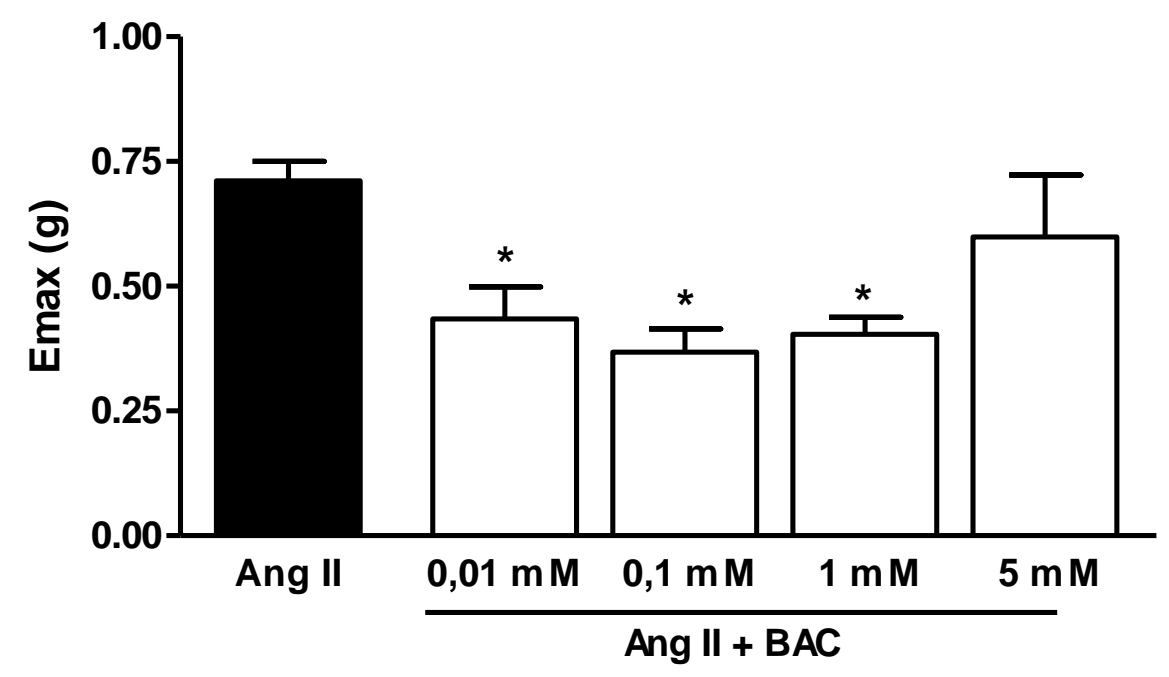

Anéis de aorta com endotélio foram submetidos a tratamento com concentrações crescentes de bacitracina (BAC; 0,01 a $5 \mathrm{mM}$ ) por 15 minutos previamente ao estímulo com Ang II. Após estimulo, a resposta contrátil foi mensurada e comparada ao grupo também estimulado com Ang II, porém sem tratamento prévio com Bacitracina. (A) Curva concentração-efeito a Ang II; (B) resposta máxima. Os resultados estão representados como média \pm EPM de no mínimo 5 animais por grupo experimental. ${ }^{*} \mathrm{p}<0.05$ vs Ang II. 
Figura 15- Papel do endotélio na inibição da resposta contrátil à Ang II pela bacitracina.

A)

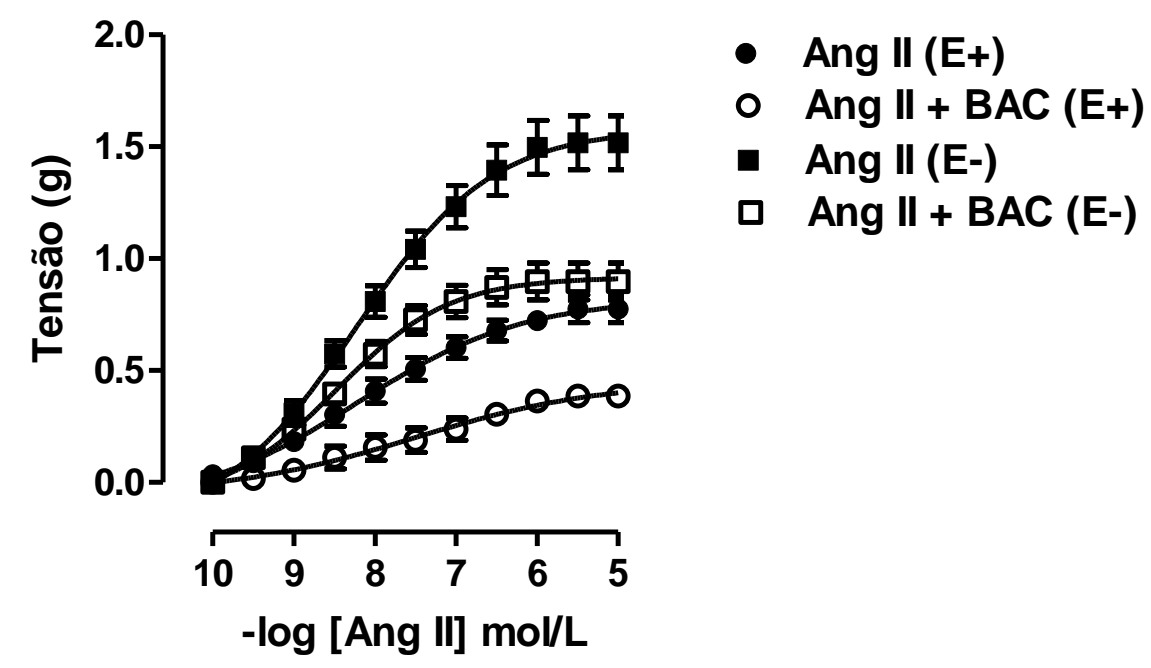

B)

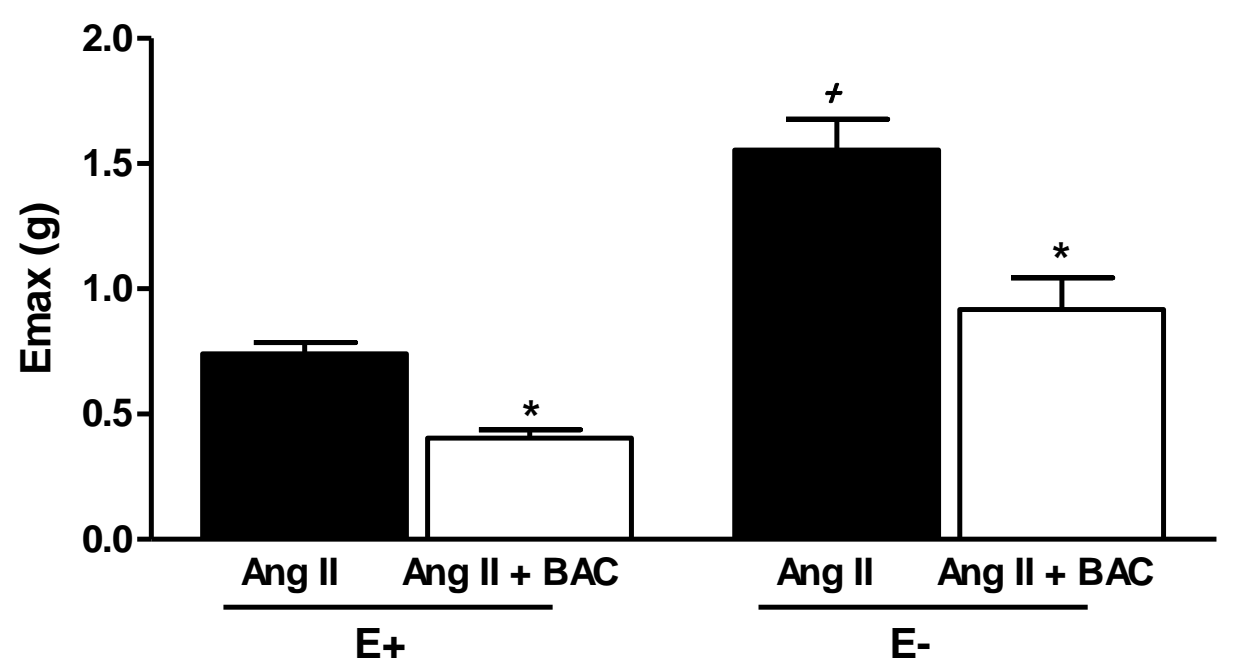

Anéis de aorta com endotélio $\left(E_{+}\right)$e sem endotélio ( $\left.E-\right)$ foram submetidos a tratamento com bacitracina (BAC; $1 \mathrm{mM}$ ) por 15 minutos previamente ao estímulo com Ang II. Após estimulo, a resposta contrátil foi mensurada e comparada ao grupo também estimulado com Ang II, porém sem tratamento prévio com BAC. (A) Curva concentração-efeito a Ang II; (B) resposta máxima. Os resultados estão representados como média \pm EPM de no mínino 5 animais por grupo experimental. ${ }^{*} p<0.05$ vs Ang II; ${ }^{+} p<0.05$ vs Ang II $-E+$. 
Figura 16 - Papel do endotélio na inibição da resposta contrátil à Angiotensina II pela Scrambled RNase.

A)

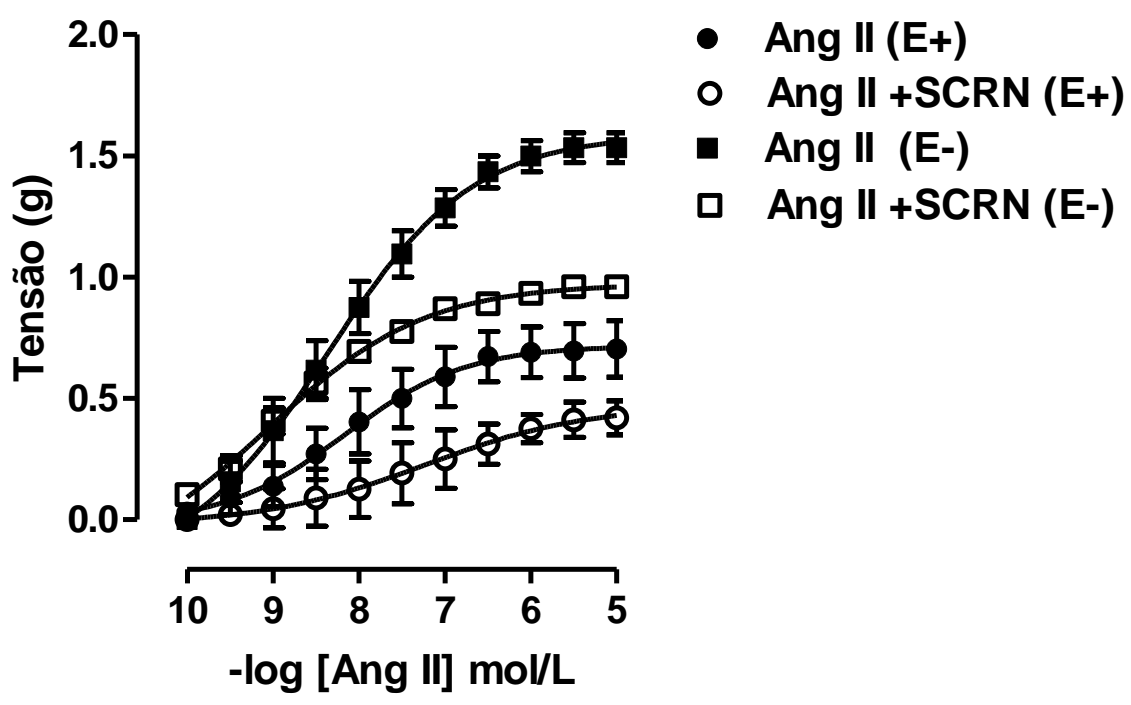

B)

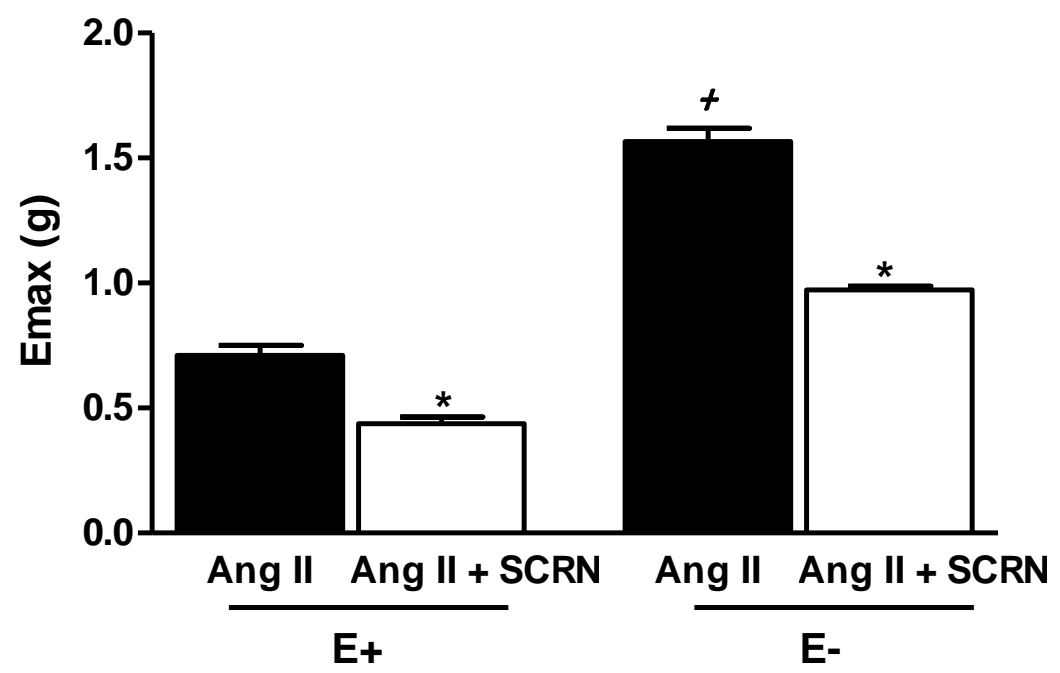

Anéis de aorta com endotélio $\left(E_{+}\right)$e sem endotélio (E-) foram submetidos a tratamento com Scrambled RNase (SCRN; $500 \mu \mathrm{M}$ ) por 30 minutos previamente ao estímulo com Ang II. Após estimulo, a resposta contrátil foi mensurada e comparada ao grupo também estimulado com Ang II, porém sem tratamento prévio com SCRN. (A) Curva concentração-efeito a Ang II; (B) resposta máxima. Os resultados estão representados como média \pm EPM de no mínimo 5 animais por grupo experimental. ${ }^{*} p<0.05$ vs Ang II; ${ }^{+} p<0.05$ vs Ang II $-E+$. 
Figura 17 - Efeito da bacitracina na inibição da resposta contrátil à Noradrenalina.

A)

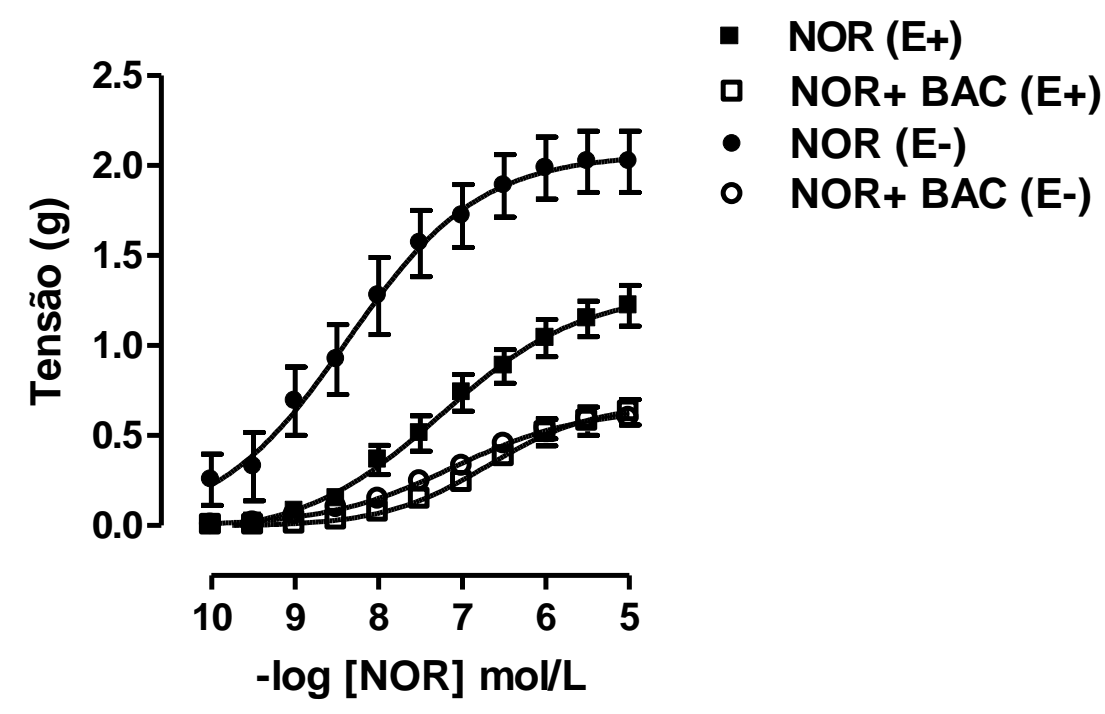

B)

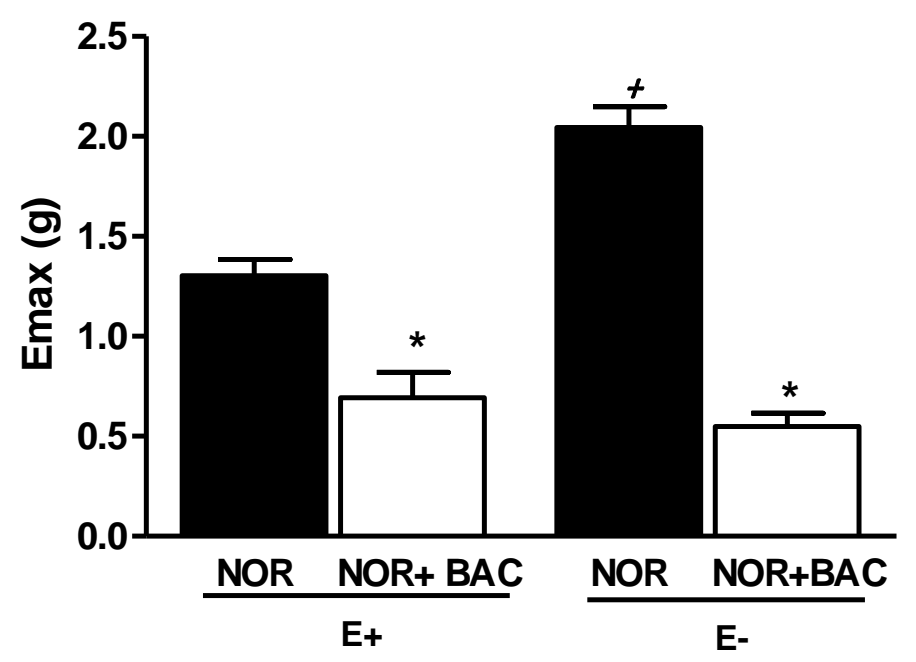

Anéis de aorta com endotélio $\left(E_{+}\right)$e sem endotélio (E-) foram submetidos a tratamento com bacitracina (BAC; $1 \mathrm{mM}$ ) por 15 minutos previamente ao estímulo com NOR. Após estimulo, a resposta contrátil foi mensurada e comparada ao grupo também estimulado com NOR, porém sem tratamento prévio com BAC. (A) Curva concentração-efeito a NOR; (B) resposta máxima. Os resultados estão representados como média \pm EPM de no mínimo 5 animais por grupo experimental. ${ }^{*} p<0.05$ vs NOR; ${ }^{+} p<0.05$ vs NOR $E+$. 
Figura 18- Papel da PDI e das espécies reativas de oxigênio na resposta contrátil à Angiotensina II.

A)

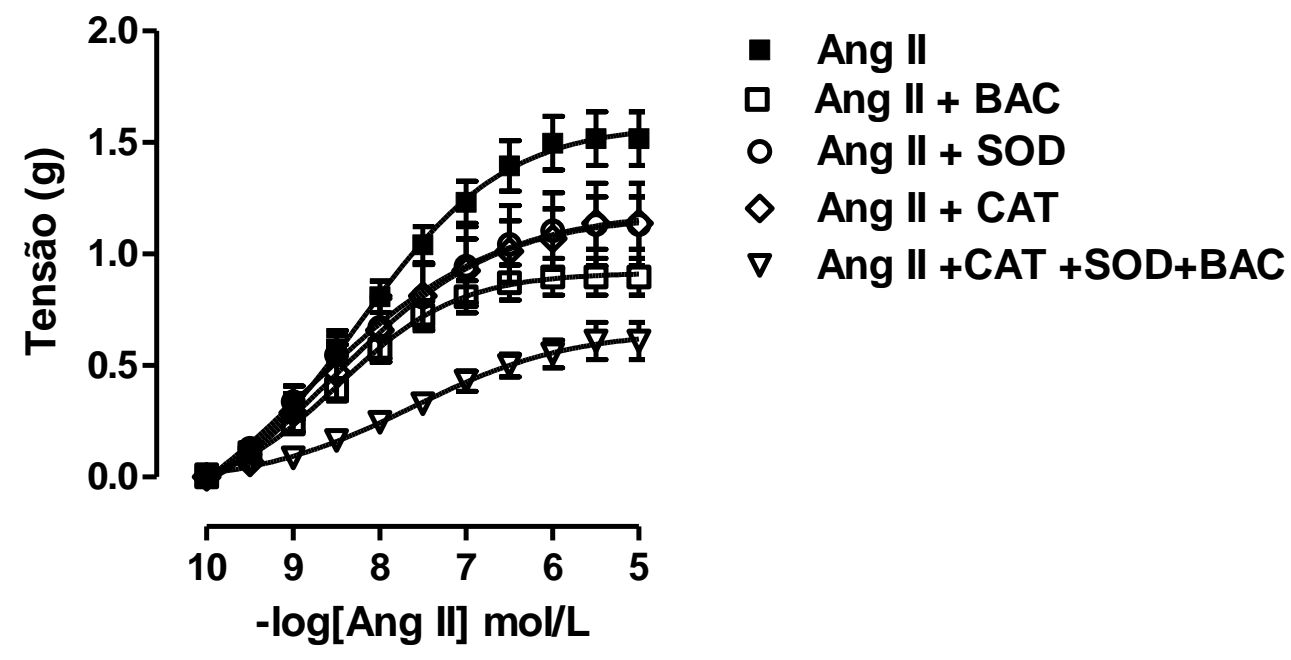

B)

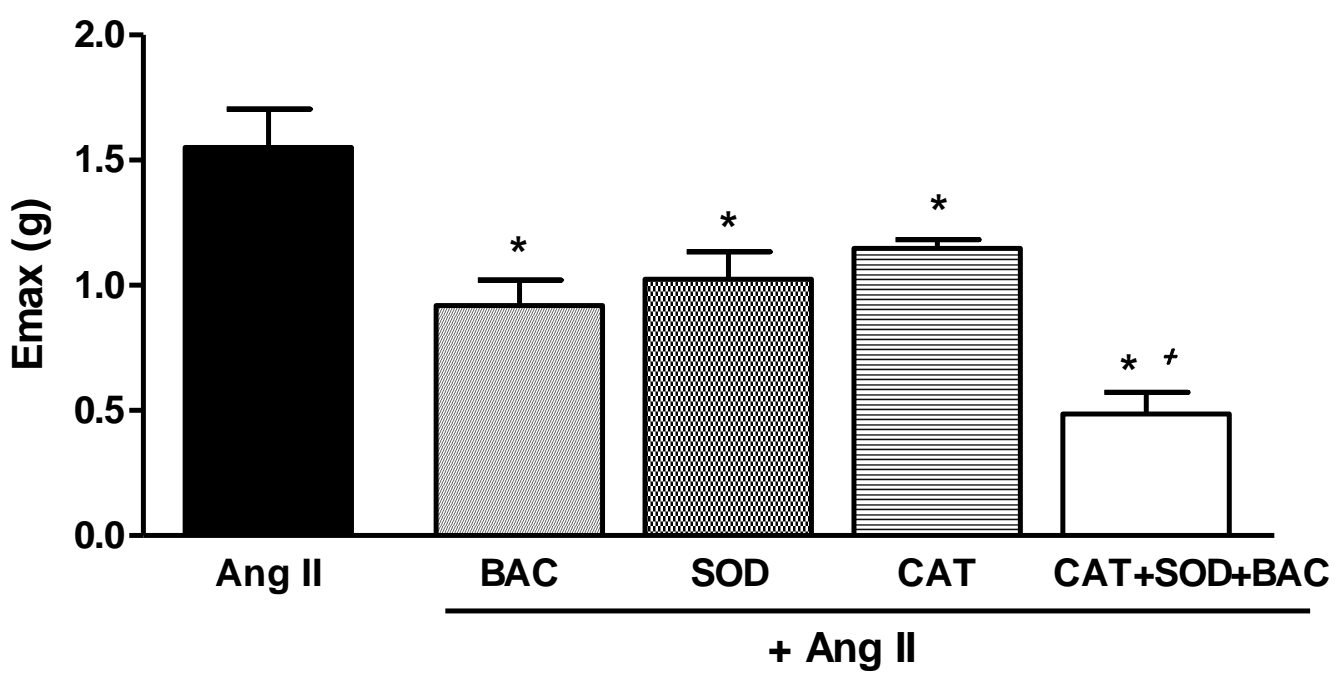

Anéis de aorta sem endotélio foram incubados com bacitracina (BAC; $1 \mathrm{mM} ; 15$ minutos); superóxido dismutase (SOD; $150 \mathrm{U} / \mathrm{ml} ; 30$ minutos); catalase (CAT; $300 \mathrm{U} / \mathrm{ml} ; 30$ minutos) isoladamente ou associados, previamente ao estímulo por Ang II. Após estímulo, a resposta contrátil foi mensurada e comparada ao grupo também estimulado por Ang II, porém sem tratamento prévio. (A) Curva concentração efeito a Ang II; (B) resposta máxima. Os resultados estão representados como média \pm EPM de no mínimo 5 animais por grupo experimental. ${ }^{*} p<0.05$ vs Ang II; ${ }^{+} p<0.05$ vs Ang II + CAT. 
Figura 19- Papel da NAPDH oxidase na inibição da resposta contrátil à Angiotensina II pela bacitracina.

A)

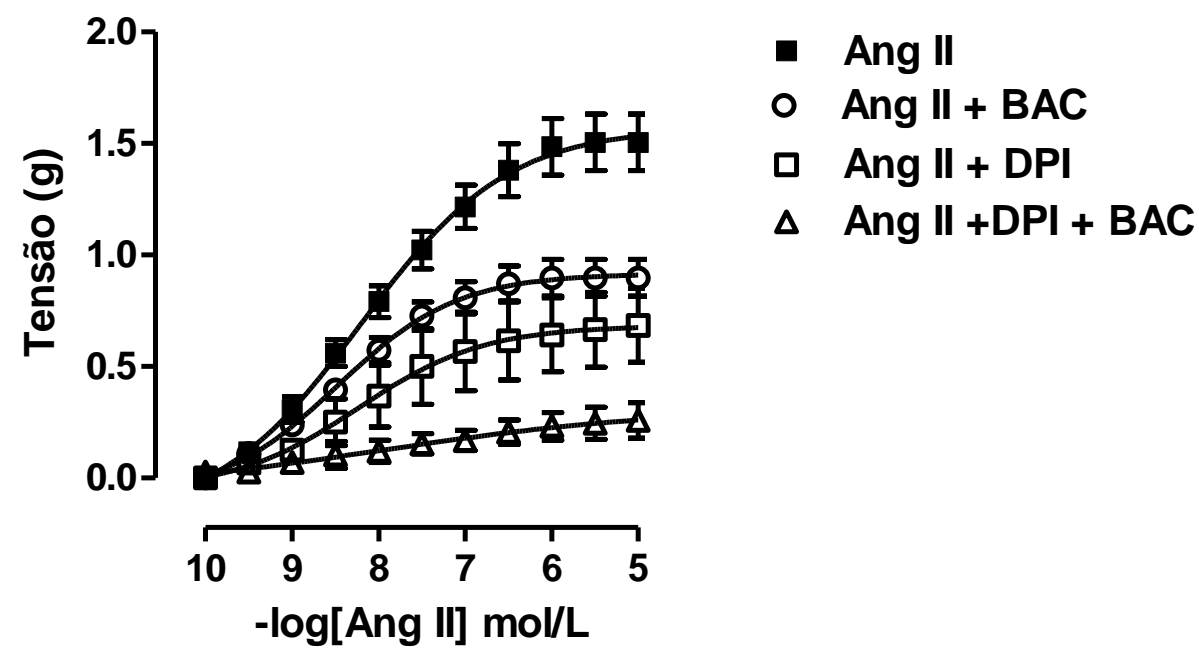

B)

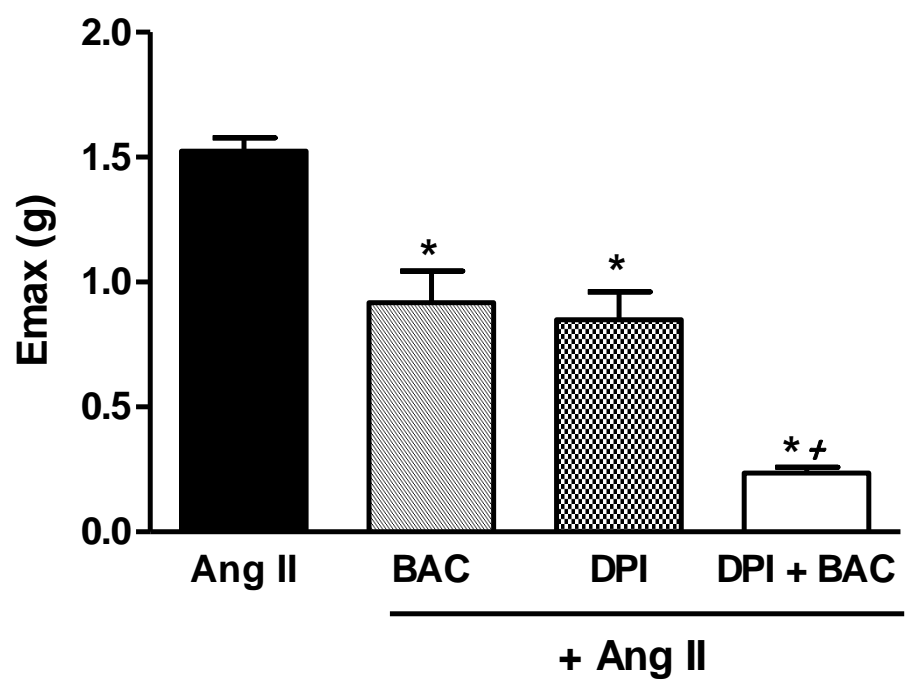

Anéis de aorta (sem endotélio) foram incubados com difenileno-iodônio (DPI; $30 \mu \mathrm{M} ; 30$ minutos) e bacitracina (BAC; $1 \mathrm{mM} ; 15$ minutos) isoladamente ou associados, previamente ao estímulo por Ang II. Após estímulo, a resposta contrátil foi mensurada e comparada ao grupo também estimulado por Ang II, porém sem tratamento prévio. (A) Curva concentração efeito a Ang II; (B) resposta máxima. Os resultados estão representados como média \pm EPM de no mínimo 5 animais por grupo experimental. ${ }^{*} p<0.05$ vs Ang II; ${ }^{+} p<0.05$ vs Ang II + DPI e Ang II + BAC. 
Figura 20 - Papel da NADPH oxidase na inibição da resposta contrátil à Noradrenalina pela bacitracina

A)

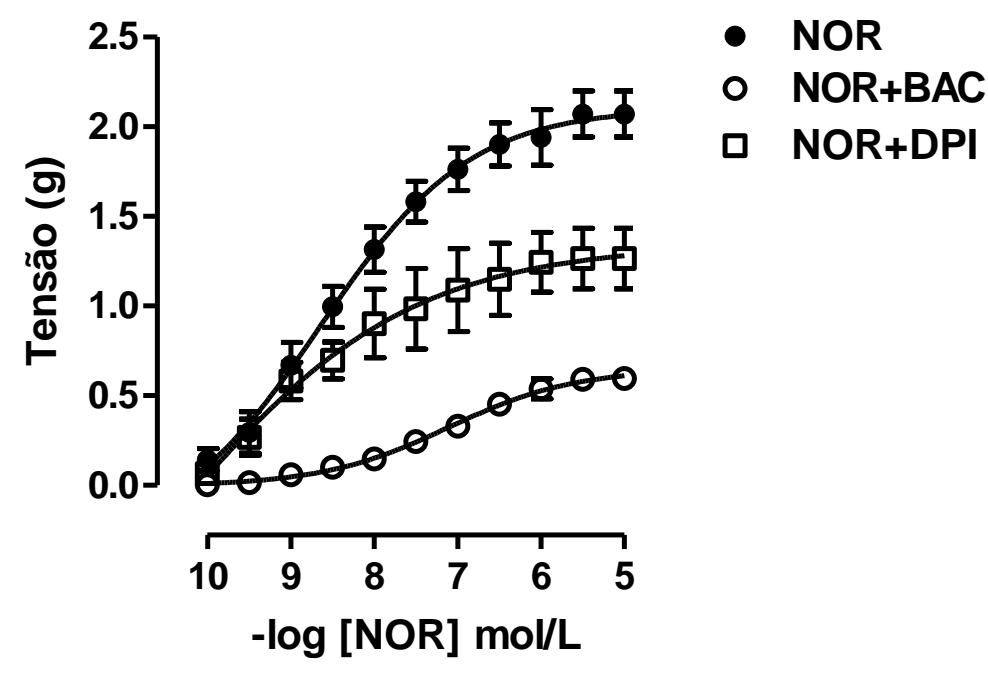

B)

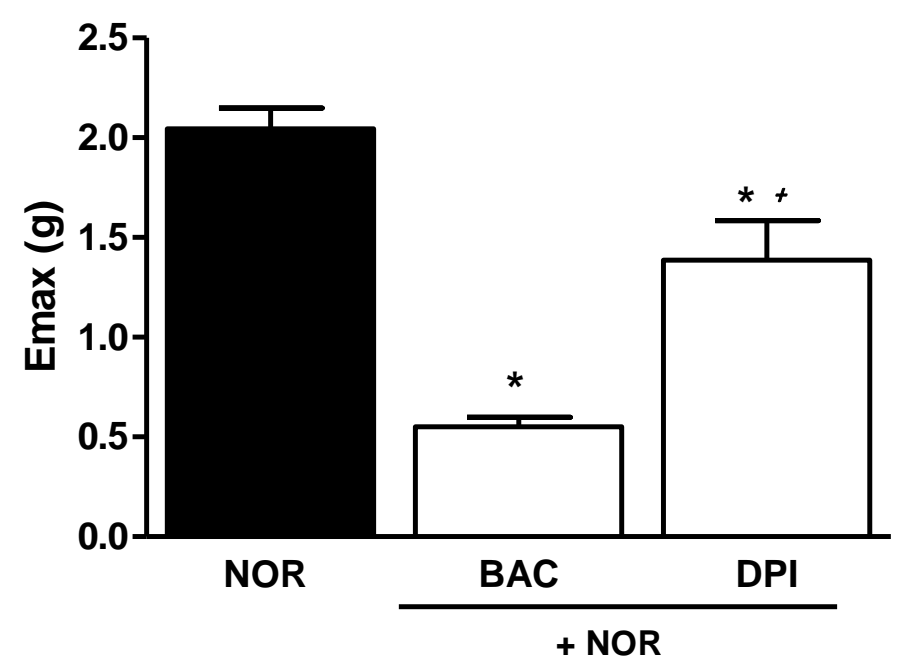

Anéis de aorta (sem endotélio) foram incubados com difenileno-iodônio (DPI; $30 \mu \mathrm{M} ; 30$ minutos) e bacitracina (BAC; $1 \mathrm{mM}$; 15 minutos) isoladamente previamente ao estímulo por NOR. Após estímulo, a resposta contrátil foi mensurada e comparada ao grupo também estimulado por NOR, porém sem tratamento prévio. (A) Curva concentração efeito a NOR; (B) resposta máxima. Os resultados estão representados como média \pm EPM de no mínimo 5 animais por grupo experimental. * $p<0.05$ vs NOR; ${ }^{+} \mathrm{p}<0.05$ vs NOR+BAC. 
Figura 21 - Papel da inibição da PDI na mobilização e influxo de cálcio durante a contração induzida por Noradrenalina em aortas isoladas

A)

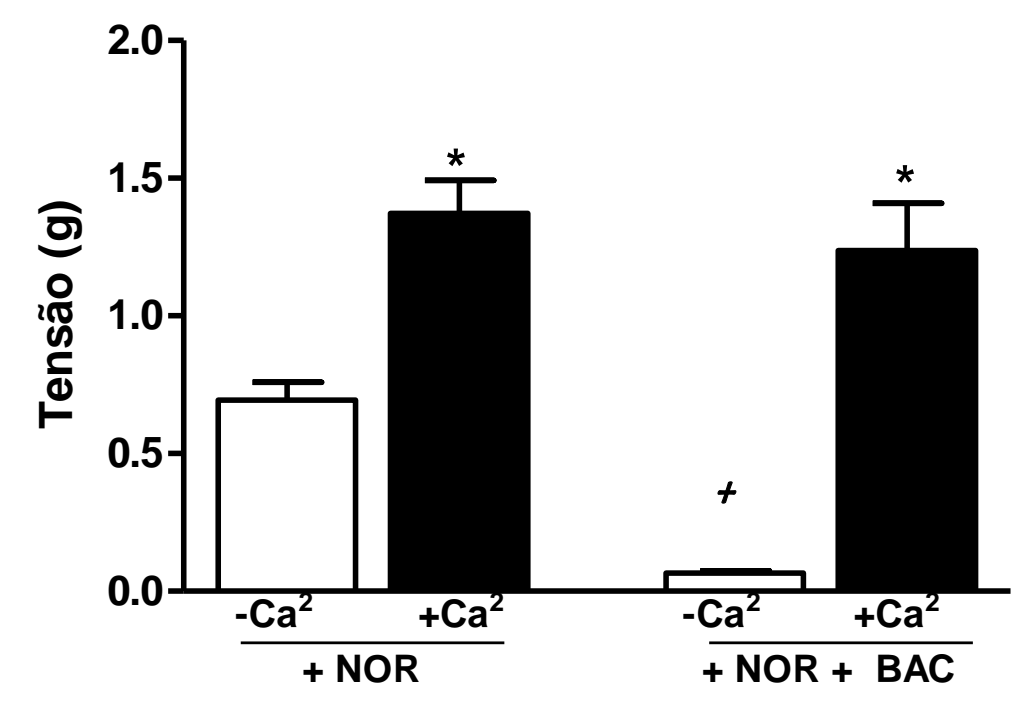

B)

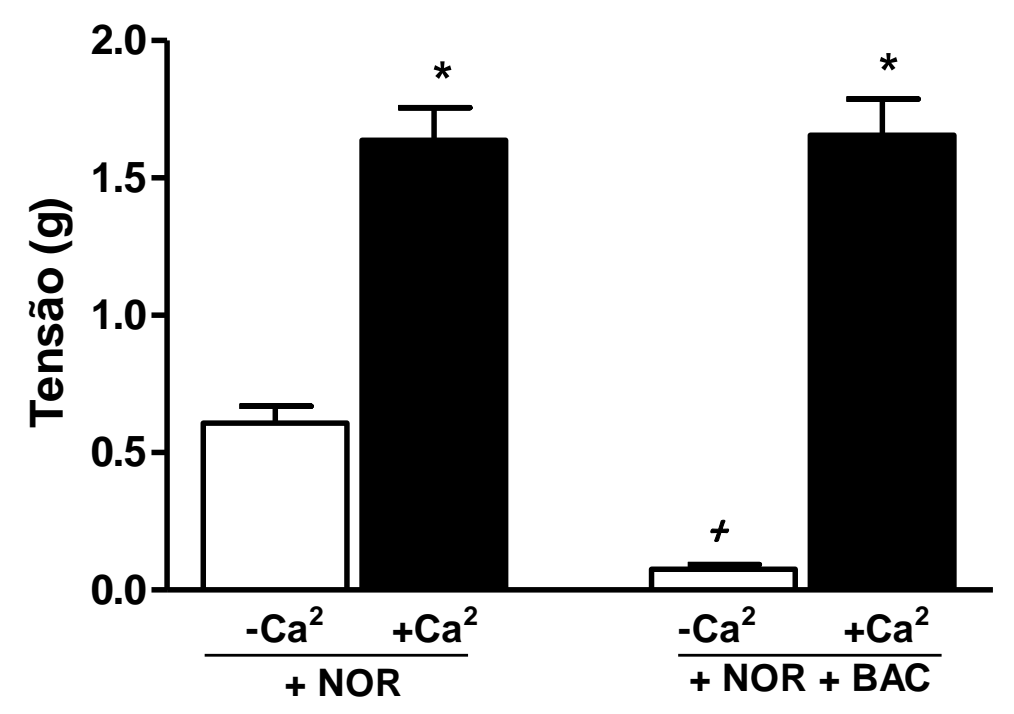

Efeito da mobilização do cálcio do reticulo sarcoplasmático $\left(-\mathrm{Ca}^{2}\right)$ e do influxo de cálcio exógeno $\left(+\mathrm{Ca}^{2}\right)$ na contração de anéis de aorta na presença ou ausência de tratamento com Bacitracina (BAC; $1 \mathrm{mM} ; 15$ minutos). (A) em anéis de aorta com endotélio; (B) na ausência do endotélio. Os resultados estão representados como média $\pm E P M$ de no mínimo 5 animais por grupo experimental. ${ }^{*} \mathrm{p}<0.05$ vs respectivo $\mathrm{NOR}-\mathrm{Ca}^{+2} ;{ }^{+} \mathrm{p}<0.05$ vs $\mathrm{NOR}-\mathrm{Ca}^{+2}$ 
Figura 22 - Efeito da estimulação de aortas isoladas com Angiotensina II e Noradrenalina na fosforilação da ERK $1 / 2$.
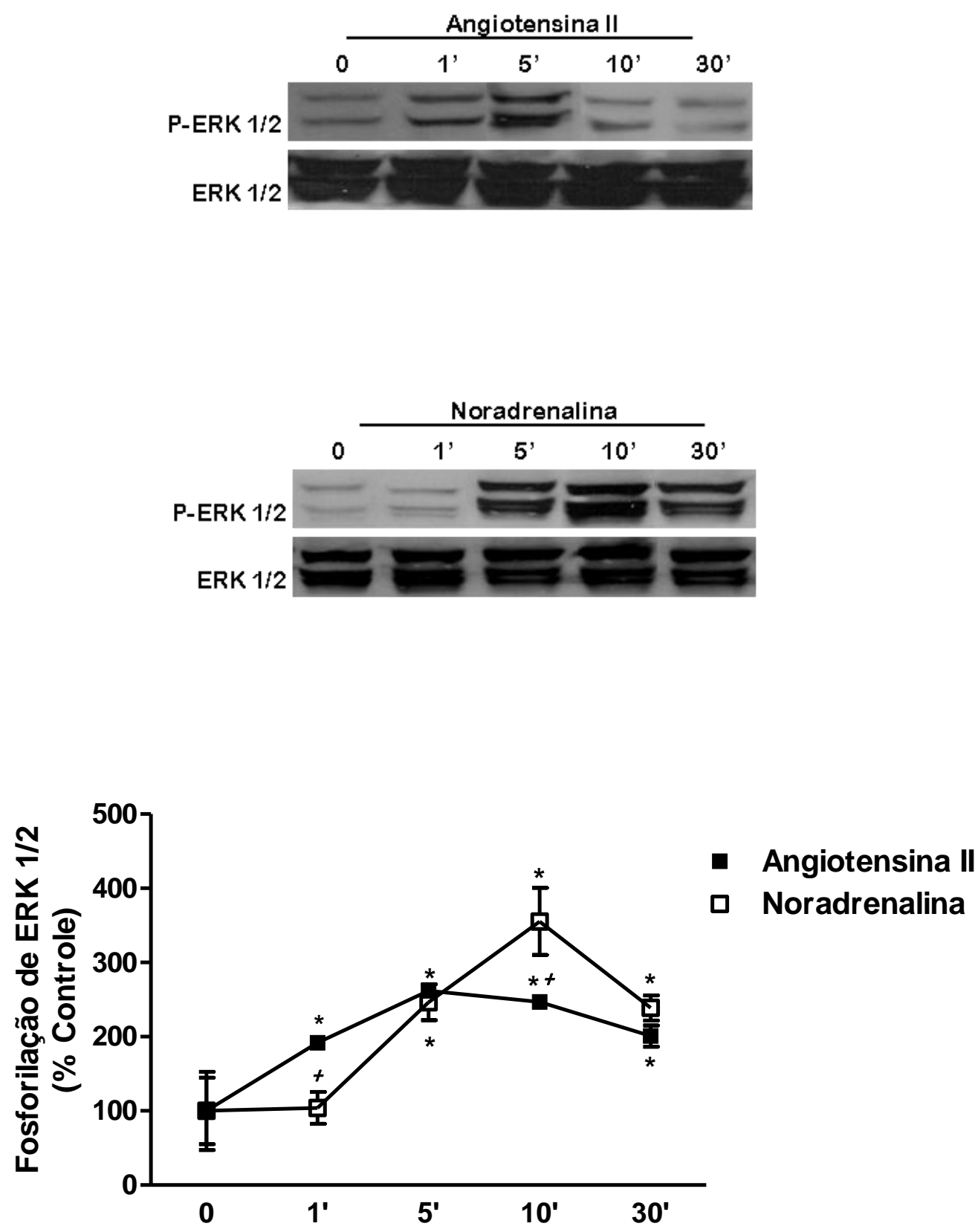

Curva temporal da fosforilação da ERK $1 / 2$ em aortas isoladas estimuladas com Angiotensina II (A; 10 $\mu \mathrm{M})$ e NOR $(\mathrm{B} ; 10 \mu \mathrm{M})$. Os resultados estão representados como média $\pm \mathrm{EPM}$ de no mínimo 3 animais por grupo experimental. ${ }^{*} p<0.05$ vs Controle; ${ }^{+} p<0.05$ vs NOR (respectivo tempo). 
Figura 23 - Efeito da inibição da PDI sobre a fosforilação da ERK 1/2 após estimulação com Angiotensina II.
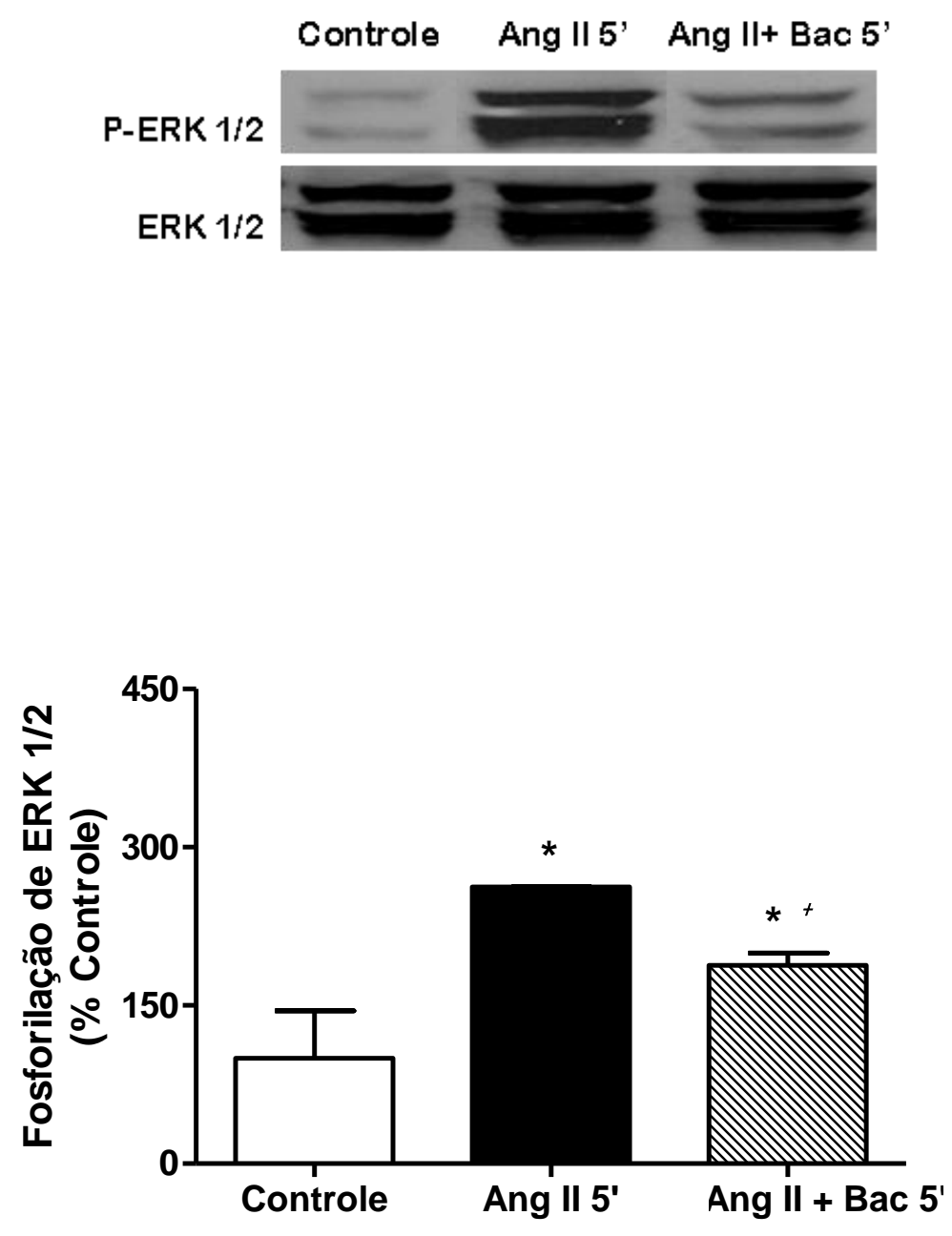

Immunobloting representativo para ERK $1 / 2$ fosforilada (P-ERK 1/2) em aortas de ratos Wistar estimuladas por 5 minutos com Angiotensina II $(10 \mu \mathrm{M})$ na presença ou ausência de bacitracina (BAC;1 mM; 30 minutos). Os resultados estão representados como média \pm EPM de no mínimo 3 animais por grupo experimental. ${ }^{*} p<0.05$ vs Controle; ${ }^{+} p<0.05$ vs Ang II. 
Figura 24- Efeito da inibição da PDI sobre a fosforilação da ERK 1/2 após estimulação com Noradrenalina.
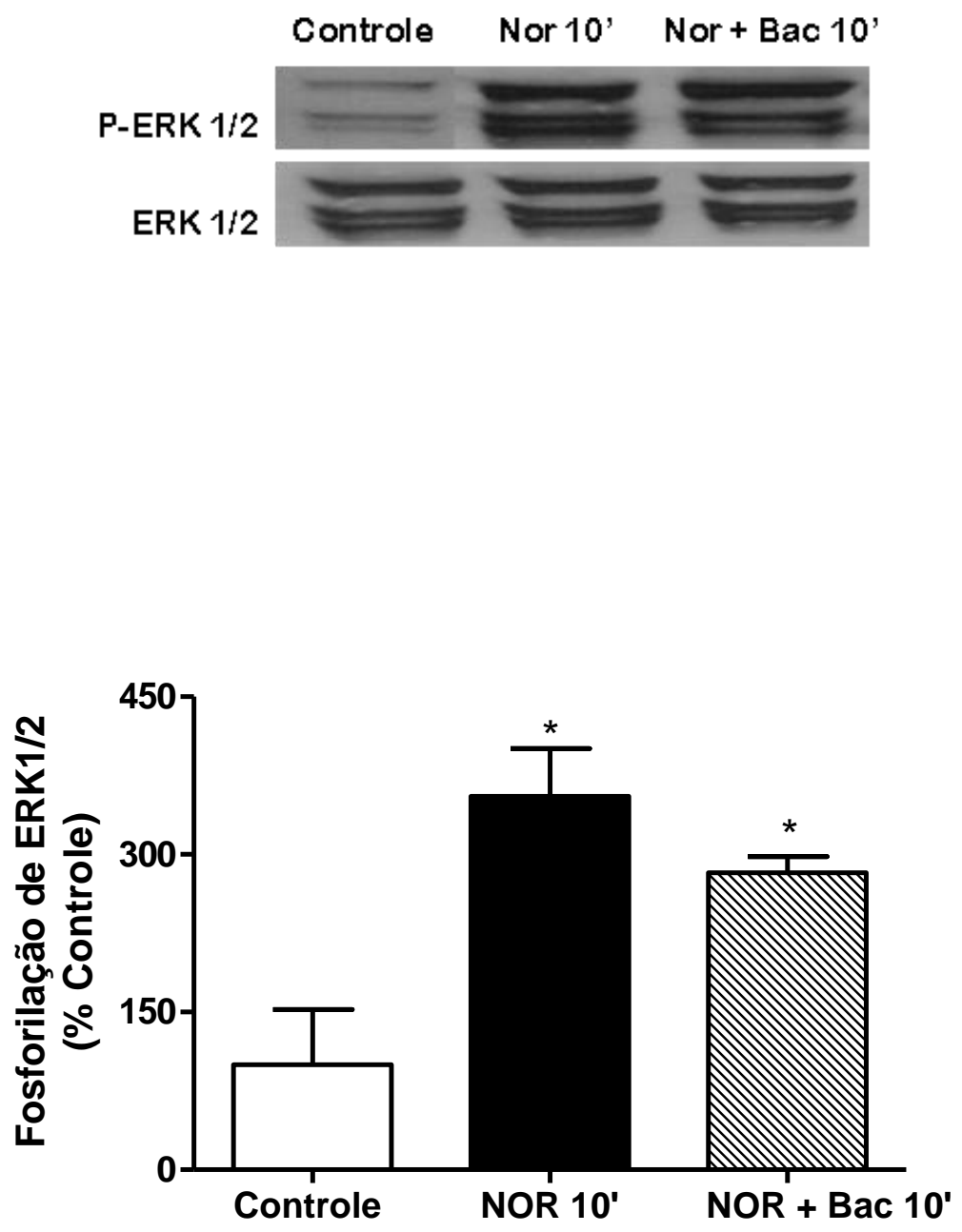

Immunobloting representativo para ERK $1 / 2$ fosforilada (P-ERK 1/2) em aortas de ratos Wistar estimuladas por 5 minutos com Noradrenalina (NOR; $10 \mu \mathrm{M}$ ) na presença ou ausência de Bacitracina (BAC; $1 \mathrm{mM} ; 30$ minutos). Os resultados estão representados como média \pm EPM de no mínimo 3 animais por grupo experimental. ${ }^{*} \mathrm{p}<0.05$ vs Controle. 


\section{DISCUSSÃo}

Atualmente, sabe-se que as EROs são produzidas em baixas concentrações exercendo uma função importante como moléculas sinalizadoras de vias envolvidas na manutenção do crescimento e tônus de CMLV (Rajagopalan et al., 1996; Griendling e Ushio-Fukai, 2000; Griendling et al., 2000). Em condições patológicas o excesso na geração de EROs leva à disfunção endotelial, proliferação e aumento da contratilidade destas células. Assim a homeostase redox é crucial para manutenção da atividade biológica e, portanto enzimas envolvidas na geração de EROs e ERNs (espécies reativas de nitrogênio) tem importante papel na fisiopatologia do sistema cardiovascular (Schafer e Buettner, 2001).

Nos últimos anos o nosso entendimento sobre o papel das EROs na fisiopatologia de doenças como a hipertensão arterial tem aumentado consideravelmente. Definida classicamente como uma elevação crônica da pressão arterial, a hipertensão arterial tem como característica hemodinâmica principal o aumento da resistência vascular periférica que é associada com alterações estruturais, mecânicas e funcionais na vasculatura. Estas mudanças incluem redução do diâmetro da luz do vaso, espessamento da camada média e aumento da reatividade à agentes vasoativos como a Ang II (Touyz e Schiffrin, 2004).

Sabidamente uma das contribuições da NADPH oxidase no desenvolvimento da hipertensão arterial decorre do fato de que o superóxido diminui a biodisponibilidade de NO, aumentando a resistência vascular periférica. Estudos do nosso grupo demonstraram que a PDI regula a geração de EROs pela NADPH oxidase vascular (Janiszewski et al., 2005) e fagocítica (Santos et al., 2009; Paes et al., 2011). Além de exercer uma importante função no reticulo relacionada com o enovelamento de proteínas, demonstramos que a PDI interage com as subunidades catalíticas (Janiszewski et al., 2005) e regulatórias da NADPH oxidase (Paes et al, 2011). Adicionalmente, a PDI é capaz de modular a geração de EROs pela NADPH oxidase induzida por Ang II pois, a inibição ou silenciamento desta tiol oxidoredutase reduz a geração de EROs e ativação de vias redox dependentes como a AKT quinase. Os efeitos biológicos e os mecanismos envolvidos na modulação da atividade da NADPH oxidase pela PDI ainda precisam ser esclarecidos. Desta 
forma, no presente estudo investigamos os efeitos da modulação da geração de EROs pela PDI na regulação de funções redox mediadas como a contração vascular.

Uma análise da expressão de PDI na aorta revelou uma maior expressão desta proteína na camada endotelial. Laurindo e colaboradores (2008) verificaram que a inibição da PDI diminuiu a geração de EROs em células endoteliais da aorta de coelho, o que poderia contribuir para aumentar a biodisponibilidade do NO. De fato, os nossos resultados demonstram que a resposta contrátil à Ang II e NOR encontra-se aumentada na ausência do endotélio. No entanto, o efeito da PDI na contratilidade independe desta camada vascular sendo de mesma magnitude em aortas com e sem endotélio. Este efeito é particularmente importante considerandose que a PDI catalisa reações de transnitrosação sendo responsável pela internalização do NO a partir de nitrosotióis de membrana (Zai et al., 1999; Ramanchandran et al., 2001). No entanto, no presente estudo a inibição da PDI não aumentou a contração das aortas, o que é indicativo de que nas concentrações utilizadas, a bacitracina não estaria inibindo a produção ou efeitos biológicos deste radical livre. No entanto na presença de altas concentrações de bacitracina, a inibição dos efeitos vasodilatadores do NO possivelmente contribuiu para o aumento da contração em resposta a Ang II. Considerando, que a inibição da resposta contrátil à Ang II e NOR pela bacitracina não foi modificada, na presença do endotélio, optamos por investigar os mecanismos envolvidos utilizando apenas aortas sem esta camada vascular.

A PDi apresenta 4 domínios estruturais semelhantes à tioredoxina $a, b, b$ ' e a'. As atividades da PDI são dependentes do estado redox do seu motivo catalítico CGHC que estão presentes nos domínios a e a' e existem na forma reduzida (ditiol) ou oxidada (disulfeto). Os domínios b, no entanto, não são catalíticos e o domínio b'possui uma região hidrofóbica por onde a PDI liga-se ao seu substrato. A bacitracina foi inicialmente descrita em 1981 e desde então tem sido largamente utilizada como um inibidor da PDI tendo sido empregada para demonstrar o papel da PDI no mecanismo de infecção por vírus (Barbouche et al., 2003) na morte de células tumorais (Fonseca et al., 2009) e na agregação de plaquetas (Essex e Li, 1999; Essex et al., 2001; Robinson et al., 2005). Recentemente, Karala e Ruddock (2010) demonstraram que a bacitracina atuaria inibindo a atividade redutase da PDI mas não teria efeito sobre a atividade oxidase ou isomerase desta proteína. Estes 
estudos foram confirmados por Dickerhof et al, que demonstrou que a bacitracina liga-se covalentemente a uma cisteína localizada numa região próxima do domínio b' inibindo a ligação da PDI ao seu substrato. Adicionalmente estes autores demonstraram que a bacitracina pode inibir outras proteínas contendo cisteínas além da PDI.

Diversas proteínas e enzimas possuem resíduos de cisteína em seus sítios ativos com grupamentos tióis que são locais para a ligação de metais e alvos para reações de oxidação e redução. Esta variedade de interações bioquímicas permite aos tióis presentes nas cisteínas dos sítios ativos das proteínas atuarem como sensores redox (Biswas et al., 2006). De fato, as EROs podem interagir com estes tióis modificando a atividade de proteínas. Por exemplo, a oxidação de tióis de sítios ativos de enzimas pelo $\mathrm{H}_{2} \mathrm{O}_{2}$ pode causar inativação de fosfatases como SHP-2 o que aumenta a atividade de tirosina quinases e consequentemente de MAPK como ERK e JNK (Winterbourn e Hampton, 2008). Assim a oxidação de tióis não afeta somente a PDI (Mandel et al., 1993) mas também a atividade da NADPH oxidase (Laurindo et al.,2008) e de tirosina quinases.

Os mecanismos envolvidos na modulação da resposta contrátil pela PDI sugerem a participação de tióis visto que a resposta à Ang II foi reduzida pelo DTNB um oxidante de tióis impermeável à membrana celular. Como a inibição da PDI e da NADPH oxidase por este agente sabidamente envolve seus tióis nossos resultados sugerem que a PDI poderia estar modulando a contração de aortas isoladas através de mecanismos redox dependentes.

Uma das prováveis fontes de EROs é a NADPH oxidase, visto que, tanto a geração quanto a contração vascular foram inibidas pelo DPI um inibidor inespecífico da geração de EROs pela NADPH oxidase. Esta hipótese é reforçada pelo fato da associação da bacitracina com o DPI potencializar a inibição da resposta contrátil a Ang II. De fato, estudos do nosso grupo demonstraram que o silenciamento da PDI em CMLV da aorta é capaz de reduzir a ativação da NADPH oxidase e a expressão gênica de NOX-1 induzida por Ang II (Fernandes et al., 2009). Esta hipótese foi confirmada no presente estudo aonde observamos em aortas isoladas a co-localização da PDI com a NOX-1 um dos principais "alvos" da Ang II. De fato animais KO para NOX-1 apresentam uma diminuição da geração de superóxido induzida pela Ang II (Garrido e Griendling, 2009). Paralelamente, a superexpessão de PDI em CMLV de aorta de coelhos induz aumento de EROs e 
aumento da expressão de NOX-1 (Fernandes et al., 2009), corroborando o papel desta isoforma da NADPH oxidase nos efeitos da PDI.

Um dos primeiros sinais de ativação da resposta contrátil à Ang II é a ativação de fosfolipase $\mathrm{C}$ e aumento da concentração intracelular de cálcio. Sabendo-se que ERos exercem um importante papel na modulação da concentração de cálcio intracelular e que a ativação de tirosina quinases induzida pela Ang II estimula a NADPH oxidase e ativa MAP quinases (Touyz et al., 2003) em CMLV decidimos investigar o papel de MAP quinases na regulação da resposta contrátil pela PDI.

Embora, a regulação da ERK 1/2 por EROs seja controversa, alguns estudos demonstram que sua regulação é redox dependente (Touyz et al., 2003) e outros não (Ding et al., 2007), a implicação desta MAP quinase na mobilização de cálcio intracelular e contração induzida pela Ang II é bem estabelecida. Corroborando estes estudos observamos um aumento da fosforilação de ERK 1/2 imediatamente após a estimulação com Ang II. Este efeito é modulado pela PDI, pois foi inibido pela bacitracina. A análise destes resultados em conjunto sugere que na aorta a PDI modularia a concentração de cálcio intracelular e, portanto, a resposta vasoconstritora a Ang II por vias redox dependentes que envolvem a ativação de ERK 1/2. De fato, a inibição desta MAP quinase diminui a mobilização do cálcio intracelular e a resposta contrátil a Ang II em células musculares lisas vasculares de animais hipertensos (Touyz et al., 1999). Desta forma, os mecanismos envolvidos na modulação da contração pela PDI podem ser múltiplos e dependentes de vias que envolvem ou não processos redox. Neste contexto é possível que a PDI regule a resposta contrátil à Ang II aumentando a geração de EROs pela NADPH oxidase ativando vias redox dependentes como tirosina quinases que por sua vez aumentariam a atividade de ERK 1/2 e a mobilização de cálcio.

$\mathrm{Na}$ tentativa de compreender melhor este efeito da PDI na mobilização de cálcio e seu papel na contração vascular decidimos investigar o papel da PDI na resposta contrátil a outros agentes vasoconstritores tais como a NOR. Assim como a Ang II, a incubação de aortas com NOR aumentou a geração de EROs pela NADPH oxidase, que foi inibida pela bacitracina. Diferentemente da Ang II, a inibição da PDI pela Scrambled RNAase não teve o mesmo efeito inibitório sobre a geração de EROs após estímulo com NOR. Paralelamente, a NADPH oxidase também participa da contração por NOR, visto que esta foi inibida pelo DPI. No entanto, a modulação da resposta contrátil a NOR pela PDI aparentemente envolve mecanismos redox 
dependentes e independentes, visto que a inibição da resposta contrátil pela bacitracina foi maior do que a inibição pelo DPI. Conforme demonstramos em leucócitos, um dos possíveis mecanismos de modulação da NADPH oxidase pela PDI envolve a associação com a subunidade regulatória p47phox organizando a formação do complexo e ativando a enzima (Paes et al., 2011). Assim, um dos possíveis mecanismos envolvidos na modulação da geração de EROs pela PDI após estímulo com NOR e Ang II estaria associada a ligação da PDI a uma das subunidades regulatórias da NOX- 1 como a p47 phox ou seu homolólogo NoxO1. Reforçando esta hipótese, dados do nosso laboratório sugerem que a PDI também interage com o $\mathrm{p} 47^{\text {phox }}$ em células vasculares.

Embora não seja tão bem estabelecida como para Ang II, estudos recentes mostram que contração induzida pela NOR também depende da geração de EROs pela NADPH oxidase (Tsai e Jiang, 2010). Contudo, existem evidências do envolvimento de outras fontes de EROs nesta resposta, como enzimas da cadeia mitocondrial (Hao et al., 2006). Estudos recentes de Bleeke e colaboradores (2004) revelam ainda um papel da NADPH oxidase na proliferação de CMLV de aortas após estimulação com NOR. Além disso, Jiang e Tsai (2010) demonstraram que o efeito da fenileferina sobre a atividade da via RhoA/Rho quinase de CMLV depende de EROs gerados pela NADPH oxidase.

A contração vascular induzida pela NOR ocorre em dois passos consecutivos, cuja origem do cálcio e duração da contração são diferentes. A liberação de cálcio intracelular é responsável pela resposta inicial rápida induzida pela noradrenalina, seguida de uma contração lenta e sustentada resultante da entrada de cálcio extracelular (Bohr, 1963; Deth e van Breemen, 1974; Rinaldi et al., 1991).

Além do influxo de $\mathrm{Ca}^{+2}$, a reposição dos estoques de $\mathrm{Ca}^{+2}$ no retículo pela SERCA tem extrema importância na contração vascular por regular a abertura de canais de cálcio regulados por estoque (SOC). Neste contexto, as EROs podem inativar a SERCA por oxidar irreversivelmente os grupamentos sufidrilícos nos sítios ativos da enzima (Grover et al., 2003). Assim, o aumento da geração de EROs pela NOR poderia inibir a SERCA aumentando os estoques intracelulares de cálcio o que favoreceria a contração. No entanto, o fato de inibidores da PDI terem diminuído a concentração de cálcio intracelular, aliado ao fato de que a bacitracina não atravessaria a membrana celular, são indicativos de que a SERCA não teria contribuído para a inibição da resposta contrátil pela bacitracina. 
Uma vez que alterações no aparato contrátil podem ser os responsáveis pela redução da função contrátil de aortas incubadas com bacitracina e o cálcio tem importante participação na contração do músculo liso vascular, uma possível explicação para a resposta diminuída à NOR na presença de inibidores da PDI poderia ser decorrente da redução da mobilização de cálcio intracelular assim como também do influxo de cálcio extracelular. Nas CLMV, o $\mathrm{Ca}^{+2}$ é estocado intracelularmente no retículo endoplasmático. Este contém no mínimo dois tipos de canais de liberação de $\mathrm{Ca}^{+2}$, isto é, canal sensível ao $\mathrm{IP}_{3}$ (receptor para $\mathrm{IP}_{3}$ ) e canal sensível à rianodina e à cafeína (receptor para rianodina) (Lesh et al., 1998). Quando a noradrenalina liga-se aos receptores adrenérgicos no músculo liso vascular, ocorre a ativação da fosfolipase C (PLC). A PLC ativada pela subunidade $\alpha$ da proteína $\mathrm{G}$ acoplada ao receptor de NOR degrada os fosfolipídios de membrana, fosfatidil-inositol 4,5-bifosfato (PIP2) em: $\mathrm{IP}_{3}$ e DAG. O IP 3 atua nos receptores para IP3 do retículo endoplasmático liberando $\mathrm{Ca}^{+2}$ e DAG que ativam a PKC levando a abertura de canais de cálcio na membrana. A manutenção da contração depende, portanto, do $\mathrm{Ca}^{+2}$ intracelular e da sensibilidade das proteínas contráteis a este íon. No presente trabalho, demonstramos que a contração à noradrenalina dependente do cálcio proveniente do retículo endoplasmático, está diminuída após incubação com inibidores da PDI. Isso sugere que a mobilização do cálcio proveniente do retículo estaria prejudicada. Embora os nossos estudos não esclareçam ainda qual o mecanismo envolvido, eles indicam que, diferentemente da Ang II, este mecanismo não seria dependente de uma redução na mobilização de cálcio via ERK 1/2. Uma possível explicação para este efeito, seria que a inibição da PDI pela bacitracina diminuiria a geração de EROs e, consequentemente a ativação de vias de sinalização redox dependentes, diminuindo a geração de IP3 e a mobilização de cálcio dos estoques intracelulares.

Uma segunda onda de $\mathrm{Ca}^{+2}$ regulada pela NOR é resultante da abertura de canais de cálcio na membrana plasmática. No entanto, embora estudos realizados por Tabet e colaboradores demonstrem que em CMLV $\circ \mathrm{H}_{2} \mathrm{O}_{2}$ induz aumento da concentração intracelular de $\mathrm{Ca}^{+2}$ por aumentar a mobilização dos estoques intracelulares e também favorecer o influxo de cálcio pelos canais do tipo $L$ e $T$. Nossos resultados indicam que a PDI não modularia estes canais, pois, a inibição da PDI não alterou o influxo de cálcio pela NOR. Entretanto, é possível postularmos que a diminuição da mobilização de cálcio dos estoques intracelulares pela bacitracina 
comprometa a abertura dos canais de cálcio na membrana diminuindo assim a resposta vasoconstritora à noradrenalina.

Finalmente, não podemos descartar a hipótese de que a inibição da PDI resulte numa redução da sensibilidade das proteínas contráteis ao cálcio. Neste contexto, a inibição da geração de EROs diminui a atividade de Rho quinases e a contração de aortas isoladas por fenilefrina (Hilgers e Webb, 2005).

Os resultados do presente trabalho tem implicações relevantes no entendimento dos efeitos fisiológicos da regulação da atividade da NADPH oxidase pela PDI. Interessantemente, nossos resultados apontam um papel da PDI na modulação da atividade da oxidase em resposta a outros fatores vasoconstritores como a NOR com implicações na mobilização de cálcio intracelular por mecanismos dependentes e independentes de processos redox. Neste sentido, é interessante salientar o fato de uma proteína, com uma função primária no enovelamento protéico no retículo endoplasmático, possuir um efeito na regulação de um fenômeno tão diferenciado como a contração vascular. Adicionalmente o presente estudo abre a perspectiva da participação da PDI na modulação da resistência periférica e controle da pressão arterial e abre uma nova frente para investigação do papel desta proteína na disfunção vascular associada a patologias como hipertensão arterial. 


\section{CONCLUSÕES}

Com base nos resultados obtidos podemos concluir que em aortas isoladas:

- A PDI é expressa em todas as camadas vasculares e co-localiza com a Nox1 principalmente na camada média.

- A inibição da PDI e NADPH oxidase diminui a geração de EROs após estímulo com Ang II e NOR.

- A inibição da PDI diminuiu a resposta contrátil à Ang II e NOR de maneira independente do endotélio.

- A PDI modula a contração à NOR aumentando a concentração de cálcio intracelular através da liberação dos estoques do RS e não da abertura de canais de cálcio da membrana plasmática.

- A mobilização de cálcio dos estoques intracelulares de cálcio pela PDI depende da ativação de MAP quinases, como a ERK 1/2 após estímulo com Ang II

- A mobilização de cálcio dos estoques intracelulares de cálcio pela PDI independe da ativação de MAP quinases como ERK 1/2 após estímulo com NOR. 


\section{REFERÊNCIAS}

Ardanaz N, Pagano PJ. Hydrogen peroxide as a paracrine vascular mediator: regulation and signaling leading to dysfunction. Exp Biol Med. 2006;231(3):237-51.

Babior BM. NADPH oxidase: an update. Blood. 1999;93(5):1464-76.

Barbouche R, Miquelis R, Jones IM, Fenouillet E. Protein-disulfide isomerase-mediated reduction of two disulfide bonds of HIV envelope glycoprotein 120 occurs post-CXCR4 binding and is required for fusion. J Biol Chem. 2003;278(5):3131-6.

Bedard K, Krause KH. The NOX family of ROS-generating NADPH oxidases: physiology and pathophysiology. Physiol Rev. 2007; 87(1):245-313.

Bennett TA, Edwards BS, Sklar LA, Rogelj S. Sulfhydryl regulation of L-selectin shedding: phenylarsine oxide promotes activation-independent L-selectin shedding from leukocytes. $J$ Immunol. 2000;164(8):4120-9.

Berridge MJ.Smooth muscle cell calcium activation mechanisms. J Physiol. 2008;586(Pt 21):5047-61.

Biswas S, Chida AS, Rahman I. Redox modifications of protein-thiols: emerging roles in cell signaling. Biochem Pharmacol. 2006;71(5):551-64.

Bleeke T, Zhang H, Madamanchi N, Patterson C, Faber JE. Catecholamine-induced vascular wall growth is dependent on generation of reactive oxygen species. Circ Res. 2004;94(1):3745.

Bohr DF. Vascular smooth muscle: dual effect of calcium. Science. 1963; 139: 597-599.

Brandes RP, Kreuzer J. Vascular NADPH oxidases: molecular mechanisms of activation. Cardiovascular Research, 2005; 65(1):16-27

Brandes RP, Weissmann N, Schröder K. NADPH oxidases in cardiovascular disease. Free Radic Biol Med. 2010; 49: 687-706.

Brozovich FV. Myosin light chain phosphatase: it gets around. Circ Res. 2002;90(5):500-2.

Byrne LJ, Sidhu A, Wallis AK, Ruddock LW, Freedman RB, Howard MJ, Williamson RA. Mapping of the ligand-binding site on the $b$ ' domain of human PDI: interaction with peptide ligands and the x-linker region. Biochem J. 2009;423(2):209-17. 
Chen K, Kirber MT, Xiao H, Yang Y, Keaney JF Jr. Regulation of ROS signal transduction by NADPH oxidase 4 localization. J Cell Biol. 2008;181(7):1129-39

Chitaley K, Weber D, Webb RC. RhoA/Rho-kinase, vascular changes, and hypertension. Curr Hypertens Rep. 2001 Apr;3(2):139-44.

Clempus RE, Sorescu D, Dikalova AE, Pounkova L, Jo P, Sorescu GP, Schmidt HH, Lassègue $B$, Griendling KK.Nox4 is required for maintenance of the differentiated vascular smooth muscle cell phenotype. Arterioscler Thromb Vasc Biol. 2007;27(1):42-8

Denisov AY, Maattanen P, Sprules T, Thomas DY, Gehring K. 1H, 13C and 15N resonance assignments of the bb' domains of human protein disulfide isomerase. Biomol NMR Assign. 2007;1(1):129-30.

Deth $\mathrm{R}$, van Breemen C. Relative contributions of $\mathrm{Ca} 2+$ influx and cellular $\mathrm{Ca} 2+$ release during drug induced activation of the rabbit aorta. Pflügers. Arch. 1974; 348 (1):13-22.

Dickerhof N, Kleffmann T, Jack R, McCormick S. Bacitracin inhibits the reductive activity of protein disulfide isomerase by disulfide bond formation with free cysteines in the substratebinding domain. FEBS J. 2011 Apr 11. doi: 10.1111/j.1742-4658.2011.08119.x. [Epub ahead of print]

Dikalov SI, Dikalova AE, Bikineyeva AT, Schmidt HH, Harrison DG, Griendling KK. Distinct roles of Nox1 and Nox4 in basal and angiotensin II-stimulated superoxide and hydrogen peroxide production. Free Radic Biol Med. 2008;45(9):1340-51.

Ding L, Chapman A, Boyd R, Wang HD.ERK activation contributes to regulation of spontaneous contractile tone via superoxide anion in isolated rat aorta of angiotensin IIinduced hypertension. Am J Physiol Heart Circ Physiol. 2007;292(6):H2997-H3005.

Dubey RK, Jackson EK, Rupprecht HD, Sterzel RB. Factors controlling growth and matrix production in vascular smooth muscle and glomerular mesangial cells.Curr Opin Nephrol Hypertens. 1997;6(1):88-105.

Ebrahimian T, Touyz RM. Thioredoxin in vascular biology: role in hypertension. Antioxid Redox Signal. 2008;10(6):1127-36.

Ellgaard L, Ruddock LW.The human protein disulphide isomerase family: substrate interactions and functional properties. EMBO Rep. 2005; 6(1):28-32.

Ermak G, Davies KJ. Calcium and oxidative stress: from cell signaling to cell death. Mol Immunol. 2002;38(10):713-21.

Essex DW, Li M, Miller A, Feinman RD. Protein disulfide isomerase and sulfhydryldependent pathways in platelet activation. Biochemistry. 2001; 40(20):6070-5.

Essex DW, Li M. Protein disulphide isomerase mediates platelet aggregation and secretion. Br J Haematol. 1999;104(3):448-54.

Essex DW, Li M. Redox modification of platelet glycoproteins. Curr Drug Targets. 2006; $7(10): 1233-41$. 
Eto K, Ohya Y, Nakamura Y, Abe I, lida M. Intracellular angiotensin II stimulates voltageoperated $\mathrm{Ca}(2+)$ channels in arterial myocytes. Hypertension. 2002;39(2 Pt 2):474-8.

Fernandes DC, Manoel AH, Wosniak J Jr, Laurindo FR. Protein disulfide isomerase overexpression in vascular smooth muscle cells induces spontaneous preemptive NADPH oxidase activation and Nox1 mRNA expression: effects of nitrosothiol exposure. Arch Biochem Biophys. 2009;484(2):197-204.

Fonseca C, Soiffer R, Ho V, Vanneman M, Jinushi M, Ritz J, Neuberg D, Stone R, DeAngelo $\mathrm{D}$, Dranoff $\mathrm{G}$. Protein disulfide isomerases are antibody targets during immune-mediated tumor destruction. Blood. 2009 Feb 19;113(8):1681-8

Fyhrquist F, Saijonmaa O. Renin-angiotensin system revisited. J Intern Med. 2008;264(3):224-36.

Galley HF, Webster NR. Physiology of the endothelium. Br J Anaesth. 2004;93(1):105-13.

Garrido AM, Griendling KK. NADPH oxidases and angiotensin II receptor signaling. Mol Cell Endocrinol. 2009;302(2):148-58

Geiszt M, Lekstrom K, Witta J, Leto TL. Proteins homologous to p47phox and p67phox support superoxide production by $\mathrm{NAD}(\mathrm{P}) \mathrm{H}$ oxidase 1 in colon epithelial cells. J Biol Chem. 2003;278(22):20006-12

Graven KK, Molvar C, Roncarati JS, Klahn BD, Lowrey S, Farber HW. Identification of protein disulfide isomerase as an endothelial hypoxic stress protein. Am J Physiol Lung Cell Mol Physiol. 2002;282(5):L996-1003

Griendling KK, Sorescu D, Ushio-Fukai M. NAD(P)H oxidase: role in cardiovascular biology and disease. Circ Res 2000;86(5):494-501

Griendling KK, Ushio-Fukai M. Reactive oxygen species as mediators of angiotensin II signaling. Regul Pept 2000;91(1-3):21-7.

Grover AK, Kwan CY, Samson SE. Effects of peroxynitrite on sarco/endoplasmic reticulum Ca2+ pump isoforms SERCA2b and SERCA3a. Am J Physiol Cell Physiol. 2003;285(6):C1537-43.

Grover AK, Samson SE, Fomin VP, Werstiuk ES. Effects of peroxide and superoxide on coronary artery: ANG II response and sarcoplasmic reticulum $\mathrm{Ca2}+$ pump. Am J Physiol. 1995;269(3 Pt 1):C546-53.

Gruber CW, Cemazar M, Heras B, Martin JL, Craik DJ. Protein disulfide isomerase: the structure of oxidative folding. Trends Biochem Sci. 2006; 31(8):455-64.

Hao L, Nishimura T, Wo H, Fernandez-Patron C. Vascular responses to alpha1-adrenergic receptors in small rat mesenteric arteries depend on mitochondrial reactive oxygen species. Arterioscler Thromb Vasc Biol. 2006;26(4):819-25. 
Helmcke I, Heumüller S, Tikkanen R, Schröder K, Brandes RP. Identification of structural elements in Nox1 and Nox4 controlling localization and activity. Antioxid Redox Signal. 2009;11(6):1279-87

Hidalgo E, Demple B. An iron-sulfur center essential for transcriptional activation by the redox-sensing SoxR protein. EMBO J. 1994;13(1):138-46.

Hilenski LL, Clempus RE, Quinn MT, Lambeth JD, Griendling KK. Distinct subcellular localizations of Nox1 and Nox4 in vascular smooth muscle cells. Arterioscler Thromb Vasc Biol 2004;(4):677-83.

Hilgers $\mathrm{RH}$, Webb RC. Molecular aspects of arterial smooth muscle contraction: focus on Rho. Exp Biol Med (Maywood). 2005;230(11):829-35.

Hughes AD. Calcium channels in vascular smooth muscle cells. J Vasc Res. 1995;32(6):35370

Ichikawa K, Ito $\mathrm{M}$, Hartshorne DJ. Phosphorylation of the large subunit of myosin phosphatase and inhibition of phosphatase activity. J Biol Chem. 1996; 271: 4733-4740.

Jackson WF. Ion channels and vascular tone. Hypertension. 200;35(1 Pt 2):173-8

Janiszewski M, Lopes LR, Carmo AO, Pedro MA, Brandes RP, Santos CX, et al. Regulation of $\mathrm{NAD}(\mathrm{P}) \mathrm{H}$ oxidase by associated protein disulfide isomerase in vascular smooth muscle cells. J Biol Chem 2005;280(49):40813-9.

Janiszewski M, Pedro MA, Scheffer RC, van Asseldonk JH, Souza LC, da Luz PL, et al. Inhibition of vascular NADH/NADPH oxidase activity by thiol reagents: lack of correlation with cellular glutathione redox status. Free Radic Biol Med 2000;29(9):889-99.

Jiang XM, Fitzgerald M, Grant CM, Hogg PJ. Redox control of exofacial protein thiols/disulfides by protein disulfide isomerase. J Biol Chem. 1999;274(4):2416-23

Karala AR, Ruddock LW. Bacitracin is not a specific inhibitor of protein disulfide isomerase. FEBS J. 2010;277(11):2454-62.

Kobayashi N, Horinaka S, Mita S, Nakano S, Honda T, Yoshida K, Kobayashi T, Matsuoka $\mathrm{H}$. Critical role of Rho-kinase pathway for cardiac performance and remodeling in failing rat hearts. Cardiovasc Res. 2002 55(4):757-67.

Kourie Jl. Interaction of reactive oxygen species with ion transport mechanisms. Am J Physiol. 1998;275(1 Pt 1):C1-24

Kuno M, Gardner P. Ion channels activated by inositol 1,4,5-trisphosphate in plasma membrane of human T-lymphocytes. Nature. 1987;326(6110):301-4

Lassegue $B$, Clempus RE. Vascular NAD $(P) H$ oxidases: specific features, expression, and regulation. Am J Physiol Regul Integr Comp Physiol 2003;285(2):R277-R297. 
Laurindo FR, Fernandes DC, Amanso AM, Lopes LR, Santos CX. Novel role of protein disulfide isomerase in the regulation of NADPH oxidase activity: pathophysiological implications in vascular diseases. Antioxid Redox Signal. 2008;10(6):1101-13

Lesh RE, Nixon GF, Fleisher S, Airey JA, Somlyo AP, Somlyo AV. Localization of ryanodine receptors in smooth muscle. Circ. Res. 1998; 82(2):175-85.

Li JM, Shah AM. Intracellular localization and preassembly of the NADPH oxidase complex in cultured endothelial cells. J Biol Chem. 2002;277(22):19952-60.

Lyle AN, Griendling KK. Modulation of vascular smooth muscle signaling by reactive oxygen species. Physiology (Bethesda). 2006; 21:269-80.

Mandel R, Ryser HJ, Ghani F, Wu M, Peak DInhibition of a reductive function of the plasma membrane by bacitracin and antibodies against protein disulfide-isomerase. Proc Natl Acad Sci U S A. 1993;90(9):4112-6.

Martyn KD, Frederick LM, von Loehneysen K, Dinauer MC, Knaus UG. Functional analysis of Nox4 reveals unique characteristics compared to other NADPH oxidases. cell Signal. 2006;18(1):69-82.

Matsumoto Y, Tanaka K, Harimaya K, Nakatani F, Matsuda S, Iwamoto Y. Small GTPbinding protein, Rho, both increased and decreased cellular motility, activation of matrix metalloproteinase 2 and invasion of human osteosarcoma cells. Jpn $\mathrm{J}$ Cancer Res. 2001;92(4):429-38.

Mehta PK, Griendling KK. Angiotensin II cell signaling: physiological and pathological effects in the cardiovascular system.Am J Physiol Cell Physiol. 2007;292(1):C82-97

Mikami T, Genma R, Nishiyama K, Ando S, Kitahara A, Natsume H, Yoshimi T, Horiuchi R, Nakamura $\mathrm{H}$. Alterations in the enzyme activity and protein contents of protein disulfide isomerase in rat tissues during fasting and refeeding. Metabolism. 1998;47(9):1083-8.

Miwa S, Kawanabe Y, Okamoto Y, Masaki T. Ca2+ entry channels involved in endothelin-1induced contractions of vascular smooth muscle cells. J Smooth Muscle Res. 2005; $41(2): 61-75$.

Miyamoto A, Laufs U, PardoC, Liao JK. Modulation of bradykinin receptor ligand binding affinity and its coupled G-proteins by nitric oxide. J Biol Chem. 1997;272(31):19601-8

Morris AP, Gallacher DV, Irvine RF, Petersen OH.Synergism of inositol trisphosphate and tetrakisphosphate in activating Ca2+-dependent K+ channels. Nature. 1987;330(6149):6535 .

Mukai Y, Shimokawa H, Matoba T, Kandabashi T, Satoh S, Hiroki J, Kaibuchi K, Takeshita A. Involvement of Rho-kinase in hypertensive vascular disease: a novel therapeutic target in hypertension. FASEB J. 2001;15(6):1062-4

Mulvany MJ, Aalkjaer C. Structure and function of small arteries. Physiol Rev. 1990;70(4):921-61.

Nguyen DCA, Touyz RM. Cell signaling of angiotensin II on vascular tone: novel mechanisms. Curr Hypertens Rep. 2011;13(2):122-8 
Noiva R. Protein disulfide isomerase: the multifunctional redox chaperone of the endoplasmic reticulum. Semin Cell Dev Biol 1999;10(5):481-93.

Paes AMA, Veríssimo-Filho S, Guimarães LL, Silva ACB, Takiuti JT, Santos CXC, Janiszewski M, Laurindo FRM, Lopes LL. Protein disulfide isomerase redox dependent association with p47phox: evidence for an organizer role in leukocyte: NADPH oxidase activation. J LeukoC Biol. 2011; 90: 799-810.

Paes AMA. Mecanismo da interação entre a proteína dissulfeto isomerase e a NADPH oxidase: papel regulatório sobre a produção de espécies reativas de oxigênio em fagócitos profissionais. Tese (doutorado) - Faculdade de Medicina da Universidade de São Paulo, Departamento de Cardio-Pneumologia; 2009

Pedruzzi E, Guichard C, Ollivier V, Driss F, Fay M, Prunet C, Marie JC, Pouzet C, Samadi M, Elbim C, O'dowd Y, Bens M, Vandewalle A, Gougerot-Pocidalo MA, Lizard G, Ogier-Denis E. $\mathrm{NAD}(\mathrm{P}) \mathrm{H}$ oxidase Nox-4 mediates 7-ketocholesterol-induced endoplasmic reticulum stress and apoptosis in human aortic smooth muscle cells. Mol Cell Biol. 2004;24(24):10703-17.

Putney JW A model for receptor-regulated calcium entry. Cell Calcium. 1986;7(1):1-12

Rajagopalan S, Kurz S, Munzel T, Tarpey M, Freeman BA, Griendling KK, et al. Angiotensin II-mediated hypertension in the rat increases vascular superoxide production via membrane $\mathrm{NADH} / \mathrm{NADPH}$ oxidase activation. Contribution to alterations of vasomotor tone. J Clin Invest 1996;97(8):1916-23.

Ramachandran N, Root P, Jiang XM, Hogg PJ, Mutus B.Mechanism of transfer of NO from extracellular S-nitrosothiols into the cytosol by cell-surface protein disulfide isomerase. ProC Natl Acad Sci U S A. 2001;98(17):9539-44

Ray R, Murdoch CE, Wang M, Santos CX, Zhang M, Alom-Ruiz S, Anilkumar N, Ouattara A, Cave AC, Walker SJ, Grieve DJ, Charles RL, Eaton P, Brewer AC, Shah AM. Endothelial Nox4 NADPH Oxidase Enhances Vasodilatation and Reduces Blood

Rinaldi GJ, Grand C, Cingolani HE. Characteristics of the fast and slow components of the response to noradrenaline in rat aorta. Can. J. Cardiol. 1991; (7): 316-322.

Robinson A, O'Neill S, Kiernan A, O'Donoghue N, Moran N. Bacitracin reveals a role for multiple thiol isomerases in platelet function. Br J Haematol. 2006;132(3):339-48.

Roth RA . Bacitracin: an inhibitor of the insulin degrading activity of glutathione-insulin transhydrogenase. Biochem Biophys Res Commun. 1981;98(2):431-8

Santos CX, Stolf BS, Takemoto PV, Amanso AM, Lopes LR, Souza EB, Goto H, Laurindo FR.Protein disulfide isomerase (PDI) associates with NADPH oxidase and is required for phagocytosis of Leishmania chagasi promastigotes by macrophages. J Leukoc Biol. 2009;86(4):989-98.

Schafer FQ, Buettner GR. Redox environment of the cell as viewed through the redox state of the glutathione disulfide/glutathione couple. Free Radic Biol Med. 2001 Jun 1;30(11):1191212.

Scherer NM, Deamer DW. Oxidation of thiols in the Ca2+-ATPase of sarcoplasmic reticulum microsomes. Biochim Biophys Acta. 1986;862(2):309-17 
Schiffrin EL. Intracellular signal transduction for vasoactive peptides in hypertension. Can J Physiol Pharmacol. 1994;72(8):954-62

Schiffrin EL. Reactivity of small blood vessels in hypertension: relation with structural changes. State of the art lecture. Hypertension. 1992;19(2 Suppl):II1-9.

Seshiah PN, Weber DS, Rocic P, Valppu L, Taniyama Y, Griendling KK. Angiotensin II stimulation of $\mathrm{NAD}(\mathrm{P}) \mathrm{H}$ oxidase activity: upstream mediators. Circ Res. 2002;91(5):406-13.

Sullivan DC, Huminiecki L, Moore JW, Boyle JJ, Poulsom R, Creamer D, Barker J, Bicknell $\mathrm{R}$. EndoPDI, a novel protein-disulfide isomerase-like protein that is preferentially expressed in endothelial cells acts as a stress survival factor. J Biol Chem. 2003;278(47):47079-88.

Tabet F, Savoia C, Schiffrin EL, Touyz RM. Differential calcium regulation by hydrogen peroxide and superoxide in vascular smooth muscle cells from spontaneously hypertensive rats. J Cardiovasc Pharmacol. 2004 Aug;44(2):200-8

Tager M, Kroning $\mathrm{H}$, Thiel U, Ansorge S. Membrane-bound proteindisulfide isomerase (PDI) is involved in regulation of surface expression of thiols and drug sensitivity of B-CLL cells. Exp Hematol 1997;25(7):601-7.

Tanaka S, Uehara T, Nomura Y. Up-regulation of protein-disulfide isomerase in response to hypoxia/brain ischemia and its protective effect against apoptotic cell death $\mathrm{J}$ Biol Chem. 2000;275(14):10388-93.

Terada K, Manchikalapudi P, Noiva R, Jauregui HO, Stockert RJ, Schilsky ML. Secretion, surface localization, turnover, and steady state expression of protein disulfide isomerase in rat hepatocytes. J Biol Chem 1995;270(35):20410-6.

Torrecillas G, Boyano-Adánez MC, Medina J, Parra T, Griera M, López-Ongil S, Arilla E, Rodríguez-Puyol M, Rodríguez-Puyol D. The role of hydrogen peroxide in the contractile response to angiotensin II. Mol Pharmacol. 2001;59(1):104-12.

Touyz RM, Deng LY, He G, Wu XH, Schiffrin EL. Angiotensin II stimulates DNA and protein synthesis in vascular smooth muscle cells from human arteries: role of extracellular signalregulated kinases. J Hypertens. 1999;17(7):907-16.

Touyz RM, Schiffrin EL. Reactive oxygen species in vascular biology: implications in hypertension. Histochem Cell Biol 2004;122(4):339-52.

Touyz RM, Schiffrin EL. Signal transduction mechanisms mediating the physiological and pathophysiological actions of angiotensin II in vascular smooth muscle cells. Pharmacol Rev 2000;52(4):639-72.

Touyz RM, Yao G, Schiffrin EL. c-Src induces phosphorylation and translocation of p47phox: role in superoxide generation by angiotensin II in human vascular smooth muscle cells. Arterioscler Thromb Vasc Biol 2003;23(6):981-7.

Touyz RM. Reactive oxygen species as mediators of calcium signaling by angiotensin II: implications in vascular physiology and pathophysiology. Antioxid Redox Signal 2005;7(910):1302-14. 
Touyz RM. Reactive oxygen species in vascular biology: role in arterial hypertension.

Expert Rev Cardiovasc Ther 2003;1(1):91-106.

Trebak M, Ginnan R, Singer HA, Jourd'heuil D. Interplay between calcium and reactive oxygen/nitrogen species: an essential paradigm for vascular smooth muscle signaling. Antioxid Redox Signal. 2010;12(5):657-74.

Tsai MH, Jiang MJ Reactive oxygen species are involved in regulating alpha1-adrenoceptoractivated vascular smooth muscle contraction. J Biomed Sci. 2010;17:67

Ulu N, Gurdal H, Landheer SW, Duin M, Guc MO, Buikema H, Henning RH. a1Adrenoceptor-mediated contraction of rat aorta is partly mediated via transactivation of the epidermal growth factor receptor. Br J of Pharmacol. 2010; 161: 1301-1310.

Wamhoff BR, Bowles DK, Owens GK. Excitation-transcription coupling in arterial smooth muscle. Circ Res. 2006;98(7):868-78.

Wang HD, Pagano PJ, Du Y, Cayatte AJ, Quinn MT, Brecher P, Cohen RA Superoxide anion from the adventitia of the rat thoracic aorta inactivates nitric oxide. Circ Res. 1998;82(7):8108

Webb RC. Smooth muscle contraction and relaxation. Adv Physiol Educ. 2003;27(1-4):2016.

Wei EP, Kontos HA. H2O2 and endothelium-dependent cerebral arteriolar dilation. Implications for the identity of endothelium-derived relaxing factor generated by acetylcholine. Hypertension. 1990;16(2):162-9.

Wingler K, Wünsch S, Kreutz R, Rothermund L, Paul M, Schmidt HH. Upregulation of the vascular $\mathrm{NAD}(\mathrm{P}) \mathrm{H}$-oxidase isoforms Nox1 and Nox4 by the renin-angiotensin system in vitro and in vivo. Free Radic Biol Med. 2001;31(11):1456-64.

Winterbourn CC, Hampton MB. Thiol chemistry and specificity in redox signaling. Free Radic Biol Med. 2008;45(5):549-61

Wrzosek A. Endothelium as target for large-conductance calcium-activated potassium channel openers. Acta Biochim Pol. 2009;56(3):393-404.

Wynne BM, Chiao CW, Webb RC.Vascular Smooth Muscle Cell Signaling Mechanisms for Contraction to Angiotensin II and Endothelin-1. J Am Soc Hypertens. 2009;3(2):84-95.

Yermolaieva O, Brot N, Weissbach $\mathrm{H}$, Heinemann $\mathrm{SH}$, Hoshi T. Reactive oxygen species and nitric oxide mediate plasticity of neuronal calcium signaling. Proc Natl Acad Sci U S A. 2000 Jan 4;97(1):448-53.

Zai A, Rudd MA, Scribner AW, Loscalzo J. Cell-surface protein disulfide isomerase catalyzes transnitrosation and regulates intracellular transfer of nitric oxide. $\mathrm{J}$ Clin Invest. 1999;103(3):393-9.

Zhang AY, Li PL. Vascular physiology of a $\mathrm{Ca}^{2+}$ mobilizing second messenger - cyclic ADPribose. J Cell Mol Med. 2006;10(2):407-22. 